\title{
INSIGHTS INTO EFFECTIVE INTERVENTIONS FOR THE PREVENTION AND MANAGEMENT OF WORKPLACE BULLYING IN THE NEW ZEALAND PUBLIC SERVICE
}

BY

HAMISH CRIMP

\author{
A thesis \\ submitted to the Victoria University of Wellington \\ In partial fulfilment of the requirements for the degree of \\ Master of Commerce
}

Victoria University of Wellington 


\begin{abstract}
Workplace bullying is widely recognised as a severe workplace health and safety issue that can have harmful consequences for both individuals and organisations. Bullying is a difficult phenomenon for organisations to deal with generally, with effective prevention and management in public sector environments considered especially challenging.

This thesis seeks to explore current workplace bullying prevention and management interventions within the New Zealand Public Service. In adopting a pragmatic exploratory mixed-model research method, research approaches aim to provide practical insights into anti-bullying interventions. Data for this research is collected from two sources; organisational anti-bullying policies, and semistructured interviews with human resource practitioners and union representatives involved in the prevention and management of workplace bullying.

Both human resource practitioners and union representatives were found to have multiple roles in the prevention and management of workplace bullying, and generally interpreted bullying allegations as being unsubstantiated. This research suggests that greater emphasis should be placed on primary intervention, and that mediation may be useful as both a secondary and tertiary intervention. The findings of this research also indicate that stakeholder interpretations, and in turn their practical responses to workplace bullying, may be influenced by a range of factors within the public sector environment; including the sedimentation of contradictory public sector approaches, the legislative and regulatory environment, personal experience, and role expectations.
\end{abstract}




\section{Acknowledgements}

Firstly, I want to say a huge thank you to my supervisor, Dr. Geoff Plimmer. You have provided the advice and direction necessary to complete this research. Your knowledge of the literature, and constructive feedback throughout has been invaluable; your patience and understanding in those difficult stages is gratefully appreciated.

To my 'Disasters from Masters' family, Erin, Alice, Evie and Cass; I quite simply could not have done this without you. You provided the support, friendship, and laughter needed to get through our Honours and Masters journey; I will remain forever 'passionate about workplace bullying'.

To my adopted Masters family, Esme, Kate and Laura; you have kept me sane in the last months of this journey. I am especially grateful to Esme for introducing me to pragmatism; I would surely still be lost in the sea of paradigms without your help!

To all those who participated in this research project, your willingness to participate in interviews and to provide requested information was gratefully appreciated; without willing participants, social research would be an impossibility.

I would like to thank everyone else who has offered their time and support throughout this journey: family, friends, colleagues, lecturers, faculty staff, and students. Your words of wisdom, encouragement, and offers of help are gratefully acknowledged; I have learnt so much from you all.

Finally, a special mention to the humble flat white and all the fantastic Wellington baristas; I could NEVER have achieved this without you. 


\section{Table of Contents}

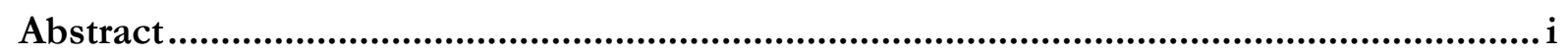

Acknowledgements ..................................................................................................... ii

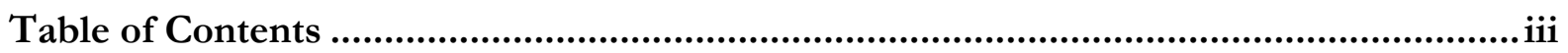

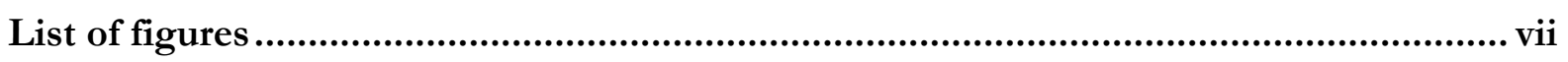

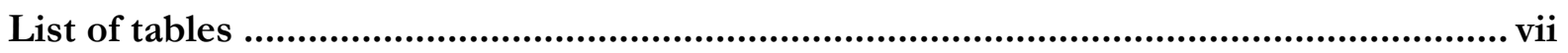

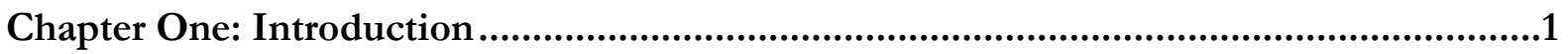

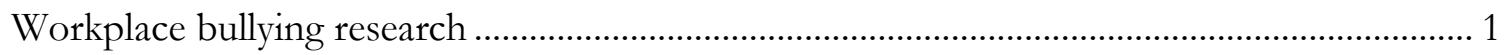

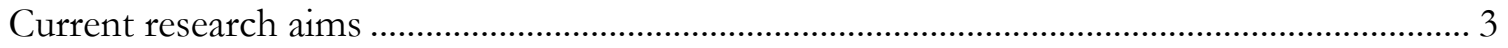

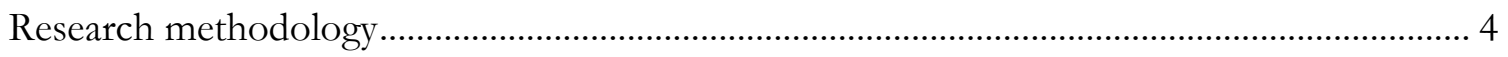

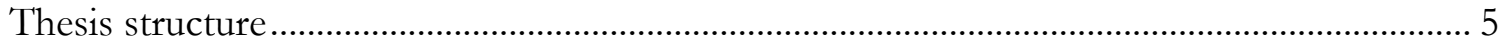

Chapter Two: Introducing and defining workplace bullying .........................................6 6

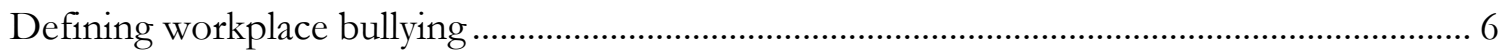

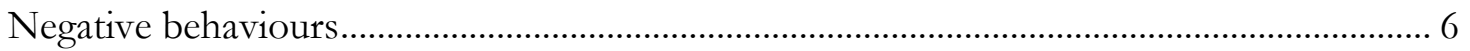

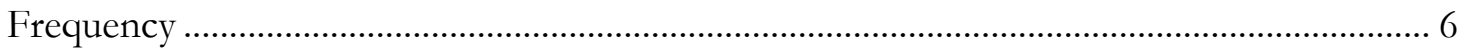

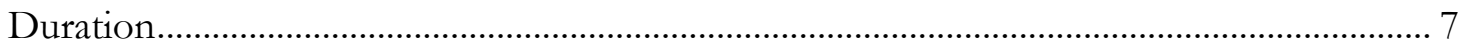

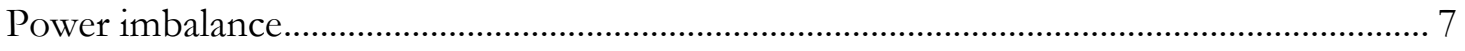

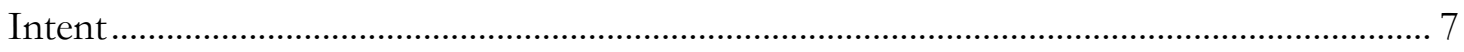

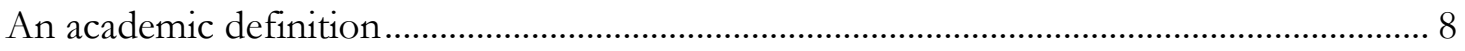

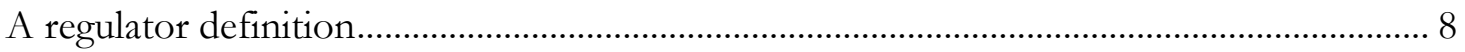

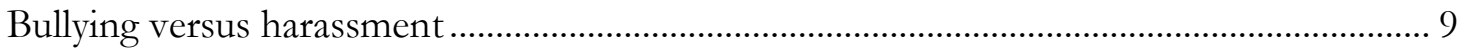

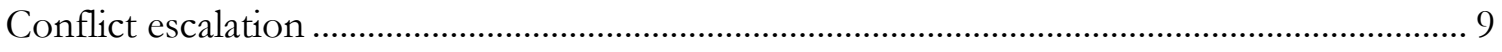

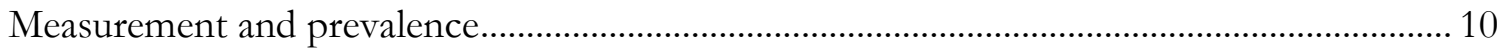

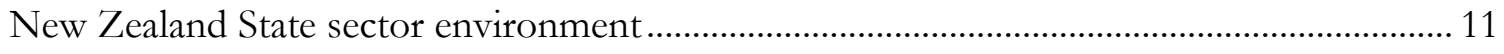

Legislation governing the Public Service …………................................................................ 13

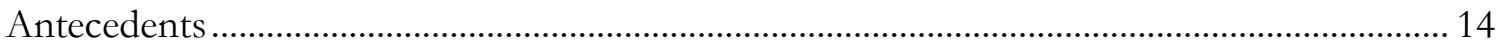

Victim and perpetrator characteristics................................................................................ 14

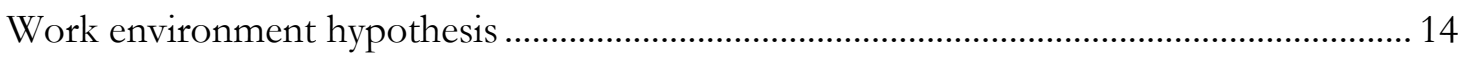

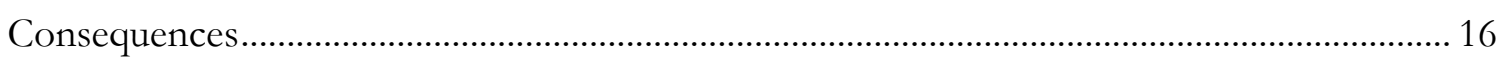

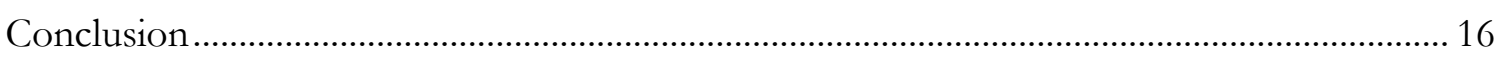

Chapter Three: Interventions for prevention and management .....................................17

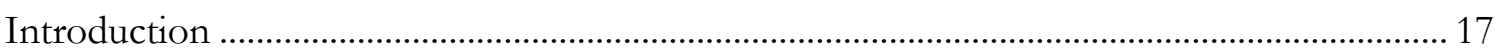

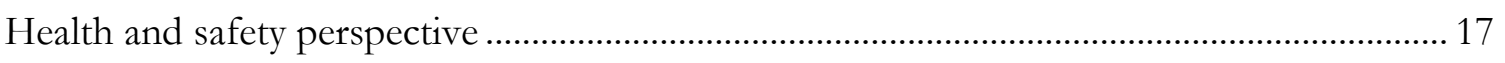

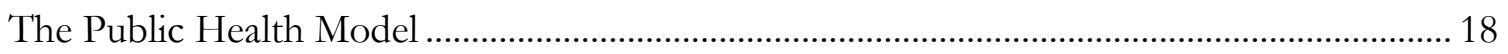




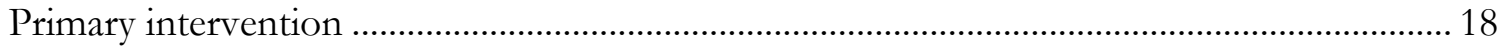

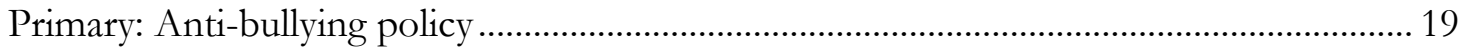

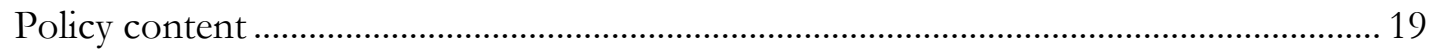

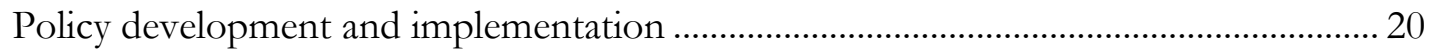

Primary: Identification of antecedents .................................................................................... 21

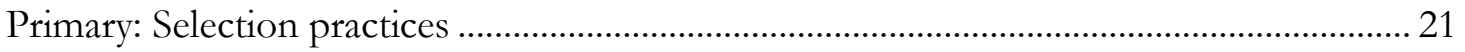

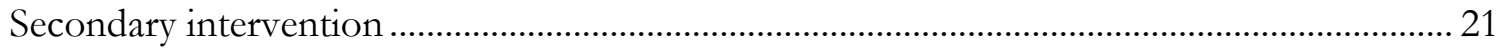

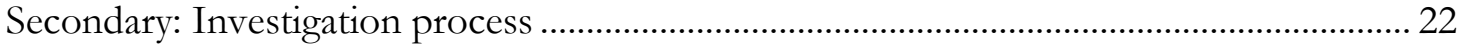

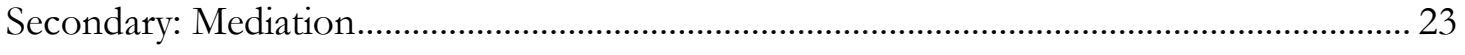

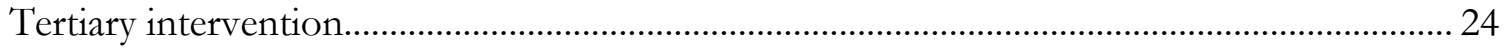

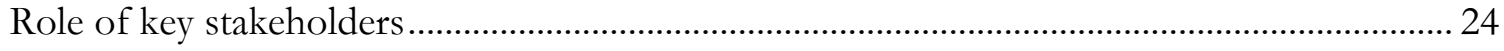

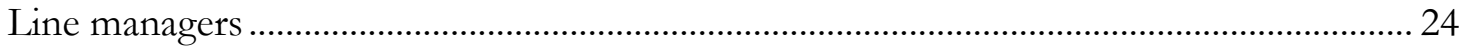

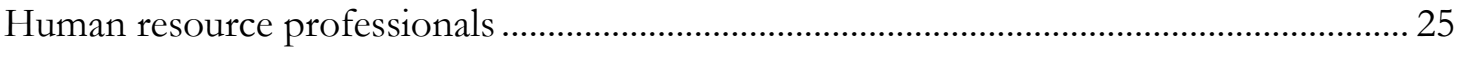

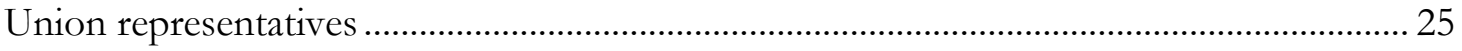

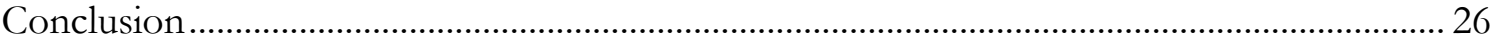

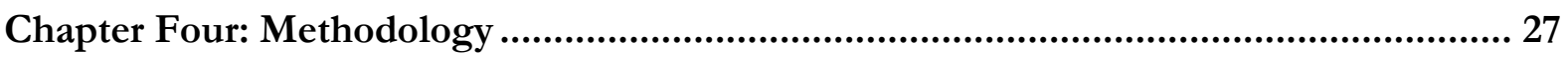

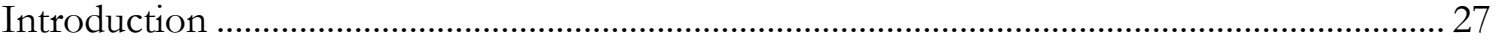

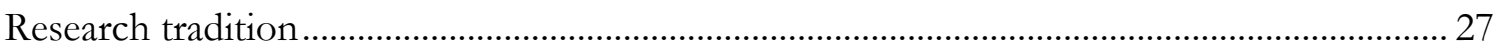

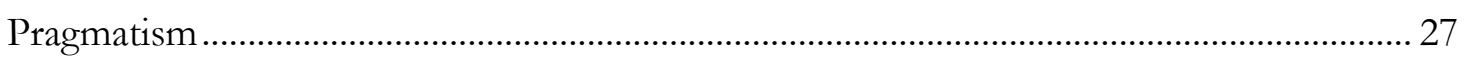

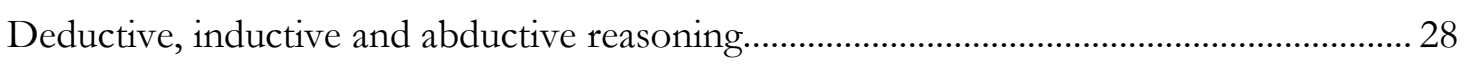

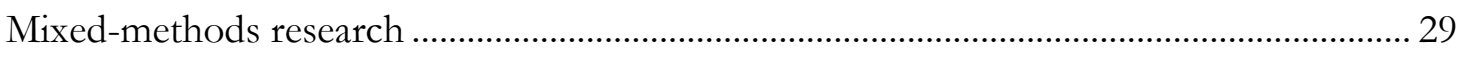

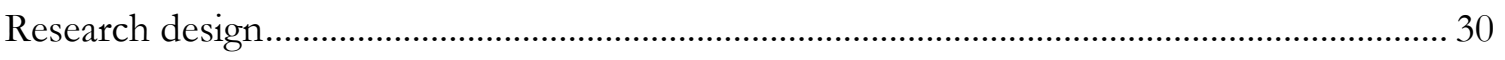

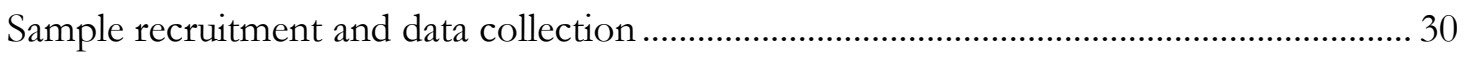

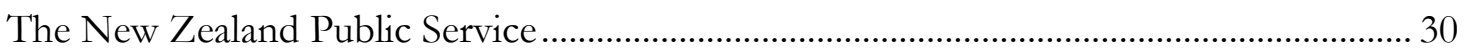

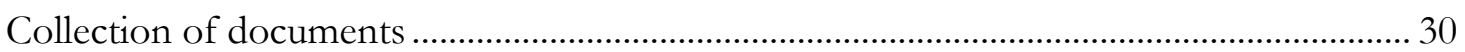

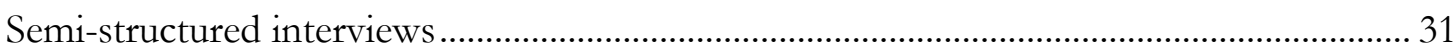

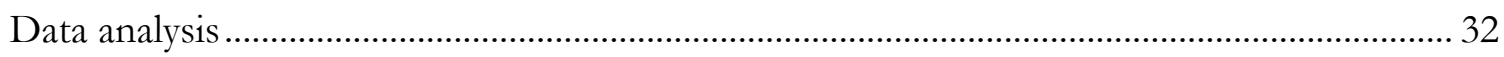

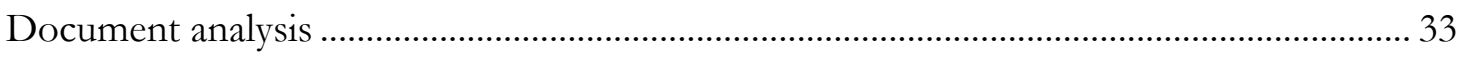

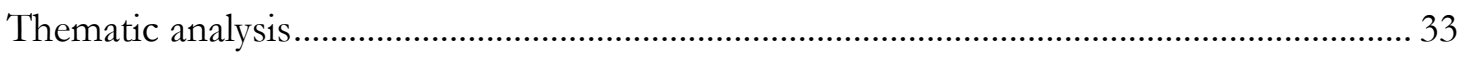

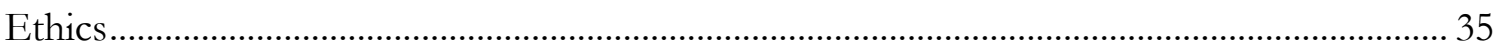

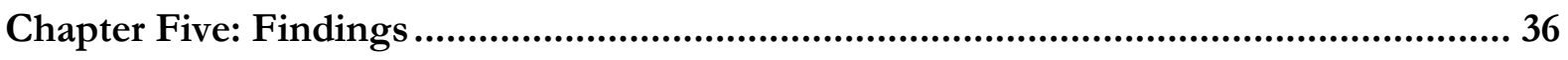

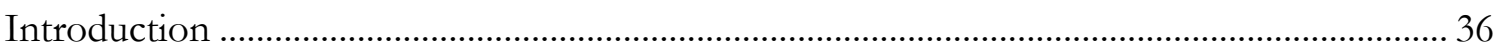

Stage one: Analysis of formal bullying complaint statistics ........................................................ 36

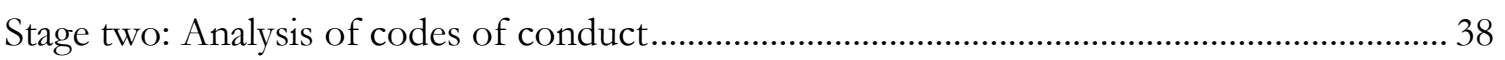

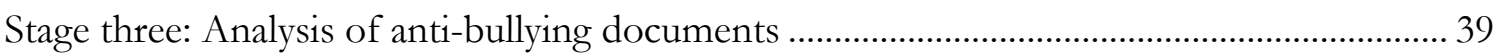




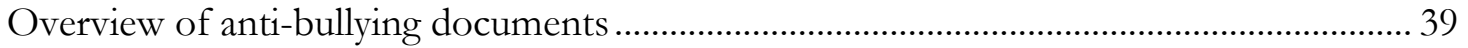

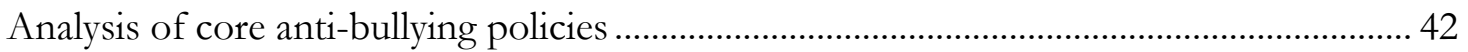

Limited provision of contact details ................................................................................. 44

Limited discussion of perpetrator consequences ................................................................. 44

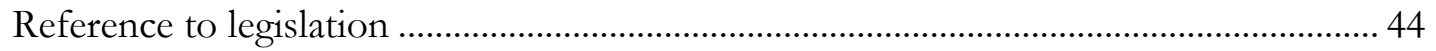

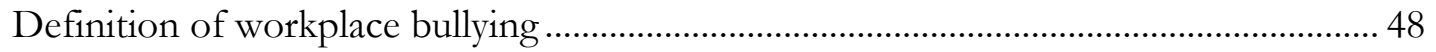

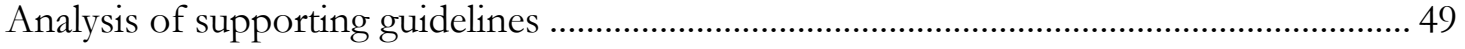

Guidance for complainants.................................................................................................. 49

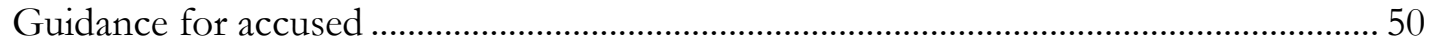

Guidance for managers ................................................................................................. 51

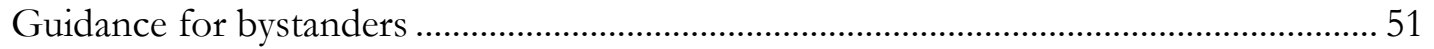

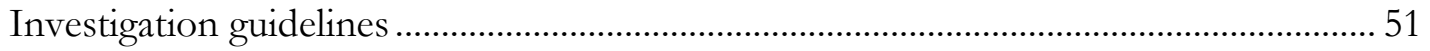

Thematic analysis of documents ........................................................................................... 52

Secondary intervention of primary importance ……….......................................................... 52

Mediation as a preferred secondary intervention method...................................................... 53

Policies communicate a minimal role for unions …………………………………............ 53

The varying role of human resources across departments................................................... 54

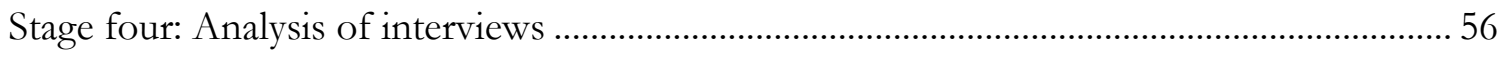

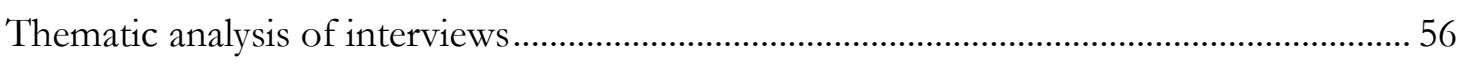

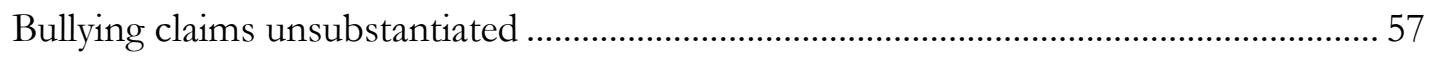

Managerial competency as a driver of bullying complaints ............................................ 58

The significance of intent in interpreting bullying complaints ......................................... 59

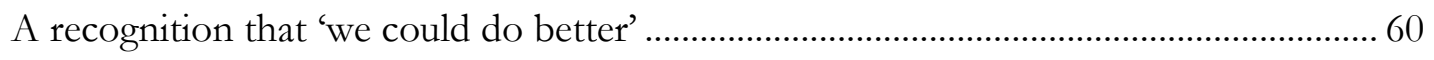

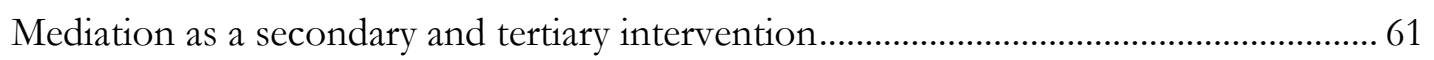

Unions as a key stakeholder in dealing with workplace bullying.......................................62

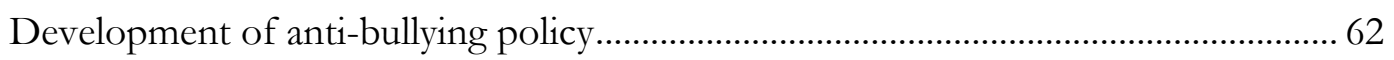

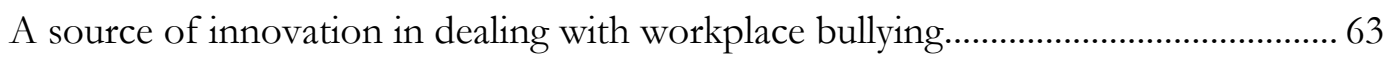

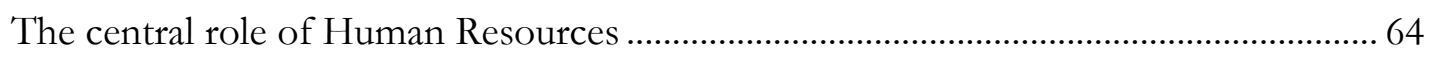

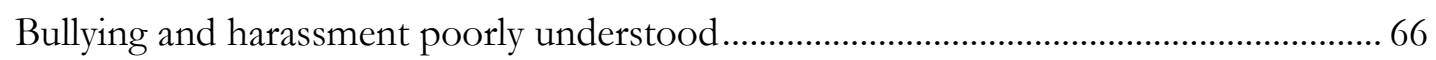

Chapter Six: Discussion, implications and conclusion................................................. 67

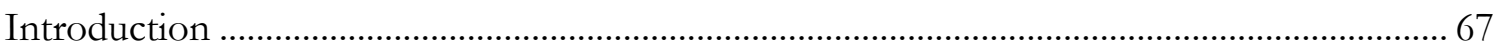

Key informants' roles and interpretations of workplace bullying intervention........................ 67

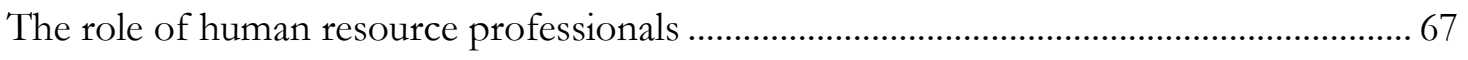

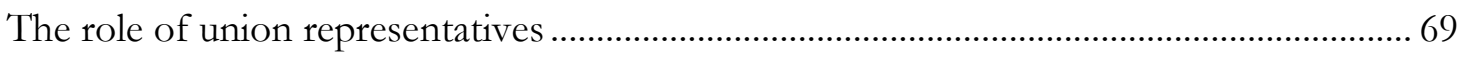

Key informant interpretations of workplace bullying complaints .......................................... 70 
A primary intervention gap

Mediation as a preferred secondary and tertiary intervention.

Intervention within a challenging public sector environment: A model for future research 76

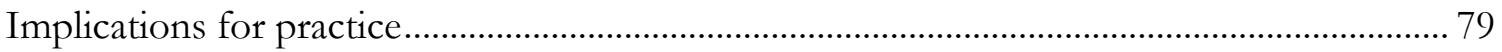

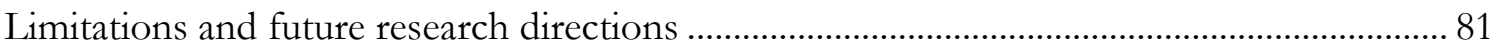

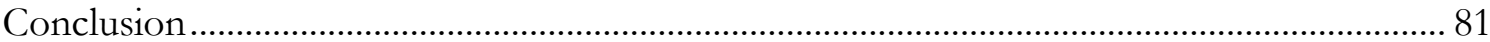

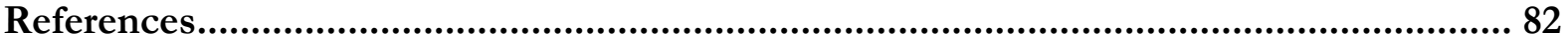

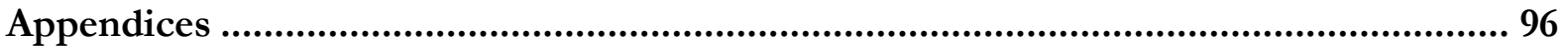

Appendix A: Participant information sheet ................................................................................ 96

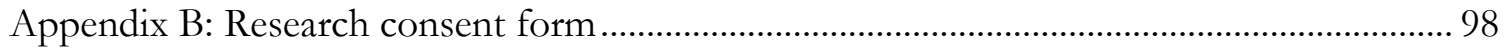

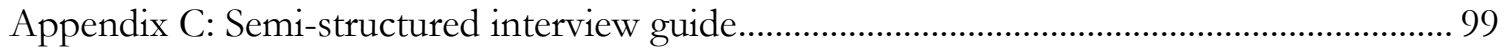




\section{List of figures}

Figure 2.1 Model of conflict escalation by Glasl (1994), as adapted and presented in Zapf and Gross (2001)

Figure 4.1 The abductive research process from van Hoek et al. (2005)

Figure 6.1 Model showing use of mediation at stages of conflict escalation and de-escalation, adapted from Glasl (1994) and Gross (2001)

Figure 6.2 Model for future research: Showing influence of environmental factors on stakeholder interpretations of workplace bullying intervention

\section{List of tables}

Table 2.1 Characteristics of public sector environments adapted from Bryson, Crosby \& Bloomberg, 2014, with additional adaptations from Hood, 1995 .................................................... 12

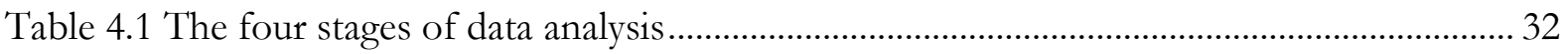

Table 4.2 Phases of thematic analysis adapted from Braun and Clarke (2006) ............................... 33

Table 5.1 Formal complaints of workplace bullying: 2010 - 2016 ................................................... 37

Table 5.2 References to workplace bullying in organisational codes of conduct........................... 38

Table 5.3 Overview of organisational anti-bullying documents....................................................... 40

Table 5.4 Core elements of anti-bullying policy ............................................................................. 43

Table 5.5 Inclusion of key elements of workplace bullying definition ........................................... 46

Table 5.6 Additional stakeholder guidance provided ......................................................................... 50

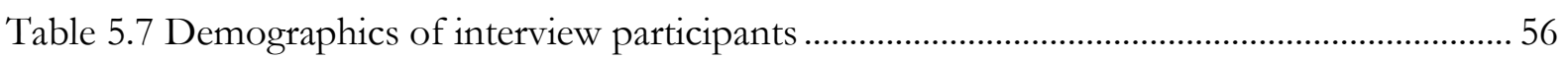




\section{Chapter One: Introduction}

Researchers, organisations and regulators are increasingly interested in explaining the poorly defined, yet potentially destructive phenomenon of workplace bullying. Research has revealed workplace bullying to be a complex, multi-causal, and highly subjective form of negative workplace behaviour, with the potential to cause severe harm to both individuals and organisations (Bartlett \& Bartlett, 2011; Hoel \& Salin, 2003; Nielsen \& Einarsen, 2012; Zapf \& Einarsen, 2011). Whilst there is a growing body of literature seeking to explain workplace bullying, our knowledge of effective prevention and management initiatives is still limited. This is especially so in core Public Service departments, where high levels of workplace bullying are reported, but where limited research into effective prevention and management initiatives has been conducted (Venetoklis \& Kettunen, 2015).

The motivation for researching workplace bullying within the New Zealand Public Service was largely driven by reports of high levels of bullying within the wider public sector (NZ State Services Commission, 2014; Plimmer et al., 2013). However, the reasons behind these reports, and what specific actions were being taken to address bullying was relatively unknown. Effective prevention and management of workplace bullying within this context is especially important given the significance of the public sector as an employer, and the potential for high levels of bullying to severely impact the effective delivery of core social, economic, and other government services (Omari, 2006).

\section{Workplace bullying research}

The concept of workplace bullying was first popularised in Scandinavia during the 1980s, however research on the subject in English-speaking nations did not become popular until the late 1990s following the widespread publication of English language books on the phenomenon (Einarsen, Hoel, Zapf, \& Cooper, 2011). Since this time there has been a focus on defining the concept (Einarsen \& Skogstad, 1996; Saunders, Huynh, \& Goodman-Delahunty, 2007); establishing bullying prevalence rates in national and sectorial contexts (Einarsen, Hoel, \& Notelaers, 2009; O'Driscoll et al., 2011; Plimmer et al., 2013); exploring negative individual and organisational impacts (Cooper-Thomas et al., 2013); and more recently, on developing effective management and prevention initiatives (Blackwood, 2015; Richards \& Daley, 2003; Salin, 2008b).

Targets of workplace bullying have reported a number of severe negative consequences including heightened anxiety, stress, and sadness; poor concentration; low self-confidence; higher 
absenteeism; increased work errors; and lower performance, commitment and job satisfaction (Bartlett \& Bartlett, 2011; Cooper-Thomas et al., 2013). For organisations, bullying could damage organisational culture and reputation; and result in low morale, high turnover, and decreased performance (Bartlett \& Bartlett, 2011; S. Gardner \& Johnson, 2001). Despite the growth in research seeking to explain workplace bullying, few studies have explored specific interventions used by organisations in effectively preventing and managing the destructive phenomenon.

Research has also generally focused on exploring the experiences of targets of workplace bullying, and has only recently begun to explore the role of other stakeholders such as human resource practitioners and union representatives (Cowan, 2011; Harrington, Warren, \& Rayner, 2015). Workplace bullying is complex, so understanding the perspectives of a range of stakeholders may help in developing effective prevention and management initiatives. Whilst victims are recognised as key stakeholders in bullying research, considering the perspectives of other stakeholders such as human resource practitioners and union representatives is likely to be important in effectively addressing workplace bullying.

New Zealand research interest in workplace bullying has grown recently. The publication of Andrea Needham's Workplace bullying: The costly business secret (2003), is credited with stimulating considerable New Zealand interest in the subject. Bentley and colleagues undertook the first largescale multi-sector study into workplace bullying in New Zealand (T. Bentley et al., 2009). Since this time, researchers have continued to explore workplace bullying within New Zealand, investigating bullying from a health and safety perspective (Catley et al., 2013); in the travel industry (T. A. Bentley et al., 2012); and within the nursing profession (Blackwood, 2015). The most significant step in dealing with workplace bullying in New Zealand was the publication of WorkSafe New Zealand's Preventing and responding to workplace bullying guidelines (2014). This guide provides a consistent workplace bullying definition for New Zealand organisations; includes bullying identification tools; outlines the responsibilities of organisational stakeholders; and describes possible organisational prevention and management initiatives (WorkSafe NZ, 2014).

In the New Zealand public sector, media coverage of high profile incidents such as the inappropriate physical behaviour displayed by Department of Building and Housing Chief Executive Katrina Bach in 2011 has stimulated some interest in the subject (Francis, 2012, April 20; Shuttleworth, 2012, April 20). The State Services Commission (SSC) has developed some guidance on dealing with workplace bullying and undesirable behaviours more generally, and also on the promotion of positive workplace behaviours (NZ State Services Commission, 2016b). However, despite the growth in research, and publication of guidance, we still have a poor 
understanding of interventions used by Public Service departments to both prevent and manage workplace bullying.

\section{Current research aims}

Researchers and practitioners have acknowledged that effectively preventing and managing workplace bullying is a significant challenge for organisations. Efforts to address bullying may be hindered by a number of factors, including the poorly defined and subjective nature of workplace bullying (D'Cruz \& Noronha, 2010; Lutgen-Sandvik, 2008); a lack of information on prevention initiatives (M. Vartia \& Leka, 2011); and weak or inconsistent implementation of interventions (Salin, 2008a; Woodrow \& Guest, 2014).

Public sector organisations seem prone to workplace bullying, and are likely to encounter additional challenges in effectively dealing with bullying behaviour (Bradbury \& Hutchinson, 2015; Omari, 2006). It has been suggested that high levels of organisational change, media scrutiny, and political interference may lead to higher levels of workplace bullying in the public sector (Omari, 2006). New Zealand Public Service organisations are seen to operate in an environment characterised by shifting performance expectations, and vague, disputed, and conflicting goals, that may both contribute to workplace bullying, and hinder effective anti-bullying interventions (Caverley, 2005; Omari, 2006). Whilst some researchers (such as Boyne, 2002), believe public sector individuality has been overstated, scholars generally emphasise the distinctiveness of public sector environments (see Lavigna, 2015; Buelens \& Van den Broeck, 2007), and the implications this brings for public sector HRM (Boon \& Verhoest, 2016). This exploratory research thus seeks to develop insights into effective interventions for the prevention and management of workplace bullying in Public Service organisations operating within a complex public sector environment.

In exploring effective interventions for addressing workplace bullying, there is a need to understand current initiatives and the extent to which Public Service organisations adhere to current recommended practice. Given the severe negative health consequences for bullying victims and bystanders, workplace bullying is commonly treated as a form of workplace stress, framed within a health and safety paradigm. This research thus takes a health and safety perspective and explores primary, secondary and tertiary interventions within the context of the Public Health Model (Tetrick \& Quick, 2003). Primary interventions focus on the prevention of workplace bullying, and secondary and tertiary interventions, respectively, on managing and reducing the negative impacts of bullying once it has occurred (M. Vartia \& Leka, 2011). The first research 
question thus seeks to explore organisational-level workplace anti-bullying practices used at the primary, secondary and tertiary levels of intervention:

Research question one: What are the current policies and practices used by Public Service departments in dealing with workplace bullying at the primary, secondary and tertiary intervention levels, and how do these compare to the extant research?

Research has begun to investigate the role and interpretations of key informants involved in the prevention and management of workplace bullying (Harrington et al., 2015; Salin, 2008b). These key informants include human resource professionals and union representatives who may be involved in the development and implementation of initiatives at all intervention levels, including the development and implementation of anti-bullying policy, complaint investigation, and training. Despite the important role of these stakeholders in effectively dealing with workplace bullying, we know very little about the specific roles they play in the New Zealand Public Service. Research question two thus asks:

Research question two: What are the roles and interpretations of human resource professionals and union representatives in the prevention and management of workplace bullying in the complex Public Service environment?

\section{Research methodology}

This research adopts an exploratory mixed-model approach within a pragmatic research paradigm. Pragmatism questions the utility of the positivist - interpretivist dichotomy, calling for a convergence of quantitative and qualitative research methods to find practical solutions to human problems (Dewey, Boydston, \& Ross, 1983; Feilzer, 2010). Pragmatism assumes that whilst "current beliefs and research conclusions are rarely, if ever, viewed as perfect, certain, or absolute" (Johnson \& Onwuegbuzie, 2004, p. 18), some social knowledge is cumulative (Corbin \& Strauss, 2008). Pragmatism is thus seen as an appropriate paradigm for researching the complex phenomenon of workplace bullying, where researchers understandings of what constitutes bullying are constantly under review (Burnes \& Pope, 2007). In alignment with pragmatism, this research also has a clear practical aim to provide advice to Public Service departments.

The data for this project was drawn from two sources. Organisational anti-bullying documents were obtained from 14 Public Service organisations, and ten semi-structured interviews were conducted with Public Service human resource practitioners and union representatives. In alignment with the pragmatic approach, the use of multiple data sources was seen as the best way 
to most fully answer the research questions and to provide practical insights into the complex phenomenon of public sector workplace bullying.

\section{Thesis structure}

Chapter Two introduces and defines workplace bullying, with a focus on discussing the key definitional elements of negative behaviour, frequency, duration, power imbalance and intent. The chapter then describes bullying prevalence rates, known antecedents, and consequences. Chapter Three discusses primary, secondary and tertiary interventions for addressing workplace bullying in terms of the Public Health Model. Primary interventions described from the literature include antibullying policies, the identification of antecedents, and the use of selection practices. Secondary interventions include the development of sound investigation processes and the use of mediation, whilst tertiary interventions include inpatient treatment and forms of redress.

Chapter Four describes the research methods and assumptions underlying this research; this includes a discussion of pragmatism and the methods of data collection and analysis of the organisational documents and interviews. Chapter Five presents the findings from the four stages of data analysis. Stage one involves an analysis of complaint statistics, stage two an analysis of codes of conduct, stage three an analysis of anti-bullying documents, and stage four an analysis of interviews. Stages two and three are illustrated with examples from the organisational documents, and phase four is supported by excerpts from the interview transcripts. Chapter Six discusses the key themes and practical implications that have emerged from this research in reference to the research questions and the literature, and offers suggestions for future research. 


\section{Chapter Two: Introducing and defining workplace bullying}

Workplace bullying is often poorly understood by organisational stakeholders, and a concise definition remains elusive. However, researchers are generally in agreement over several core definitional elements, including the presence of negative or unwanted behaviours, that occur frequently, and over a period of time. The definitional elements of power imbalance and intent are sometimes incorporated within academic and practitioner definitions; although their inclusion is contentious.

\section{Defining workplace bullying}

\section{Negative behaviours}

Bullying behaviours must be negative and unwanted by the victim and are more often psychological rather than physical in nature (Einarsen et al., 2011). Bullying has been classified as job-based, person-based, or physically intimidating, with examples of these bullying behaviours found in the most popular bullying measurement tool, the Revised Negative Acts Questionnaire (NAQ-R). Job-based bullying behaviours could include but are not limited to the withholding of information that could impact job performance, excessive monitoring of work, or having opinions ignored (Einarsen et al., 2009). Person-related bullying may include the spreading of personal gossip and rumours, persistent criticism of errors or mistakes, or being the subject of excessive teasing and sarcasm (Einarsen et al., 2009). Physically intimidating bullying behaviours could include finger-pointing, invasion of personal space, threats of physical violence, or actual physical abuse (Einarsen et al., 2009).

\section{Frequency}

Workplace bullying definitions generally require that a victim experience negative behaviours on a regular basis. The most commonly used definition of frequency is that the negative behaviours are experienced by the victim at least once a week (Leymann, 1996; Zapf, Einarsen, Hoel, \& Vartia, 2003). Isolated negative behaviours are not generally classified as bullying, however being subjected to a permanent negative situation, such as being required to undertake one's job without the necessary resources, may constitute bullying (Einarsen et al., 2011). It is suggested by Einarsen et al. (2011) that " $\ldots$ the main criterion is that the behaviours or their consequences are repeated on a regular, as opposed to occasional basis" (p. 11). 


\section{Duration}

Many bullying victims are targets of persistent negative behaviour over a prolonged period of time, with those who are bullied more frequently generally reporting a longer bullying experience (Einarsen \& Skogstad, 1996). Whilst Zapf, Escartin, Einarsen, Hoel, and Vartia (2011) have shown that the mean duration of the bullying experience can range from twelve to thirty-six months, the period of six months has emerged as the most common measure of duration; allowing researchers to distinguish between severe social stress and workplace bullying (Einarsen et al., 2011).

\section{Power imbalance}

The existence of a power imbalance between an alleged perpetrator and victim may be used to differentiate workplace bullying from other forms of workplace conflict (Leymann, 1990). A power imbalance may occur in a situation where someone, commonly a manager, abuses their formal position of power over a subordinate (i.e. manager-subordinate bullying) (Einarsen et al., 2011). A power imbalance may also exist where a perpetrator holds informal power over a target, such as where they hold superior knowledge or experience, or where the target is dependent on them (Einarsen et al., 2011). Upward bullying, such as where a subordinate bullies their manager, or peer to peer bullying, may occur in situations where there is an abuse of informal power. However, some researchers have questioned the utility of distinguishing bullying from general workplace conflict on the basis of a power imbalance; arguing that such a distinction only adds confusion to an already complex situation (Rayner \& Cooper, 2006).

\section{Intent}

Perpetrators intent is a contested element of the bullying definition. Whilst Einarsen et al. (2011) argue that the inclusion of intent in the bullying definition could distinguish bullying from workplace incivility and innocent workplace behaviours; they, and others (see Hoel and Cooper, 1999) also recognise that intent is nearly impossible to prove. It is argued by Einarsen et al. (2011) that only the perpetrator can confirm the presence of intent, thus if intent was required, the alleged perpetrator would essentially be given the final say in whether their behaviour constituted bullying or not. Intent is clearly problematic, and is generally excluded from definitions of workplace bullying (Parzefall \& Salin, 2010). 


\section{An academic definition}

Einarsen et al. (2011) provide the following academic definition of workplace bullying, incorporating most of the commonly accepted elements except perpetrator intent:

Bullying at work means harassing, offending, or socially excluding someone or negatively affecting someone's work. In order for the label bullying (or mobbing) to be applied to a particular activity, interaction, or process, the bullying behavior has to occur repeatedly and regularly (e.g., weekly) and over a period of time (e.g., about six months). Bullying is an escalating process in the course of which the person confronted ends up in an inferior position and becomes the target of systematic negative social acts. A conflict cannot be called bullying if the incident is an isolated event or if two parties of approximately equal strength are in conflict (p. 20).

\section{A regulator definition}

An alternative definition of workplace bullying from a health and safety perspective is offered by WorkSafe NZ (2014):

Workplace bullying is repeated and unreasonable behaviour directed towards a worker or a group of workers that creates a risk to health and safety. Repeated behaviour is persistent and can involve a range of actions over time. Unreasonable behaviour means actions that a reasonable person in the same circumstances would see as unreasonable. It includes victimising, humiliating, intimidating or threatening a person. A single incident of unreasonable behaviour is not considered workplace bullying, but it could escalate and should not be ignored. Harassment and discrimination, which can be part of bullying, have their own legal remedies that are explained in the section on 'Other undesirable behaviour'(p. 6).

Practitioner and regulator definitions differ from those offered by academics and "tend to be more generally worded, and to emphasise the types of behaviours involved and the negative effects that bullying may have on the targets of the conduct" (Saunders et al., 2007, p. 342). It can be seen that the WorkSafe definition incorporates a number of the elements identified in the academic literature; albeit within a workplace health and safety context. Whilst it does not provide the same specificity regarding repetition and regularity of the negative behaviours, it does specify that they must be 'repeated' and occur 'over time'. This research does not adopt a single definition of workplace bullying. The aim of this research is not to determine prevalence rates of bullying, but rather explore current interventions and stakeholder interpretations of workplace bullying using a 
pragmatic research approach. Thus, whilst knowledge of key definitional elements is required by the researcher, a strict definition is not necessary.

\section{Bullying versus harassment}

The distinction between bullying and harassment has been debated by a number of researchers. Einarsen et al. (2011), view bullying and harassment as merely different terms describing the same phenomenon, and use the terms interchangeably. However it has been argued by others (see Zapf 2004), that bullying is distinct from harassment, and can be distinguished based on factors such as the targets defencelessness in bullying situations. Bullying and harassment have also been differentiated based on persistency, with harassment definitions offering a less strict interpretation of the frequency criterion (Branch, 2008).

In New Zealand, sexual harassment and discrimination are defined in the Human Rights Act 1993, whilst bullying has no legal definition. The WorkSafe definition does distinguish general harassment from bullying, although still allows for the possibility that harassment may form part of bullying (WorkSafe NZ, 2014). Bullying is also discussed as a form of harassment in State Services Commission guidance, although no definition is provided (NZ State Services Commission, 2003). From an organisational prevention and management perspective, bullying and harassment are likely to demand similar organisational responses. However, where an unclear distinction may negatively impact effective intervention, or where terms are legally defined, it would likely be necessary to clearly distinguish between forms of negative workplace behaviour.

\section{Conflict escalation}

Workplace bullying has been described as an escalated form of workplace conflict (Glasl, 1994; Leymann, 1990). The model of conflict escalation presented by Glasl (1994), and shown in Figure 2.1, provides a useful framework for understanding how negative behaviour may escalate into bullying and at what stages various interventions may be effective.

According to Zapf and Gross (2001), severe workplace bullying develops between stages six and seven, and is characterised by the development of destructive conflict. Organisations may attempt to de-escalate conflict situations by working back down the stages and using recommended methods at each next lower stage of model in order to resolve the conflict (Keashly \& Nowell, 2003). 


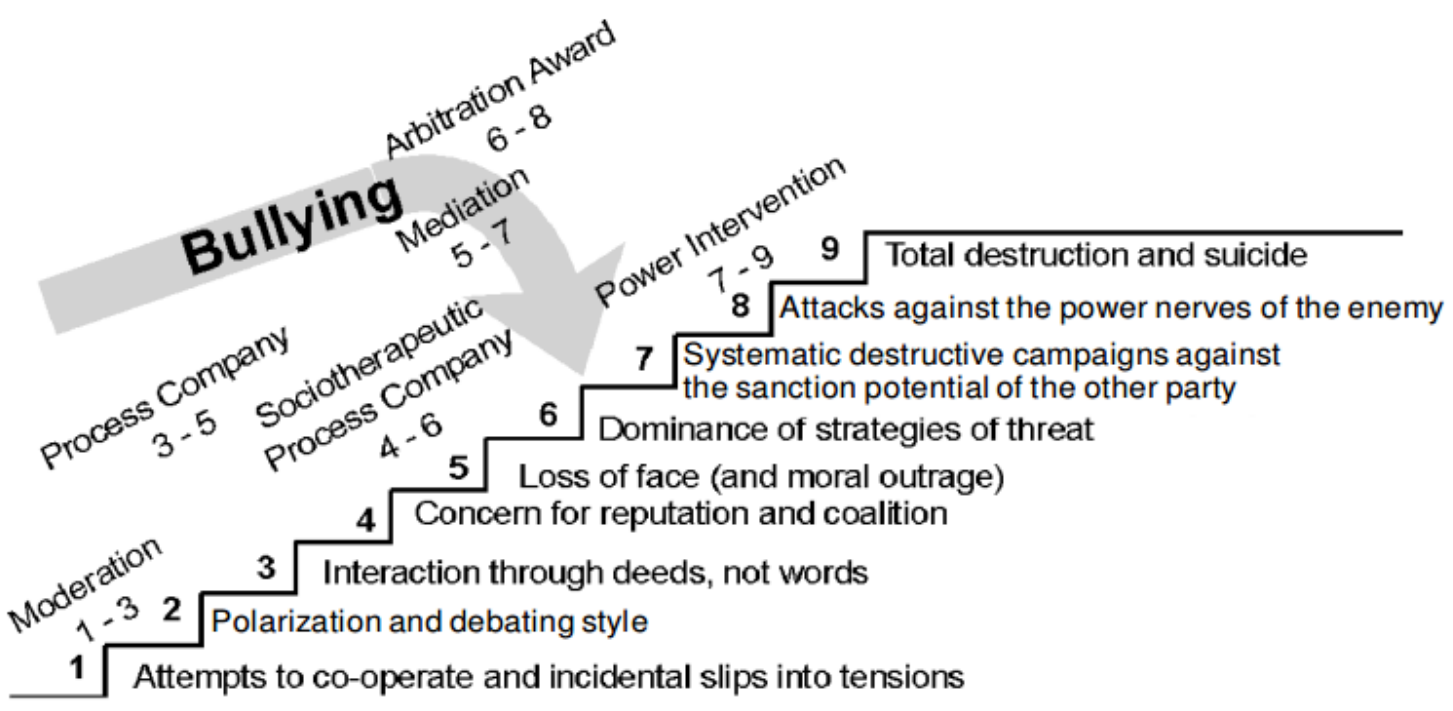

Figure 2.1 Model of conflict escalation by Glasl (1994), as adapted and presented in Zapf and Gross (2001)

\section{Measurement and prevalence}

The difficulties in defining workplace bullying are reflected in the debate surrounding measurement of the phenomenon. The self-labelling method and the behavioural experience method are the two most common methods for establishing bullying prevalence rates. The selflabelling method provides participants with a single question asking them if within a specific time period they believe they have been bullied; sometimes a definition of bullying may also be provided, with participants asked if their experiences align with that definition (Nielsen, Notelaers, \& Einarsen, 2011). The behavioural experience method comprises a list of negative behaviours where participants are asked to report the frequency with which they have experienced each in a stated time period (Nielsen et al., 2011). The Revised Negative Acts Questionnaire (NAQ-R) is the most commonly used behavioural method, measuring the frequency of individuals' exposure to a range of 22 negative behaviours (Einarsen et al., 2009). For studies measuring prevalence, it is generally recommended that both the self-labelling and behavioural experience methods are used (Nielsen et al., 2011).

International workplace bullying prevalence rates generally range between $11 \%$ and $18 \%$; however, higher rates up to around 20\% have also been reported (Nielsen, Matthiesen, \& Einarsen, 2010). Variation in prevalence is seen across industry sectors, with high bullying rates reported in health, education and public sector organisations (T. Bentley et al., 2009). In the public sector context, high rates of workplace bullying have been reported in state and regional public sector 
organisations both internationally (Ariza-Montes, Leal-Rodríguez, \& Leal-Millán, 2015; Hoel \& Cooper, 2000; Leymann \& Gustafsson, 1996; Salin, 2001; Zapf et al., 2011) and in New Zealand (NZ State Services Commission, 2014; Plimmer et al., 2013; Proctor-Thomson, Donnelly, \& Plimmer, 2011). However, despite the high levels of workplace bullying reported in public sector contexts, it is noted by Venetoklis and Kettunen (2015) that very little research has actually been conducted on workplace bullying in core government administrative organisations such as those within the New Zealand Public Service.

\section{New Zealand State sector environment}

The New Zealand State sector includes core Public Service departments, non-Public Service departments, and Crown Entities within the wider public sector, deriving much of its current character from the radical New Public Management (NPM) reforms beginning in the mid-1980s. Driven by desires to control bureaucracy, reduce government debt, and promote economic growth (Jun, 2009; G. Scott, Bushnell, \& Sallee, 1990); these diverse reforms emphasised autonomous government agencies, privatisation, formal performance indicators, and private sector managerial styles (G. Scott et al., 1990), (Jun, 2009; G. Scott et al., 1990). Despite generally serving New Zealand well, NPM has been criticised on a number of grounds; including the haste of implementation (Colley, McCourt, \& Waterhouse, 2012), the lack of central oversight (M. E. Gardner, 1993), and the general appropriateness of private sector management practices within the public sector (Radin, 2006).

Current public sector HRM has been described as not only incoherent with traditional public sector practice and worker experience, but also 'ill-equipped' to deal with the complex challenges of the Twenty-First Century (Colley et al., 2012; Ryan \& Gill, 2011). de Waal (2010) has criticised performance management initiatives for failing to improve public sector effectiveness; whilst Colley et al. (2012) believe that HR has failed in successfully attracting and retaining a quality public sector workforce. Palmer (2014) believes the New Zealand Public Service undervalues technical skills, suffers from poor inter-departmental coordination, and is stymied by a lack of training, and weak central leadership. It has further been suggested that contradictions inherent within evolved NPM environments may be conducive to forms of worker mistreatment such as workplace bullying (Plimmer, Proctor-Thomson, Donnelly, \& Sim, 2016). 
Table 2.1 Characteristics of public sector environments adapted from Bryson, Crosby \& Bloomberg, 2014, with additional adaptations from Hood, 1995.

\section{Traditional bureaucratic public management}

Bureaucratic government

Focus on formal rules and hierarchy

Public service ethic

$\stackrel{\mathfrak{N}}{ }$

\section{New Public Management Emerging public (NPM) governance}

Competitive nature Creation of public value

\section{Efficiency focused Citizen involvement}

Emphasis on private sector managerial practices

Use of performance

management practices

Autonomous government agencies
Factors in current public sector environment that may conflict to influence

bullying levels

Pressure to perform in a bureaucratic environment

\section{Multiple management layers}

Emphasis on collaboration with a range of government and non-government actors

\section{Greater centralised}

monitoring of trends
Focus on innovation within legislative and regulatory constraints

\section{Multiple stakeholder} involvement

Combination of centralised and decentralised HR responsibility - unique organisational practices may conflict with central agency guidance

Privatisation of government

functions

Decentralised HR with

practices devolved to

unskilled line managers 
Recent efforts to improve public sector performance have included the Better Public Services program focusing on collaboration and results-based frameworks, and the development of Public Service performance improvement frameworks (Better Public Services Advisory Group, 2011; NZ State Services Commission, 2015a). Better Public Services aligns with the emerging public governance approach outlined in Table 2.1, with R. Scott and Boyd (2016) arguing that the program has been relatively effective in achieving its aim. However, it is argued that there is potential for programs promoting innovation and collaboration, within an environment constrained by legislation and sedimentations of traditional public sector bureaucracy, to result in worker frustration, and potentially workplace bullying (Omari, 2006).

As outlined in Table 2.1, the current New Zealand public sector context emphasises features of traditional public management, NPM, and emerging public governance approaches (Chapman \& Duncan, 2007). It has been suggested that the combination of features from each of these approaches have resulted in a contradictory public sector environment, characterised by shifting performance expectations, and vague, disputed, and conflicting goals, that may be conducive to high levels of bullying, and also make it difficult to effectively prevent and manage (Colley et al., 2012; Omari, 2006). For example, the focus on performance management brought about by NPM reforms, may conflict with traditional notions of public service ethos and motivation; whilst the standardised and bureaucratic nature of traditional public management (Dunleavy \& Hood, 1994), may not allow for the flexibility of approach required in the prevention and management of a highly subjective and variable phenomenon. Furthermore, the de-centralised nature of HRM following NPM reforms, may result in poor central oversight and monitoring of trends in the Public Service (M. E. Gardner, 1993); possibly resulting in workplace bullying not being identified until it becomes a significant problem.

\section{Legislation governing the Public Service}

Public Service responses to workplace bullying are likely shaped by legislation. The Health and Safety at Work Act 2015 accounts for psychosocial hazards such as bullying through explicitly defining worker health as including mental health, whilst the section 56 good employer provisions within the State Sector Act 1988 obligate public sector organisations to ensure good and safe working conditions; essentially holding organisations accountable for preventing workplace bullying through effective primary intervention (Blackwood \& Bentley, 2013). Section 103A(3) of the Employment Relations Act 2000 (ERA 2000) influences secondary intervention by requiring all employers to carry out employment investigations, including into allegations of workplace bullying, following fair and proper process. 


\section{Antecedents}

Researchers have attempted to identify potential workplace bullying antecedents that may be helpful in developing effective prevention and management initiatives. Workplace bullying is commonly described as a multi-causal phenomenon seldom explained by any single factor, and is likely the result of an interaction between victim and perpetrator characteristics, and factors in the work environment (Salin, 2003; Zapf, 1999; Zapf \& Einarsen, 2011).

\section{Victim and perpetrator characteristics}

Several victim personality characteristics have been identified as potential workplace bullying antecedents. These characteristics include being an outsider within the work group (Zapf, 1999); displaying both low levels of social competence and self-assertiveness (Matthiesen \& Einarsen, 2007; Zapf \& Einarsen, 2011); and showing high levels of achievement (Kim \& Glomb, 2010).

Whilst these factors may be useful in helping to explain workplace bullying, Zapf and Einarsen (2011) urge caution in applying these characteristics to all victims of workplace bullying, with perpetrator and work environment factors also playing a role.

A number of perpetrator characteristics have also been identified by researchers attempting to explain workplace bullying. Authoritarian and autocratic leadership styles, where the person in charge has total authority and control over decision making, task delegation, and monitoring are seen as potential bullying antecedents (Johan Hauge, Skogstad, \& Einarsen, 2007; Mathisen, Einarsen, \& Mykletun, 2011; Skogstad, Einarsen, Torsheim, Aasland, \& Hetland, 2007). A laissezfaire leadership style, often characterised by indecision, a failure to provide feedback, and a general lack of involvement resulting in a failure to meet subordinate expectations may also help explain bullying behaviours (Johan Hauge et al., 2007; Mathisen et al., 2011; Skogstad, Einarsen, et al., 2007). Mathisen et al. (2011) also argue that low conscientiousness and high neuroticism amongst managers may contribute to the occurrence of bullying (Mathisen et al., 2011).

\section{Work environment hypothesis}

Moving beyond personality as an explanation for bullying behaviours, the work environment hypothesis emphasises organisational and psychosocial work environment factors as antecedents of workplace bullying (Skogstad, Torsheim, Einarsen, \& Hauge, 2011). Informed by the workplace stress literature, the work environment hypothesis posits that certain workplace factors may act as stressors which result in workplace bullying (Bartlett \& Bartlett, 2011). According to Salin (2003), factors contributing to the creation of a poor psychosocial work environment can fall into the three broad categories of enabling, motivating and precipitating factors. Enabling factors include 
structures and processes making it possible for bullying to occur in the first place (Salin, 2003). Motivating structures and processes make it rewarding to bully others in the workplace, and precipitating processes are triggers of workplace bullying (Salin, 2003).

Work-related enabling factors include high levels of role ambiguity (Bowling \& Beehr, 2006); excessive and unreasonable job demands (Tuckey, Dollard, Hosking, \& Winefield, 2009); high levels of role conflict (Bowling \& Beehr, 2006); unclear work and organisational goals (Bowling \& Beehr, 2006); limited job autonomy (Tuckey et al., 2009); and high levels of perceived job insecurity (Baillien \& De Witte, 2009). Enablers of workplace bullying include an organisational culture where bullying behaviours are normalised and where there is little support for prevention and management initiatives (Skogstad et al., 2011; Zapf, Knorz, \& Kulla, 1996); where workers perceive that there are strong imbalances of organisational power (Salin, 2003); and where there are low perceived costs to bullying, with sanctions either non-existent or not enforced (Salin, 2003).

A number of motivating factors have also been identified in the work environment. Motivating factors could include the use of performance based remuneration where workers may undermine and bully each other in competition for finite organisational resources (Salin, 2003); the use of collective reward systems where under-performing team members are bullied as punishment for their low performance (Salin, 2003); and where poor organisational systems and climate allow or promote bullying as a way to remove employees from the workplace (Salin, 2003). Several processes have also been identified as potential triggers of workplace bullying. These include more extensive use of part-time or temporary workers (Hoel \& Salin, 2003); pay cuts or freezes (Salin \& Hoel, 2011); changes in organisational management (Hoel \& Cooper, 2000; Salin, 2003); and organisational restructures (Hoel \& Cooper, 2000; Salin, 2003; Skogstad, Matthiesen, \& Einarsen, 2007).

Within the public sector environment, Ironside and Seifert (2003) have discussed the potential for competitive practices associated with NPM reforms, to be linked to bullying. Studies have also indicated that the higher rates of change often experienced in public sector environments (Beale \& Hoel, 2010), high levels of media scrutiny and political interference (Omari, 2006), and the high levels of emotional labour and personal involvement required in many public sector jobs (Zapf et al., 2011), may result in higher levels of workplace bullying. 


\section{Consequences}

Researchers have identified a number of organisational and individual consequences of workplace bullying. Individual consequences could include heightened anger and anxiety; poor concentration; experiencing feelings of isolation and sadness; low self-confidence and high stress levels (Bartlett \& Bartlett, 2011; Cooper-Thomas et al., 2013); higher absenteeism and intentions to quit; increased work errors and lost time; and lower performance, commitment and job satisfaction (Bartlett \& Bartlett, 2011; Cooper-Thomas et al., 2013). These factors can result in increased organisational costs associated with recruitment and also compensation for unjustified dismissals (Bartlett \& Bartlett, 2011). An organisation's culture and reputation may also suffer, as a climate of low morale, ineffective teams and poor interpersonal relationships takes hold (Bartlett \& Bartlett, 2011). In the context of the New Zealand Public Service there is evidence of high graduate turnover and poor departmental performance (NZ State Services Commission, 2016a). Whilst workplace bullying could also negatively impact individuals and organisations responsible for the delivery of core government policy in areas such as health, education, and social welfare.

\section{Conclusion}

Workplace bullying has been explained as a complex process encompassing frequent negative behaviours displayed over an extended period of time, where a power imbalance between a target and perpetrator may exist. Higher rates of bullying have been reported within public sector contexts internationally and in New Zealand, with researchers emphasising the difficulty of effectively dealing with the harmful phenomenon in public sector environments characterised by underperformance and weak HRM.

Chapter Three will discuss primary, secondary and tertiary interventions for effectively dealing with workplace bullying. It will be demonstrated that our understanding of effective workplace bullying interventions in core government agencies is severely limited, with this research seeking to provide insights into effective workplace bullying interventions within the New Zealand Public Service. 


\section{Chapter Three: Interventions for prevention and management}

\section{Introduction}

Effective workplace bullying intervention is important in complex public sector environments where high levels of bullying constitute a severe worker health and safety risk. Whilst a number of practices have been recommended by researchers, it is noted that there is a weak evidence base for some interventions; especially in public administration contexts. This chapter provides a summary of the literature on primary, secondary and tertiary workplace bullying interventions framed within the Public Health Model, and of the role of human resource practitioners and union representatives in their development and implementation.

\section{Health and safety perspective}

Bullying is commonly understood as a workplace health and safety hazard (Caponecchia \& Wyatt, 2009; Catley et al., 2013). As discussed in Chapter Two, the role of stress as a health concern is commonly explained through the work environment hypothesis; positing that certain psychosocial factors in the work environment act as stressors giving rise to workplace bullying (Johan Hauge et al., 2007; Skogstad et al., 2011). Consequently, the health of not only targets (Hogh, Mikkelsen, \& Hansen, 2011; Mikkelsen \& Einarsen, 2002), but also of bystanders (Johan Hauge et al., 2007; M. A. Vartia, 2001), and of others outside the organisation such as the victim's family members (Duffy \& Sperry, 2007), may be severely impacted. In an attempt to prevent these negative outcomes, health and safety legislation has been developed with the aim of regulating psychosocial hazards in the workplace. Legislation directing employers to take action against such hazards exists in a number of countries including Australia, Sweden, the Netherlands (Law, Dollard, Tuckey, \& Dormann, 2011); and is also explicitly provided for in New Zealand's Health and Safety at Work Act 2015. In addition to legislation, government health and safety regulators such as those in New Zealand (WorkSafe NZ, 2014), and Australia (Safe Work Australia, 2016; WorkSafe Victoria, 2012), have also provided workplace bullying prevention guidance framed within a health and safety context. At the organisational level, it is thus recommended developing organisational antibullying initiatives, such as anti-bullying policies, from a health and safety perspective (Rayner \& Lewis, 2011). 


\section{The Public Health Model}

Given the framing of workplace bullying as a serious health and safety hazard with the potential to cause severe harm to a range of societal stakeholders, it is argued that the Public Health Model can provide a useful framework for explaining workplace bullying interventions. The Public Health Model originates in the preventative medicine literature, and outlines primary, secondary, and tertiary intervention opportunities at the organisational, job and individual levels (Bartlett \& Bartlett, 2011; Quick, Quick, \& Nelson, 1998). Primary interventions are proactive in preventing the occurrence of harmful phenomena (M. Vartia \& Leka, 2011). Secondary interventions slow, reduce or reverse the progression of events, prevent recurrence, and provide individuals with effective coping resources (M. Vartia \& Leka, 2011). Whilst tertiary interventions aim to reduce negative impacts, provide individuals with coping mechanisms, and restore health and wellbeing (Cooper, Dewe, \& O'Driscoll, 2001). Research employing the Public Health Model has primarily been undertaken in the field of job stress (Cooper et al., 2001; Hurrell \& Murphy, 1996; LaMontagne, Keegel, \& Vallance, 2007); with workplace bullying researchers commonly distinguishing between primary, secondary and tertiary interventions (M. Vartia \& Leka, 2011). Whilst effective primary level prevention is argued as being of high importance, bullying is unlikely to ever be completely eliminated, and effective secondary and tertiary interventions are necessary (Blackwood, 2015); especially given the importance of third-party intervention in escalated conflict situations (Zapf \& Gross, 2001). This research thus adopts the view that to effectively deal with workplace bullying, organisations must adopt strong primary, secondary and tertiary interventions.

\section{Primary intervention}

The development of robust primary interventions is an important step in protecting individuals and organisations from the harmful impacts of workplace bullying (M. Vartia \& Leka, 2011). Primary interventions are proactive in nature and seek to prevent harm from occurring; they can be targeted at both the organisational and individual levels (Lamontagne, Keegel, Louie, Ostry, \& Landsbergis, 2007; M. Vartia \& Leka, 2011). In the context of workplace stress, there is a focus on reducing or eliminating workers exposure to stressors, by making changes in the psychosocial and physical work environments (Lamontagne, Keegel, Louie, et al., 2007).

Researchers have recommended a limited number of specific primary interventions that may be used in the development of an organisational anti-bullying culture. Organisations with a strong anti-bullying culture view bullying as unacceptable, and implement a range of initiatives at all organisational levels to eliminate harmful workplace behaviour (Duffy, 2009). The development 
and implementation of an organisational anti-bullying policy is the most commonly recommended primary intervention (Cowan, 2011; Duffy, 2009; Fox \& Cowan, 2015; Harrington, Rayner, \& Warren, 2012; Rayner \& Lewis, 2011; Richards \& Daley, 2003; Salin, 2008b). Staff and management training is also recommended in the recognition and reporting of workplace bullying and other negative behaviours (Richards \& Daley, 2003); in the consequences of bullying (Ferris, 2009); in the practice of positive behaviours, conflict management, interpersonal communication, and stress management (Richards \& Daley, 2003). The identification of bullying antecedents, and the use of selection policies to screen-out applicants with undesirable traits are also recommended by academics and practitioners (S. Gardner \& Johnson, 2001; Glendinning, 2001).

\section{Primary: Anti-bullying policy}

Developing an organisational anti-bullying policy is commonly promoted as a way to raise the profile of workplace bullying, and help to prevent its occurrence within organisations (Salin, 2008b; M. Vartia \& Leka, 2011). Richards and Daley (2003) argue that policies have the dual role of being an organisational statement of intent and a guide for all stakeholders navigating formal and informal workplace bullying interventions. Policies may be bullying specific, or incorporate other negative workplace behaviours such as sexual harassment or discrimination; either approach is acceptable (Caponecchia \& Wyatt, 2009). Research by Cowan (2011) has revealed some policies do not use the term 'bullying' at all, yet are still perceived by human resource professionals to encompass workplace bullying behaviours. However, such an approach is not recommended as it may discourage complaints of workplace bullying, and undermine wider organisational prevention initiatives (Cowan, 2011).

\section{Policy content}

Researchers have recommended a number of components for inclusion within anti-bullying policies. Policies generally begin with a statement of intent clearly establishing the organisation's stance towards workplace bullying (Rayner \& Lewis, 2011). Often this will espouse a zero-tolerance stance where organisation's state they have no-tolerance for bullying (Richards \& Daley, 2003). A definition of workplace bullying should then be included. Given the complexity of bullying and to prevent policies from becoming outdated, a relatively broad definition is often used; however this should incorporate the core elements discussed in Chapter Two (M. Vartia \& Leka, 2011). The inclusion of specific bullying examples reflecting the organisations interpretation of workplace bullying is also recommended (Richards \& Daley, 2003; M. Vartia \& Leka, 2011). Examples should thus relate to the organisation's definition of workplace bullying, and provide a range of potential bullying scenarios in the context of the specific activities undertaken by the organisation. 
Describing the informal and formal processes for making and resolving complaints of workplace bullying is important. Informal approaches are generally desirable, and whilst it is recommended that policies provide sufficient practical guidance for targets and managers to successfully resolve informal workplace bullying complaints, it is noted that the literature provides little practical guidance in this area. A detailed description of the formal complaint making and investigation process is also necessary. This should include a time-frame for complaint investigation, an explanation of how findings will be reported, and a discussion of the appeals process (Duffy, 2009). Policies should reference other related policy documents where relevant, and also provide specific contact details for stakeholders wanting further advice or guidance (M. Vartia \& Leka, 2011). In addition, policies should be relatively short, and use clear language that is easy for all users to understand (Richards \& Daley, 2003; Salin, 2008b). The specificity of policies is also important, as research has shown that human resource practitioners believe some organisational anti-bullying policies are not specific enough to actually help them deal with situations of workplace bullying (Cowan, 2011). There is also growing recognition of the importance of providing additional support and guidance for those who have been accused of bullying and also for managers and complainants (M. Vartia \& Leka, 2011). This may mean that extra guidance is provided for individual stakeholders in separate or attached documents.

\section{Policy development and implementation}

The process of policy development and implementation is important, yet often poorly executed by organisations (Rayner \& Lewis, 2011). It has been argued that the existence of a policy may raise employee expectations about the organisations role in dealing with workplace bullying, thus increasing the importance of following through with effective processes (Salin, 2008b). Research suggests that the mere existence of a policy is on its own unlikely to reduce the occurrence of workplace bullying (Salin, 2008a), and even policies which adhere to best practice are unlikely to be effective if they are inconsistently or incorrectly implemented (Woodrow \& Guest, 2014).

A number of actions have been recommended to ensure effective policy implementation and development. The involvement of a range of stakeholders in policy development and implementation is recommended to increase stakeholder awareness and acceptance of policies (Einarsen \& Hoel, 2008; Richards \& Daley, 2003). Employees at all levels, line managers, senior management, human resource personnel and union representatives should all be involved in policy development and implementation (Lewis \& Rayner, 2003). Those tasked with implementing policy functions, such as informal and formal resolution processes, should be trained in their application. Policies should be promoted in a variety of ways, such as through training, induction, meetings, 
the organisations intranet and other electronic and print publications to increase stakeholders awareness of the policy (Rayner \& Lewis, 2011).

Rayner and Lewis (2011) and Richards and Daley (2003) argue that monitoring and review of antibullying policies is an important aspect of policy implementation that is often ignored, and can lead to policy failure. Effective monitoring should include staff perception surveys and measuring statistics such as complaints made, to help evaluate a policy's effectiveness. It is recommended that anti-bullying policies and any associated data is reviewed on an annual basis (Rayner \& Lewis, 2011).

\section{Primary: Identification of antecedents}

A range of antecedents to workplace bullying have been identified by researchers, including those previously discussed in Chapter Two. The identification and subsequent elimination of antecedents is promoted as an important primary intervention to minimise the risk of workplace bullying occurring. Antecedents could be identified in a number of ways, including through surveys, meetings, focus groups, interviews, or document analysis (M. Vartia \& Leka, 2011). Tools such as the Bullying Risk Assessment Tool (BRAT) have also been developed for the specific purpose of antecedent identification. The BRAT assesses organisational fairness, team conflict, role conflict, workload, and leadership (Hoel \& Giga, 2006).

\section{Primary: Selection practices}

The use of staff selection systems to screen out applicants with undesirable traits that could lead to bullying behaviour has been cautiously promoted by researchers. The use of interviews and psychological tests to reduce the likelihood of hiring workers with identified undesirable traits has been suggested by S. Gardner and Johnson (2001). Screening can be undertaken to look for individual bullying antecedents such as those identified in Chapter Two. However, it is still recommended that applicant selection measures be strictly job-related, and designed to primarily assess job-related skills and knowledge; any use of screening practices to identify potential bullies should be seen as a secondary function (Fodchuk, 2007).

\section{Secondary intervention}

Secondary interventions endeavour to resolve an existing bullying situation and prevent further escalation. A common secondary intervention recommended for the management of workplace bullying is the development of sound complaint investigation processes for alleged bullying complaints (Hoel \& Einarsen, 2011). Other recommended secondary interventions include the use of mediation (Fox \& Stallworth, 2009); the provision of social support and counselling services 
(Djurkovic, McCormack, \& Casimir, 2008; M. Vartia \& Leka, 2011); the development of target coping strategies (Zapf \& Gross, 2001); and managerial training in conflict management and complaint investigation (Hoel \& Einarsen, 2011).

\section{Secondary: Investigation process}

Effective complaint investigation processes should send a strong signal to employees that workplace bullying is taken seriously and is not tolerated by the organisation. Investigation processes should be detailed in an organisation's anti-bullying policy and governed by the principle of natural justice or due process (Hoel \& Einarsen, 2011). All parties should be treated fairly and equally throughout the investigation process, with the accused given an opportunity to respond to any allegations made (Hoel \& Einarsen, 2011). The importance of providing guidance and support for all organisational participants is emphasised by Jenkins, Winefield, and Sarris (2011), whose research found the investigation process can take a significant toll on those accused of bullying; whether found guilty or not.

Investigations are best conducted internally, unless the complaint involves very senior members of the organisation (Hoel \& Einarsen, 2011). Relevant legislation should be accounted for in the investigation process. In New Zealand, the Employment Relations Act 2000 requires organisations to have an investigation process in place. There exists some contestation with regard to confidentiality and anonymity in the investigation process. Realistically, complainant's confidentiality can only be assured as far as it does not impede the investigation process, or the organisation's duty of care towards other workers at risk from similar negative behaviours (Merchant \& Hoel, 2003). Anonymity should also not be offered to witnesses; even though this might discourage their coming forward (Hoel \& Einarsen, 2011).

Investigations usually follow four main steps, including preparation and planning, gathering evidence, reaching a conclusion, and writing a report (Hoel \& Einarsen, 2011). In the preparation and planning stage, authority must first be given for the investigation to proceed; this is usually provided by the head of the Human Resources Department (Hoel \& Einarsen, 2011). Investigators should ensure their roles are clearly defined, and that the investigation process is aligned with any timeframe specified in organisational policies (Hoel \& Einarsen, 2011). It is important that no judgement is made by investigators until the conclusion of a proper investigation.

Given interviews are generally the primary method of evidence collection, organisations should establish a robust interview process. The complainant, alleged perpetrator and any witnesses should be interviewed. When communicating information about the interview process both the claimant an the alleged perpetrator should receive the same information; including any right to be 
accompanied by a support person (Merchant \& Hoel, 2003). It is important interviewers are well trained in interview techniques, dealing with emotions, and managing personal biases (Hoel \& Einarsen, 2011). The interviewer needs to give the complainant and the alleged perpetrator scope to tell their story, but also keep the interview under control and focused on the issue at hand (Merchant \& Hoel, 2003). In addition to interviews, evidence could include any unusual behaviours, physical evidence and an inspection of the physical environment; these forms of evidence may be particularly important if there are no witnesses to the alleged behaviours.

In determining a conclusion, it is noted that the more serious the implications, the stronger the evidence required to support the case. A final report should be produced including relevant legislation, policy, evidence, conclusions, and any other issues that may have arisen during the investigation.

\section{Secondary: Mediation}

Mediation is commonly recommended for the resolution of workplace bullying, and involves a neutral third party, such as an internal supervisor or an external consultant, working with affected parties to find a solution to the issue (Saam, 2010). Whilst mediation can be a valuable tool, its use in workplace bullying complaint resolution has been criticised. Hoel and Einarsen (2011) argue that given its popularity, mediation may be forced on complainants, even when it may actually cause further harm to the victim. For instance, given that victims' of bullying may be disempowered following their experiences, and that mediation is seen to enforce existing power imbalances, mediation may be an inappropriate resolution tool (Keashly \& Nowell, 2003). The confidential nature of mediation may obscure patterns of negative behaviour, and also insufficiently punish past behaviours; engendering feelings of injustice amongst victims (Keashly \& Nowell, 2011). Ensuring high levels of procedural justice when conducting mediation is considered important, as procedural justice perceptions are related to perceptions of mediation effectiveness (Ittner, Bollen, \& Euwema, 2009). Researchers have recommended that mediation should only be used in the early stages of bullying development where both parties are generally interested in resolving the conflict situation reasonably; mediation is not recommended as a resolution pathway in escalated cases of bullying (Jenkins, 2011; Keashly \& Nowell, 2003). Accordingly, Glasl (1994) recommends the use of mediation around stages five to seven of the conflict escalation model (see section 2.3), where there may be advanced conflict, but this has not yet developed into a severe and destructive form of bullying. 


\section{Tertiary intervention}

Individual and group orientated tertiary interventions aim to reduce the negative impacts of bullying and restore the health of victims. Counselling is a commonly recommended tertiary intervention for victims and perpetrators of workplace bullying. However, traditional one-to onecounselling may not be appropriate for cases of workplace bullying, and instead an integrated approach should be taken. An integrated counselling program should focus on not only on the victim, but also other stakeholders and organisational factors which may have contributed to the bullying situation (Tehrani, 2011). Inpatient treatment for victims of workplace bullying who have suffered severe harm is also recommended as a tertiary intervention. Inpatient treatment involves bullying victims participating in a rehabilitation program where they can distance themselves from the bullying situation, understand personal and organisational contributions to the bullying situation, and find practical and therapeutic measures to deal with the harm (Schwickerath \& Zapf, 2011). Other tertiary interventions advocated by researchers include physiotherapy and physical exercise, which may form part of an inpatient treatment program (Mikkelsen \& Einarsen, 2006); monetary and non-monetary forms of redress (Meglich-Sespico, Faley, \& Knapp, 2007); and group recovery programmes (Mikkelsen \& Einarsen, 2006).

\section{Role of key stakeholders}

Stakeholders including line managers, human resource practitioners and union representatives are commonly involved in the prevention and management of workplace bullying. These stakeholders are likely to have an intimate understanding of the development and implementation of organisational initiatives designed to deal with workplace bullying (Baillien, Neyens, De Witte, \& De Cuyper, 2009); their views are thus important in understanding effective intervention in complex public sector environments.

\section{Line managers}

Line managers have an important role as they are often best placed to identify and deal with both one off instances of workplace incivility and instances of workplace bullying (Rayner \& Lewis, 2011). Many anti-bullying policies thus direct employees who believe they have been bullied to approach their line manager in the first instance (Richards \& Daley, 2003; Salin, 2008b). However, this approach can present challenges when the manager is the one accused of bullying, or when managers display laissez-faire styles of management (Skogstad, Einarsen, et al., 2007). Reinforcing the importance of line manager involvement, employees have reported more positive intervention experiences when line managers proactively intervened in alleged cases of workplace bullying and 
correctly followed informal resolution pathways (Woodrow \& Guest, 2014). Bullying experiences also appear to be highly personalised, emphasising the need for well-trained managers who have the skills to effectively tailor interventions based on the circumstances of individual bullying cases (Blackwood, 2015). Managerial inaction in alleged cases of workplace bullying could exacerbate bullying problems as perpetrators believe the costs of their behaviour are low (Woodrow \& Guest, 2014). Thus, line managers must possess the skills to both identify and intervene in suspected cases of workplace bullying (Rayner \& Lewis, 2011).

\section{Human resource professionals}

There has been growing interest in the role of human resource practitioners in the prevention and management of workplace bullying, with the Human Resource Department often central to the development and implementation of anti-bullying initiatives; especially in larger organisations (Lewis \& Rayner, 2003). Human resource practitioners are commonly involved in the development of organisational anti-bullying policies and the implementation of anti-bullying training and awareness initiatives; with the investigation of alleged instances of workplace bullying through formal process generally the domain of human resource practitioners (Cowan, 2011). However, anti-bullying policies rarely portray the Human Resource Department as the main contact point for complainants (Salin, 2008b). In dealing with workplace bullying, human resource practitioners see their role as one which includes being a trusted listener, an objective and neutral third-party investigator, an advisor to management, a mediator, trainer, coach, and an emotional labourer (Cowan \& Fox, 2015). Human resource professionals have thus reported that their role in dealing with workplace bullying may clash with senior manager and target expectations, and managers may be treated more favourably than other employees (Cowan \& Fox, 2015). There is also some evidence to suggest that human resource practitioners may perceive bullying complaints differently to victims (Harrington et al., 2015).

\section{Union representatives}

Empirical research investigating the role of union representatives in the prevention and management of workplace bullying is limited; especially from union representatives perspectives (for an example see Baillien et al., 2009). Union representatives may play a number of roles, including as a point of contact for alleged victims of bullying to obtain further information (Mikkelsen, 2004); as a support person for victims of bullying (Richards \& Daley, 2003); as collaborators in the development and implementation of organisational anti-bullying initiatives (Lewis \& Rayner, 2003); as interveners in the early stages of workplace bullying (Beale, 2011); as lobbyers of organisational change to address workplace bullying (Einarsen et al., 2011); and as 
disseminators of information regarding organisational anti-bullying initiatives (Mellish, 2001; Rayner \& Lewis, 2011). It does appear that much of the research discussing the role of URPs is anecdotal, with very little empirical evidence available; possibly a result of declining academic interest in researching unions following falling membership densities, coinciding with the rise in interest in researching workplace bullying.

\section{Conclusion}

A number of interventions to prevent and manage workplace bullying have been suggested at the primary, secondary and tertiary levels of the Public Health Model. A commonly recommended primary intervention is the development of an anti-bullying policy, with the identification of possible bullying antecedents and the screening of applicants for undesirable traits at the recruitment stage also suggested. If cases of bullying do occur in the workplace, a number of secondary and tertiary interventions are recommended. Secondary interventions include the development of a fair and comprehensive bullying complaint investigation process, the possible use of mediation in early stages of conflict escalation, and the development of victim coping strategies. Counselling and inpatient treatment are recommended tertiary interventions, along with monetary and non-monetary forms of redress, and group recovery programs. Training in a range of areas is recommended at all levels of intervention.

It is noted by the researcher that there is a fine line between intervention levels and some contention amongst researchers as to which level they are placed. For instance, the development of an anti-bullying policy is a primary intervention, however much of policy content, such as complaint processes, are secondary in nature. 


\section{Chapter Four: Methodology}

\section{Introduction}

This chapter will describe the methods and assumptions fundamental to this research. An overview of the research tradition in the workplace bullying field is offered, and then justification is given for the use of a pragmatic research approach. Several aspects of the research process are then discussed, including the collection of documents; recruitment of interview participants; use of semi-structured interviews; and the process of thematic analysis for documents and interview transcripts.

\section{Research tradition}

Workplace bullying research is commonly undertaken within the positivist or post-positivist paradigm, and has primarily focused on defining and measuring bullying, as well as the identification of perpetrator and victim characteristics (Cowan, 2009; Samnani, 2013). However, there have been calls to investigate the multi-causal and deeply subjective phenomenon of workplace bullying from other perspectives to provide additional depth and detail to advance our understandings of the subject, and to enable effective intervention (Lutgen-Sandvik, 2008; Tracy, Lutgen-Sandvik, \& Alberts, 2006).

In response, researchers have promoted (Samnani, 2013) and used (Cowan, 2009, 2012) an interpretative approach to studying workplace bullying. The interpretative approach is based on the underlying assumption that knowledge is subjective, and utilises qualitative research methods to understand and interpret individual and locally situated experiences (Bryman \& Bell, 2003). It was the intention for this research to take an interpretative approach, however it soon became clear that an interpretative approach was not the most appropriate to provide insights into effective workplace bullying interventions; the alternative paradigm of pragmatism was thus chosen.

\section{Pragmatism}

According to Feilzer (2010, p. 7), pragmatism “...focuses on the problem to be researched and the consequences of the research". It is an explicitly value orientated approach to research, freeing the researcher from the constraints imposed by the positivist/interpretivist dichotomy, and allowing research approaches to be mixed and used in ways that offer the best opportunities to achieve research aims (Johnson \& Onwuegbuzie, 2004). The pragmatic method is rooted in the traditions of classical pragmatists such as Charles Sanders Peirce, William James and John Dewey, who sought to clarify and explain intellectual concepts through a focus on the consequences of 
actions (Cherryholmes, 1992). Johnson and Onwuegbuzie (2004) argue that looking at both empirical findings and practical consequences can help researchers in their understandings of philosophical positions and thus better guide their research into real-world phenomena.

Pragmatism offers the opportunity to develop our understanding of the process of workplace bullying through its assumption that practice and inquiry are in constant interplay; in effect pragmatism endorses practical theory or praxis (Johnson \& Onwuegbuzie, 2004). Pragmatists assume that truth is akin to the notion that "for the time being this is what we know - but eventually it may be judged partly or even wholly wrong" (Corbin \& Strauss, 2008, p. 4); knowledge is treated as a provisional truth. This is important in the study of workplace bullying where our understanding of what constitutes bullying is constantly under review, and where we seek to define a moving target (Burnes and Pope, 2007). However, pragmatism does also assume that “... some social knowledge certainly is cumulative and provides the basis for the evolution of thought and society" (Corbin \& Strauss, 2008, p. 4). Pragmatism is thus well suited to the study of workplace bullying, where despite individual experiences being highly contextual (Blackwood, 2015), some aspects such as the core definitional elements, provide the basis for our understanding of the phenomenon.

\section{Deductive, inductive and abductive reasoning}

Researchers may use three possible modes of inquiry when conducting research; deduction, induction and abduction. Deductive reasoning is focused on testing and confirming hypotheses and theories (Reichertz, 2004); inductive reasoning is focused on the development of generalisations through observation, reflection and the construction of explanations (Kelemen \& Rumens, 2008); whilst abductive reasoning provides insights into phenomena within a particular situation, although it may also lead to the development of general 'rules' (Reichertz, 2004; Svennevig, 2001). In an abductive approach, the researcher plays an interpretative role in distinguishing between factors relating to a particular situation, and those that may be applicable more generally (van Hoek, Aronsson, Kovács, \& Spens, 2005). Whilst both abduction and induction are essentially focused on 'theory' creation, they are distinguished on the point that abduction seeks to develop new understandings, whilst induction is more focused on producing generalised findings from data (van Hoek et al., 2005). It is possible to use all three modes of inquiry within a single research study, where the researcher analyses "the data sets abductively as well as deductively and inductively, separately at first, then moving back and forth between the data sets with the knowledge produced by each one, finally bringing them together" (Feilzer, 2010, p. 10). 


\section{The abductive research process}

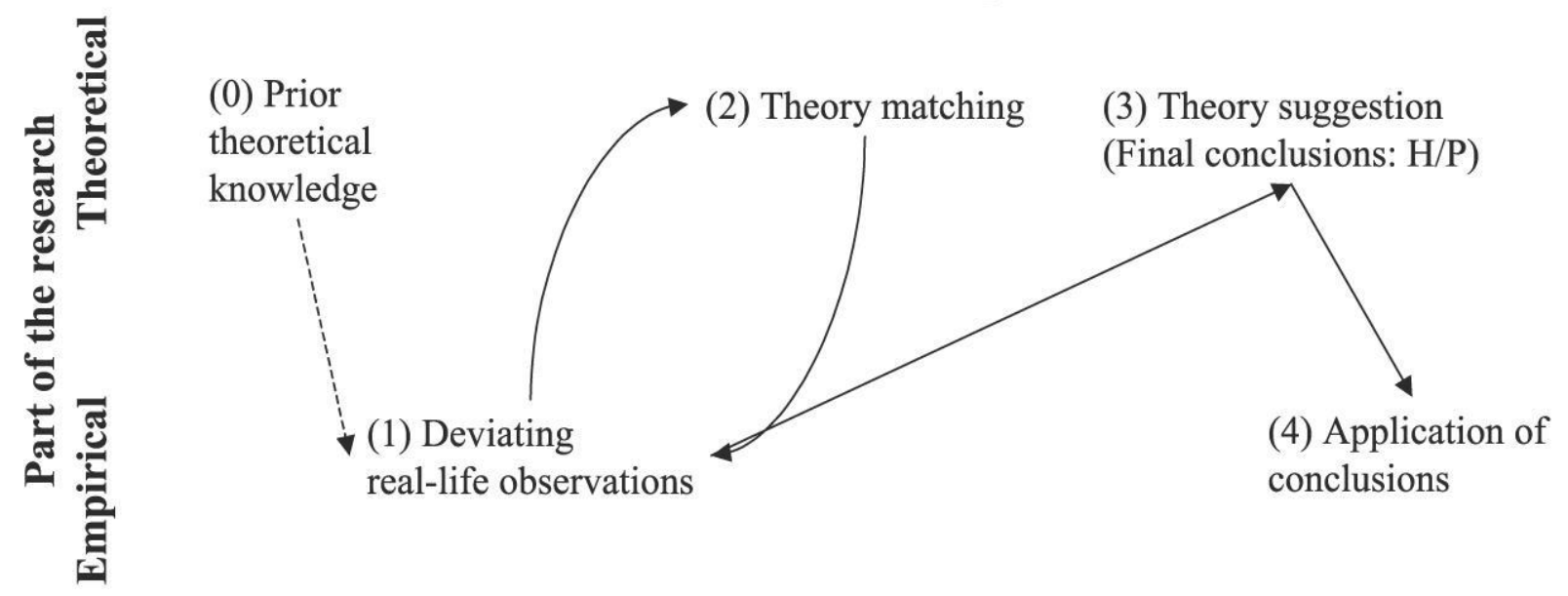

Figure 4.1 The abductive research process from van Hoek et al. (2005)

The current research project aligns with the abductive research process based on the work of pragmatist Charles Sanders Pierce, and described by van Hoek et al. (2005). Whilst abductive inquiry does not yield the certainty of either deduction or induction (for the researcher plays an interpretative role), it does produce new ideas, and aligns with the need to develop deeper understandings of workplace bullying (Svennevig, 2001). As shown in Figure 4.1, the starting point for the abductive research process is a real life observation at point 1, which cannot be explained by existing 'theory'; in the current research project, existing workplace bullying research was unable to explain the reported high rates of public sector workplace bullying, and the difficulty in developing effective interventions. Thus an iterative process of theory building between steps 1 and 2 was undertaken; documents were initially analysed deductively, then documents and interviews were analysed inductively. The process resulted in a number of insights into effective workplace bullying interventions, and the development of theory (step 3) to be tested in future deductive research (step 4).

\section{Mixed-methods research}

Pragmatism is often associated with mixed methods research, that is the inclusion of quantitative and qualitative techniques, methods, approaches, concepts or language in a single research study (Johnson \& Onwuegbuzie, 2004). Quantitative research generally focuses on “... deduction, confirmation, theory/hypothesis testing, explanation, prediction, standardised data collection and statistical analysis.” (Johnson \& Onwuegbuzie, 2004, p. 18). Qualitative research on the other hand encompasses “ “... induction, discovery, exploration, theory/hypothesis generation, the researcher as the primary 'instrument' of data collection, and qualitative analysis" (Johnson \& Onwuegbuzie, 
2004, p. 18). This research adopts a similar approach to what Johnson and Onwuegbuzie (2004) call a mixed model design, where qualitative and quantitative approaches are mixed across the stages of the research process in order to best answer the projects central research question. This approach also aligns with O'Leary (2014), where the quantification of qualitative data such as documents is undertaken in a mixed-method research design.

\section{Research design}

\section{Sample recruitment and data collection}

This research relies on two main data sources: documents and interviews. Organisational documents pertaining to the prevention and management of workplace bullying in Public Service departments, and interviews with key organisational stakeholders involved in dealing with Public Service workplace bullying. Two forms of data were chosen as it was seen as the best way to fully answer the research questions.

\section{The New Zealand Public Service}

The core New Zealand Public Service includes 28 departments (as at December 2016) defined in Schedule One of the State Sector Act 1988. Public Service departments are involved in the delivery of core government services and employ just over 45,000 full-time equivalent workers who are spread across New Zealand; the largest proportion of the workforce is based in the cities of Wellington (41.94\%) and Auckland (20.32\%) (NZ State Services Commission, 2016a). Union densities in the Public Service are on average higher than private sector organisations, with the New Zealand Public Service Association (PSA) representing around 60,000 workers across the wider public sector (NZ Companies Office, 2015). It has been recognised that the Public Service has an ageing workforce, with an average age of 44.8 years (NZ State Services Commission, 2015b). Public Service departments are also subject to a high degree of scrutiny by media and the general public (Samkin \& Schneider, 2010).

\section{Collection of documents}

A broad view of anti-bullying policy was taken in this research, and is seen to encompass all organisational documentation used to support workplace anti-bullying initiatives. Documentation could be in paper or electronic format, including anti-bullying policies, harassment policies, codes of conduct, and guidance for complainants and other stakeholders including managers and bystanders. An initial internet search revealed that organisational anti-bullying policies were not freely available on agencies' public websites. 
An email was thus sent to 15 Public Service departments requesting copies of their organisational anti-bullying policy; organisational harassment policy; organisational code of conduct; any other policy or guidance documents used by the department in the prevention or management of workplace bullying; the number of formal bullying complaints made by Ministry staff, each year, for the period 2010-2016; and the number of bullying complaints made by Ministry staff that were upheld as acts of bullying, each year, for the period 2010-2016. The 15 departments were chosen as they were seen as reflective of the wider Public Service, with a mix of small and large workforces, and diverse functions. All 15 Departments who were contacted responded to the email request and supplied varying levels of information; see Table 5.1 for breakdown of information supplied. Note that organisation NC failed to attach the required documents and only supplied figures on complaints; subsequent attempts to obtain the documents were unsuccessful.

\section{Semi-structured interviews}

Key informants involved in the prevention and management of workplace bullying were identified through both purposive and snowball sampling. In the first instance three organisations, including two Public Service departments and a public sector union, were contacted to gauge their interest in participating in the research. Contacting the organisation first, rather than individual applicants was primarily for practical reasons, with the organisation being in a better position to identify those who are actively involved in dealing with workplace bullying. Once organisations were confirmed, they then provided the contact details of one or more persons involved in dealing with workplace bullying.

Additional informants were identified by the initial contact in each organisation, and one further participant from a fourth organisation was identified during the process of collecting anti-bullying policies. In total, ten semi-structured interviews were conducted with human resource practitioners $(n=6)$ and union representatives $(n=4)$; saturation was reached when no new information emerged in additional interviews, and existing themes were confirmed by subsequent participants (Guest, Bunce, \& Johnson, 2006). To ensure participants were interviewed in a location that was both convenient and somewhere they felt comfortable, participants were asked where they would prefer the interview to take place; all participant interviews were thus undertaken at the participant's organisation at their request.

Semi-structured interviews are a flexible approach to interviewing that generally follow broad predetermined themes or areas of discussion outlined in an interview guide (Bryman \& Bell, 2003). Whilst these may be phrased as questions, they are left vague enough to foster further conversation and discussion. Semi-structured interviews allow the researcher to explore pre-determined areas 
of interest, and also for the discussion of additional questions and topics that may arise during the interview process. Semi-structured interviews with key informants was seen as appropriate for this research as this is an exploratory research project and it was important that participants had the opportunity to share their experiences with the researcher. With the participant's consent all interviews were voice recorded to enable later analysis of the interview data. All ten interviews were transcribed verbatim by the researcher soon after the interview had taken place. A basic interview guide is provided in Appendix C.

\section{Data analysis}

The data collected for this research project was analysed in four separate, but interrelated stages outlined in Table 4.1. Stage one involved an initial analysis of bullying complaint statistics; stage two involved a document analysis of codes of conduct; stage three involved a document and thematic analysis of organisational documents to identify policy characteristics and key themes; whilst stage four involved the thematic analysis of the key informant interviews.

\section{Table 4.1 The four stages of data analysis}

\begin{tabular}{ll} 
Stage & Aim \\
\hline $\begin{array}{l}\text { 1. Analysis of bullying } \\
\text { complaint statistics }\end{array}$ & $\begin{array}{l}\text { Identify pattern of bullying complaints, including those } \\
\text { upheld and unsubstantiated 2010-2016 }\end{array}$ \\
\hline $\begin{array}{l}\text { 2. Analysis of codes of } \\
\text { conduct }\end{array}$ & $\begin{array}{l}\text { Understand core features and relationship with anti- } \\
\text { bullying policy and broader intervention initiatives }\end{array}$ \\
& $\begin{array}{l}\text { a. Provide broad overview of document characteristics } \\
\text { b. Understand core policy features and comparison with }\end{array}$ \\
3. Analysis of anti-bullying & $\begin{array}{l}\text { recommended practice from the literature } \\
\text { documents }\end{array}$ \\
c. Analysis of supporting guidelines \\
d. Identify key themes through thematic analysis of \\
documents
\end{tabular}

4. Analysis of interviews Identify key themes through thematic analysis 


\section{Document analysis}

Basic features and trends within the surface of the codes of conduct and policies were identified through an initial document analysis. In total, 42 documents, comprising 432pp were subjected to an initial document analysis in stages two and three. Features identified were informed by both existing research and also emerged as part of the analysis process. In analysing documents, Bowen (2009) states that the researcher should aim to "establish the meaning of the document and its contribution to the issues being explored" (p. 33). This form of document analysis was conducted by Salin (2008b) in the context of Finnish anti-bullying policies, where factors such as policy design, layout, professionalism, and inclusion of policy elements recommended in the literature were analysed. This document analysis also aligns with the type discussed by O'Leary (2014) and Grbich (2012), where the researcher may analyse data through tallying and other quantitative or qualitative methods.

\section{Thematic analysis}

Organisational anti-bullying documents and the interview transcripts were also thematically analysed in stages three and four, respectively. In total, 29 policy documents and ten interview transcripts, totalling 409pp were subjected to thematic analysis. The use of thematic analysis in workplace bullying research is growing, and has been used by Cowan (2009) to analyse organisational bullying policies, and by Blackwood (2015) to analyse victim interviews. Braun and Clarke (2006) describe thematic analysis as a broad method used for the identification and analysis of patterns within research data, which is suitable for use with a range of theoretical frameworks.

Table 4.2 Phases of thematic analysis adapted from Braun and Clarke (2006)

\section{Phase}

1. Data familiarisation through transcription and reading

2. Initial code generation

3. Organising codes into potential themes

4. Checking accuracy of themes and production of thematic map

5. Refining themes, defining and naming themes

6. Analysis of data, and selection of relevant examples to include in report 
The six stages of thematic analysis proposed by Braun and Clarke (2006) and outlined in Table 4.2 were used as a guideline to analyse the documents and interview transcripts. Braun and Clarke (2006) note that the process of thematic analysis is not necessarily linear, and that the movement back and forth between steps in an iterative and reflexive manner is often necessary. Data familiarisation occurred with the documents through an initial reading of all documents provided by organisations, and with the interviews through their transcription and subsequent re-reading by the researcher; in both cases any initial thoughts or ideas were noted down in a Word document. With the interviews, notes were also made within the transcriptions at points where participants changed their tone of voice or showed a change in emotion.

The documents and transcribed interviews were then uploaded to NVivo where initial codes were assigned to relevant pieces of text. In the search for themes, both semantic and latent coding was conducted. Semantic coding focuses on themes and patterns on the surface of data, whereas latent thematic analysis "goes beyond the semantic content of the data, and starts to identify or examine the underlying ideas, assumptions, and conceptualizations" (Braun \& Clarke, 2006, p. 84). The decision to code for both semantic and latent themes was seen as the best way to answer the research questions, and also to meet the needs of an exploratory research project aiming to gain familiarity with, and provide insights into, the complex phenomenon of workplace bullying in the New Zealand Public Service (Kothari, 2004).

Codes were then analysed in order to identify potential themes. Throughout this stage related codes were grouped together, and initial broad themes began to emerge. In the refinement phase, a number of similar themes were combined, and unsupported themes discarded altogether. In determining which themes are most relevant, Braun and Clarke (2006) explain that prevalence is not necessarily a determinant of a theme's importance, and that what is important is "....whether it captures something important in relation to the overall research question” (p. 82).

Credibility was established through another researcher experienced in the thematic analysis methods of Braun and Clarke (2006), but not involved in the current research, to generate codes for a selection of the documents and interview transcripts (Patton, 2005). These codes were then referenced against those initially generated by the researcher, where they were found to be sufficiently similar. 


\section{Ethics}

Although participants were not specifically recruited as targets of workplace bullying, care was taken to protect participant rights given the sensitive nature of bullying. Should a participant reveal that they believe they have been a victim of bullying, they would be made aware of resources such as the Work Safe New Zealand guidelines for the prevention and management of workplace bullying (2014). In addition, participants would have the opportunity to terminate the interview at any point. Permission was granted by the Victoria University Ethics Committee to undertake this research. 


\section{Chapter Five: Findings}

\section{Introduction}

This chapter presents the findings from each of the four stages of data analysis. In stage one, formal bullying complaint statistics were analysed and the data summarised. Stage two involved the analysis of organisational codes of conduct. Stage three saw the analysis of anti-bullying documents with a focus on identifying key policy content and structural features, and also the identification of key themes. In stage four, key informant interviews were analysed thematically, with findings supported by quotes and presented according to the key themes identified.

\section{Stage one: Analysis of formal bullying complaint statistics}

As detailed in Table 5.1, all 15 organisations who were contacted indicated that they centrally maintained a record of formal workplace bullying complaints. Twelve organisations provided data they believed represented formal complaints of workplace bullying, including the number of substantiated and unsubstantiated complaints; three organisations were unable to provide data due to the complexity of retrieval. There was considerable variation in the specificity of data provided. Only four organisations stated they were able to provide data solely of bullying incidents, with data from other organisations encompassing both bullying and harassment statistics, personal grievances related to bullying, and breaches of the code of conduct; for several organisations the specificity of the data was unknown. Organisations $\mathrm{NO}$ and $\mathrm{NH}$ could only provide data from 2014 onwards, with complaint data not centrally collected prior to this point. The inconsistent and varying specificity of data collected by departments, may present difficulties for monitoring workplace bullying trends across the Public Service. However, it is clear from the data collected that the majority $(72 \%)$ of bullying/harassment complaints are found to be unsubstantiated; just $28 \%$ were upheld over the period 2010-2016. 
Table 5.1 Formal complaints of workplace bullying: 2010 - 2016

\begin{tabular}{|c|c|c|c|c|}
\hline Organisation & $\begin{array}{c}\text { Formal bullying complaint statistics collected by } \\
\text { organisation? }\end{array}$ & $\begin{array}{c}\text { Alleged } \\
2010-2016\end{array}$ & $\begin{array}{c}\text { Upheld } \\
2010-2016\end{array}$ & $\begin{array}{l}\text { Unsubstantiated } \\
2010-2016\end{array}$ \\
\hline \multirow{2}{*}{$\begin{array}{l}\text { NA } \\
\text { NB }\end{array}$} & Yes - unknown to what level & 1 & 0 & 1 \\
\hline & Yes - data not in readily available form & $\mathrm{N} / \mathrm{A}$ & $\mathrm{N} / \mathrm{A}$ & $\mathrm{N} / \mathrm{A}$ \\
\hline \multirow{2}{*}{$\begin{array}{l}\text { NC } \\
\text { ND }\end{array}$} & Yes & 12 & 0 & 12 \\
\hline & Yes & $18^{*}$ & 0 & 18 \\
\hline NE & Yes - data not provided & $\mathrm{N} / \mathrm{A}$ & $\mathrm{N} / \mathrm{A}$ & $\mathrm{N} / \mathrm{A}$ \\
\hline NF & Yes & 2 & 0 & 2 \\
\hline NG & Yes - unknown to what level & 0 & 0 & 0 \\
\hline NH & Yes - bullying only - from 2014 & 18 & 1 & 17 \\
\hline NI & Yes - unknown to what level & 0 & 0 & 0 \\
\hline \multirow{2}{*}{$\begin{array}{l}\text { NJ } \\
\text { NK }\end{array}$} & Yes - started 2015 - data not provided & $\mathrm{N} / \mathrm{A}$ & $\mathrm{N} / \mathrm{A}$ & $\mathrm{N} / \mathrm{A}$ \\
\hline & Yes & 13 & 4 & 9 \\
\hline NL & $\begin{array}{l}\text { Yes - information provided on personal grievances including } \\
\text { allegation of bullying or harassment }\end{array}$ & 16 & 3 & 13 \\
\hline $\mathbf{N M}$ & Yes - bullying and harassment combined & $60 * *$ & 36 & 24 \\
\hline \multirow{3}{*}{$\begin{array}{l}\text { NN } \\
\text { NO }\end{array}$} & Yes - unknown to what level & 0 & 0 & 0 \\
\hline & Yes - breaches of code of conduct - from 2014 & $15^{*}$ & 0 & 15 \\
\hline & Total & 155 & $44(28 \%)$ & $111(72 \%)$ \\
\hline
\end{tabular}

* Two complaints still under investigation

** A further 55 complaints were centrally recorded as 'relationship issues' - these were excluded from the data. Four complaints still under investigation 


\section{Stage two: Analysis of codes of conduct}

Public Service departments are required to comply with the State Services Commissioner's minimum standards of integrity and conduct through the development of an organisational code of conduct (NZ State Services Commission, 2010). Twelve of the fourteen organisations who provided documents to the researcher included a copy of their code of conduct. These codes were analysed for references to workplace bullying and the results provided in Table 5.2.

Only three of the twelve codes of conduct provided included any reference to bullying of internal staff members. Organisation NL stated the unacceptability of harassment towards other staff members. Whilst organisation NJ only discussed the unacceptable nature of bullying external clients. Codes of conduct did not refer to anti-bullying/harassment policy; although it is noted that several anti-bullying policies did refer to codes of conduct. Most organisations had unique codes of conduct, but they still drew heavily on the State Services Commission Minimum Standards of Integrity and Conduct; strongly emphasising impartiality, fairness, responsibility, and trustworthiness, rather than interpersonal workplace behaviours such as bullying and harassment. (NZ State Services Commission, 2010).

Table 5.2 References to workplace bullying in organisational codes of conduct

\begin{tabular}{c|cccc} 
Organisation & Total pages & $\begin{array}{c}\text { Bullying } \\
\text { mentioned in } \\
\text { code of conduct }\end{array}$ & $\begin{array}{c}\text { Personalised } \\
\text { Code of } \\
\text { Conduct }\end{array}$ & $\begin{array}{c}\text { Reference anti- } \\
\text { bullying/ } \\
\text { harassment } \\
\text { policy }\end{array}$ \\
\hline NA & 19 & No & No & No \\
NB & 17 & Yes & Yes & No \\
NC & Not provided & Not provided & Not provided & Not provided \\
ND & 23 & No & Yes & No \\
NE & Not provided & Not provided & Not provided & Not provided \\
NF & 6 & No & Yes & No \\
NG & 1 & No & No & No \\
NH & 10 & No & Yes & No \\
NI & 1 & No & No & No \\
NJ & 7 & for external clients & Yes & No \\
NK & 13 & Yes & Yes & No \\
NL & 12 & harassment only & Yes & No \\
NM & 21 & No & Yes & No \\
NN & 1 & No & No & No \\
NO & 15 & Yes & Yes & No
\end{tabular}




\section{Stage three: Analysis of anti-bullying documents}

\section{Overview of anti-bullying documents}

As detailed in Table 5.3, departments used a range of documents when dealing with workplace bullying. Whilst anti-bullying policies were not publicly available on organisation's websites, all departments made documents freely available to staff via the organisation's intranet. Documents were most commonly available in the form of Microsoft Word or PDF files; however, in two organisations these documents were presented in web page format on the organisation's intranet. Organisations generally had one primary policy, supported by additional guidelines and procedures for investigating complaints.

Organisations provided between one and twelve separate documents, equating to between five and fifty-two printed pages per organisation. Whilst there was no clear indication as to why the length of policies varied so significantly, subsequent discussions with union representatives and human resource practitioners by the researcher, revealed that union representatives were heavily involved in the development of two of the longer policies; organisation NDs (41pp) and NFs (32pp). It is also noted that these two policies provided the most specific practical advice for preventing bullying. Table 5.3 shows that all organisations combined anti-bullying policies with both harassment and discrimination. Combining policies is sometimes explained as a response to ensure compliance with legislative requirements such as the Human Rights Act 1993; this is discussed in greater detail later in the analysis.

Several of the organisations mentioned in their response email that their anti-bullying policies were to be updated within the next year; with most of the organisations who provided a policy revision date, having reviewed their policy recently. This seems to indicate current organisational interest in dealing with workplace bullying and may be in response to recent high profile bullying cases and the release of WorkSafe New Zealand's anti-bullying guidance in 2014 (WorkSafe NZ, 2014). However, with the oldest review date being 2002, it does indicate some legacy from the previous decade that may not account for changes in recommended practice.

In sum, there appears to be current Public Service interest in dealing with workplace bullying; although policies are not publicly available. Union involvement may lead to more comprehensive policies, and most anti-bullying policies are combined with harassment and discrimination. 
Table 5.3 Overview of organisational anti-bullying documents

\begin{tabular}{|c|c|c|c|c|c|}
\hline Organisation & $\begin{array}{l}\text { Anti-bullying policy } \\
\text { combined with } \\
\text { harassment and } \\
\text { discrimination }\end{array}$ & $\begin{array}{c}\text { Main policy document } \\
\text { name }\end{array}$ & $\begin{array}{l}\text { Total relevant documents } \\
\text { provided (excluding code of } \\
\text { conduct) }\end{array}$ & $\begin{array}{c}\text { Total number of printed } \\
\text { pages (excluding code } \\
\text { of conduct) }\end{array}$ & $\begin{array}{l}\text { Policy last } \\
\text { updated }\end{array}$ \\
\hline NA & Yes & $\begin{array}{l}\text { Harassment - What is it } \\
\text { and how to deal with it }\end{array}$ & 1 & $52 \mathrm{pp}$ & Nov-07 \\
\hline NB & Yes & $\begin{array}{c}\text { Preventing Bullying and } \\
\text { Harassment }\end{array}$ & 1 & $5 p p$ & Unknown \\
\hline NC & Not provided & Not provided & Not provided & Not provided & Not provided \\
\hline ND & Yes & $\begin{array}{c}\text { Managing Unacceptable } \\
\text { Behaviour Policy }\end{array}$ & 3 & 41pp & Oct-15 \\
\hline $\mathbf{N E}$ & Yes & $\begin{array}{l}\text { Harassment, Bullying \& } \\
\text { Discrimination Policy }\end{array}$ & 1 & $7 \mathrm{pp}$ & Mar-16 \\
\hline $\mathbf{N F}$ & Yes & $\begin{array}{c}\text { Zero Tolerance: } \\
\text { Workplace Harassment, } \\
\text { Discrimination, Bullying } \\
\text { and Violence Policy }\end{array}$ & 3 & 32pp & Sep-15 \\
\hline NG & Yes & $\begin{array}{l}\text { Prevention of Harassment } \\
\text { and Discrimination }\end{array}$ & 1 & $21 p p$ & Sep-02 \\
\hline
\end{tabular}




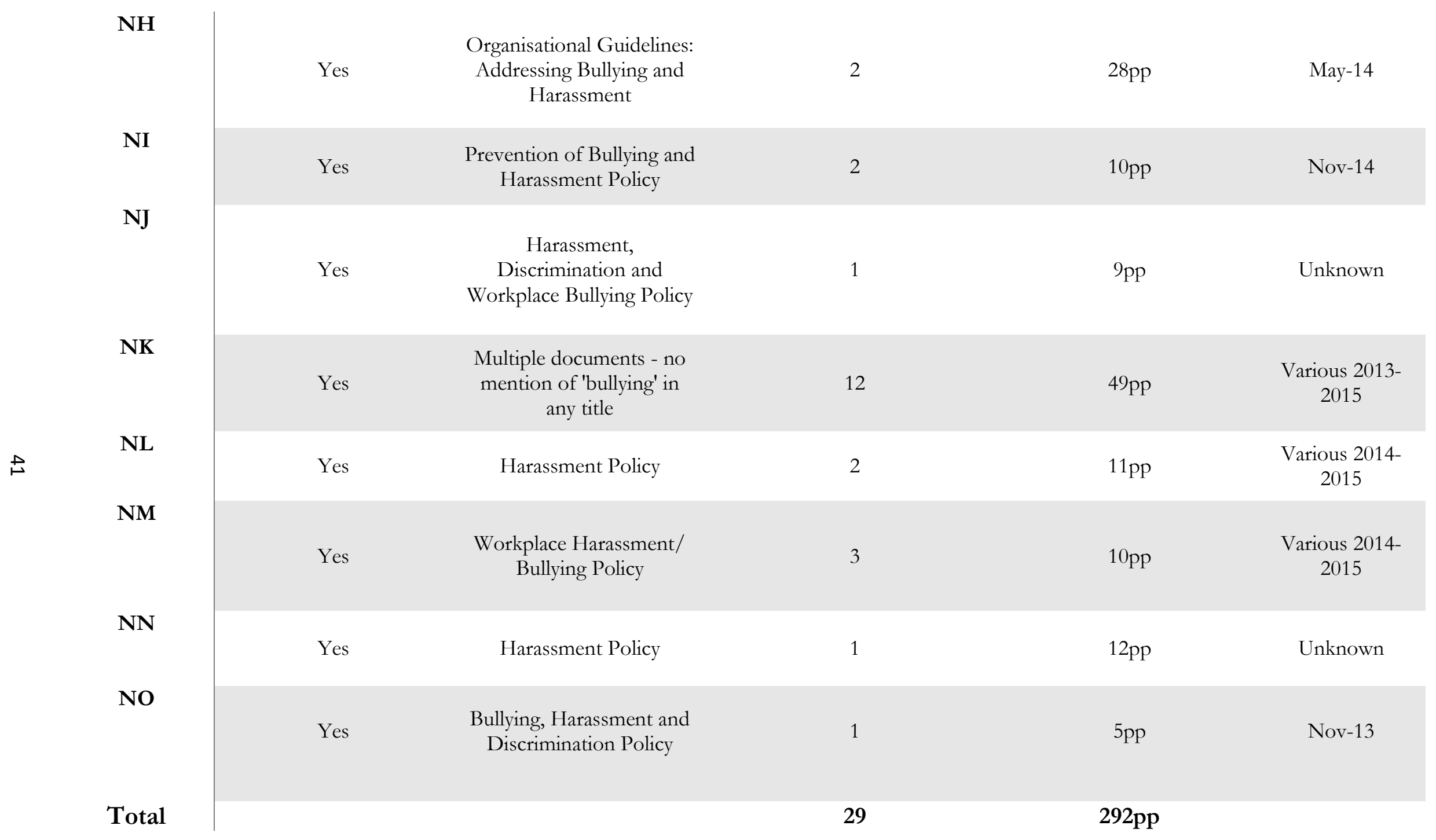




\section{Analysis of core anti-bullying policies}

As outlined in Chapter Three, researchers and practitioners have recommended a number of items for inclusion in organisational anti-bullying policies (see Rayner and Lewis, 2011; Richards and Daley, 2003; Salin, 2008b). Table 5.4 provides an overview of the inclusion of these key elements for each organisational policy analysed. There was some variation in the inclusion of recommended elements across the organisations analysed, with only three organisational policies (ND, NE \& $\mathrm{NF}$ ) found to include all of the core elements recommended in the literature. Most organisations however, did take ownership of the issue and clearly state that bullying was unacceptable; provide a definition of bullying; outline stakeholder responsibilities; provide informal and formal complaint options; and outline complaint investigation procedures. Some examples of what is, and is not considered bullying behaviour was provided in most $(n=12)$ policies. Although these were generally not context specific, most policies did state clearly that performance management is not considered workplace bullying.

Furthermore, despite all organisations stating that they used the policies provided for the purpose of dealing with workplace bullying, there was little reference to bullying in some organisational policies. Organisation NG did not mention the word 'bullying' in any documents provided; instead the term 'harassment' was used to describe typical bullying behaviours. Furthermore, of the main policy documents provided, six organisations (NA, ND, NG, NK, NL and NN) did not use the word 'bullying' in their title at all. Whilst previous research has found organisational policies perceived by human resource practitioners to cover bullying, may not use 'bullying' in their title (see Cowan, 2008); this may send the message to other staff that the policies do not cover bullying behaviours and could hinder effective intervention. 
Table 5.4 Core elements of anti-bullying policy

$\begin{array}{ccccccccc}\text { Organisation } & \begin{array}{c}\text { Statement of } \\ \text { commitment }\end{array} & \begin{array}{c}\text { Definition of } \\ \text { workplace } \\ \text { bullying }\end{array} & \begin{array}{c}\text { Examples of } \\ \text { bullying } \\ \text { behaviour }\end{array} & \begin{array}{c}\text { Consequences } \\ \text { of breaching } \\ \text { policy }\end{array} & \begin{array}{c}\text { Clarifying } \\ \text { responsibility } \\ \text { of stakeholders }\end{array} & \begin{array}{c}\text { Specific } \\ \text { contact } \\ \text { details of key } \\ \text { persons }\end{array} & \begin{array}{c}\text { Informal and } \\ \text { formal } \\ \text { complaint } \\ \text { resolution } \\ \text { options }\end{array} & \begin{array}{c}\text { Complaint } \\ \text { investigation } \\ \text { procedures }\end{array} \\ & & & & & & \text { pens }\end{array}$

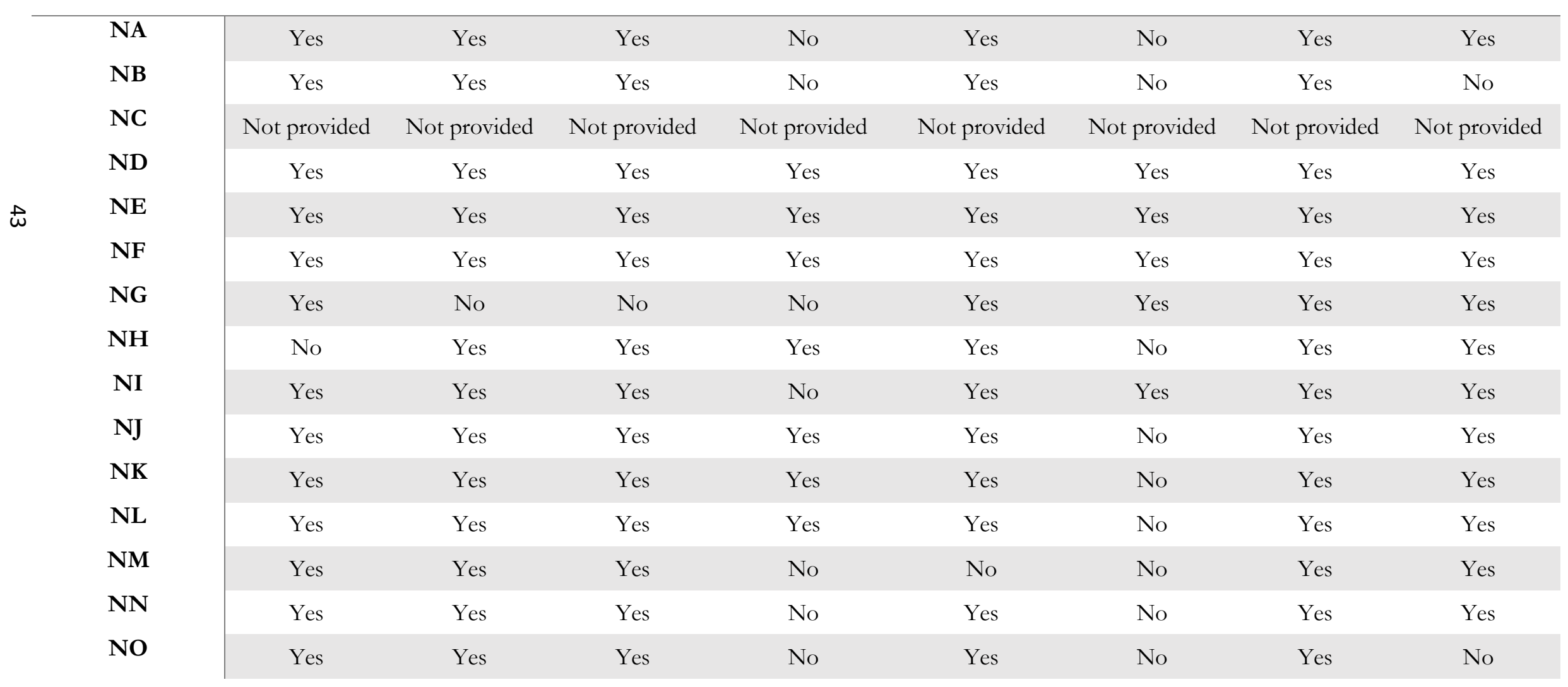




\section{Limited provision of contact details}

Whilst the inclusion of contact details for complainants is recommended (Rayner \& Lewis, 2011); it can be seen in Table 5.4 that specific details were largely absent from organisational policies. The contact details provided by organisations were generally quite limited, with complainants encouraged to “... discuss with your manager...” or “... contact your human resources advisor...”. Some organisations did provide contact numbers for their Employee Assistance Program, where employees can seek advice and counselling services for a range of issues. A few organisations also provided contact numbers for WorkSafe New Zealand, The Ministry of Business Innovation and Employment's mediation service, and for the Public Sector Association union. It may be that specific contact details of human resource advisors and managers were excluded for practical reasons, such as to avoid contact phone numbers or email addresses becoming outdated. Additionally, several policies ( $\mathrm{n}=5$ ), still included the contact details for the Department of Labour as a source of external advice; the Department of Labour ceased to exist in 2012.

\section{Limited discussion of perpetrator consequences}

Policies provided limited discussion of perpetrator consequences, despite researchers suggesting that bullying is less likely to occur in organisations where there are clear consequences for perpetrators (Hoel \& Einarsen, 2011). Whilst most policies outlined in Table 5.4 did include a statement or internal link referring to their organisational disciplinary policy, further discussion of disciplinary action was limited. Where included, consequences were rarely prominent, generally being in standard font and combined with other policy sections. The most comprehensive discussion of the consequences of breaching the policy was from organisation NL, and stated that:

Harassment of any kind may be regarded by the Ministry as serious misconduct and a finding that harassment has occurred may lead to disciplinary action being taken against the person being complained about. Disciplinary action may include dismissal. (NL)

\section{Reference to legislation}

Anti-bullying policies consistently reference a number of Parliamentary Acts. These include the State Sector Act 1988, The Health and Safety at Work Act 2015, The Employment Relations Act 2000, the Harmful Digital Communications Act 2015, and the Human Rights Act 1992.

Health and safety legislation was the most commonly referenced law. All organisations referenced, either explicitly or implicitly, various aspects of health and safety legislation. Explicitly, policies discussed how organisations have an obligation to adhere to applicable health and safety legislation. In introducing their policy, organisation ND stated that: 
Under the State Sector Act (1988) and the Health and Safety in Employment Act (1992) [now Health and Safety at Work Act 2015] [Organisation ND] has a statutory obligation to be a good employer and a duty to control all workplace hazards including unacceptable behaviour. (ND)

Similarly, in implicitly referring to legislative health and safety requirements, organisation NE states that "undesirable behaviours in the workplace can constitute a work-related hazard", which the organisation has "a legislative duty to manage". These statements are generally presented in the policies overview or purpose section explaining or justifying why the department has adopted the policy.

The need to comply with multiple Acts may also explain the combined nature of the policies. As seen in Table 5.3, all policies cover harassment and/or discrimination in addition to workplace bullying. Rayner and Lewis (2011) assert that combining policies is a common approach internationally to ensure compliance with all relevant employment legislation. For instance, references to the Human Rights Act 1992, were related solely to anti-discrimination sections of policies, rather than workplace bullying. 
Table 5.5 Inclusion of key elements of workplace bullying definition

$\begin{array}{cccccccc}\text { Organisation } & \begin{array}{c}\text { Bullying and } \\ \text { harassment }\end{array} & \begin{array}{c}\text { Negative } \\ \text { behaviours }\end{array} & \begin{array}{c}\text { Frequency of } \\ \text { behaviour } \\ \text { (repeated nature) }\end{array} & \begin{array}{c}\text { Duration of } \\ \text { behaviour } \\ \text { (persistent) }\end{array} & \begin{array}{c}\text { Power } \\ \text { Imbalance } \\ \text { emphasised }\end{array} & \begin{array}{c}\text { Intent } \\ \text { excluded }\end{array} & \begin{array}{c}\text { Reasonable } \\ \text { person/ } \\ \text { unreasonable } \\ \text { behaviour }\end{array}\end{array}$

\begin{tabular}{|c|c|c|c|c|c|c|c|}
\hline NA & $\begin{array}{c}\text { Bullying as a form of } \\
\text { harassment }\end{array}$ & Yes & $\begin{array}{l}\text { Yes - no time } \\
\text { period }\end{array}$ & No & No & Yes & Yes \\
\hline NB & $\begin{array}{l}\text { Bullying as distinct but } \\
\text { related to harassment }\end{array}$ & Yes & $\begin{array}{l}\text { Yes - no time } \\
\text { period }\end{array}$ & $\begin{array}{l}\text { Yes - no time } \\
\text { period }\end{array}$ & No & No & No \\
\hline NC & Not provided & Not provided & Not provided & Not provided & Not provided & Not provided & Not provided \\
\hline ND & $\begin{array}{l}\text { Bullying as distinct, but } \\
\text { related to harassment }\end{array}$ & Yes & $\begin{array}{l}\text { Yes - no time } \\
\text { period }\end{array}$ & $\begin{array}{l}\text { Yes - no time } \\
\text { period }\end{array}$ & No & Yes & Yes \\
\hline $\mathbf{N F}$ & $\begin{array}{l}\text { Bullying as distinct but } \\
\text { related to harassment }\end{array}$ & Yes & $\begin{array}{l}\text { Yes - no time } \\
\text { period }\end{array}$ & $\begin{array}{l}\text { Yes - no time } \\
\text { period }\end{array}$ & No & Yes & Yes \\
\hline NG* & $\begin{array}{c}\text { Bullying as a form of } \\
\text { harassment }\end{array}$ & Yes & $\begin{array}{l}\text { Either repeated or } \\
\text { isolated }\end{array}$ & No & No & Yes & No \\
\hline
\end{tabular}




\begin{tabular}{|c|c|c|c|c|c|c|c|}
\hline$N J$ & $\begin{array}{l}\text { Bullying as distinct but } \\
\text { related to harassment }\end{array}$ & Yes & $\begin{array}{l}\text { Yes - no time } \\
\text { period }\end{array}$ & No & No & Yes & No \\
\hline $\mathbf{N K}$ & $\begin{array}{l}\text { Bullying as distinct but } \\
\text { related to harassment }\end{array}$ & Yes & $\begin{array}{l}\text { Yes - no time } \\
\text { period }\end{array}$ & $\begin{array}{l}\text { Yes - no time } \\
\text { period }\end{array}$ & No & Yes & Yes \\
\hline$N L$ & $\begin{array}{l}\text { Bullying as distinct but } \\
\text { related to harassment }\end{array}$ & Yes & $\begin{array}{l}\text { Yes - no time } \\
\text { period }\end{array}$ & No & No & Yes & Yes \\
\hline$N M$ & $\begin{array}{c}\text { Bullying as a form of } \\
\text { harassment }\end{array}$ & Yes & $\begin{array}{l}\text { Either repeated or } \\
\text { isolated }\end{array}$ & No & No & Yes & No \\
\hline $\mathbf{N} \mathbf{N}$ & $\begin{array}{c}\text { Bullying as a form of } \\
\text { harassment }\end{array}$ & Yes & $\begin{array}{l}\text { Yes - no time } \\
\text { period }\end{array}$ & $\begin{array}{l}\text { Yes - no time } \\
\text { period }\end{array}$ & Yes & Yes & No \\
\hline $\mathbf{N O}$ & $\begin{array}{l}\text { Bullying as distinct, but } \\
\text { related to harassment }\end{array}$ & Yes & $\begin{array}{l}\text { Yes - no time } \\
\text { period }\end{array}$ & No & No & Yes & No \\
\hline
\end{tabular}




\section{Definition of workplace bullying}

All organisational policies examined, except that of organisation NG, contained a definition of workplace bullying. Rayner and Lewis (2011) state that a key feature of any good anti-bullying policy is a clear definition. As discussed in Chapter Two, it is recommended that definitions emphasise bullying as frequent negative behaviours experienced over an extended period of time where there is a power imbalance between the target and perpetrator. It can be seen in Table 5.5 that all organisational definitions emphasised negative or unwanted behaviours. Definitions of workplace bullying provided in organisational documents can be divided into two main categories: where bullying is seen as distinct from harassment, and where bullying is seen as a form of harassment.

The below definition of workplace bullying from organisation NJ views bullying as distinct from harassment (harassment is given a separate definition), and excludes one-off instances of negative behaviour:

Workplace bullying is unwanted and unwarranted behaviour that a person finds offensive, intimidating or humiliating and is repeated so as to have a detrimental effect upon a person's dignity, safety and well-being. Behaviours that amount to bullying may be both overt and covert.

Note: An isolated incident of the behaviour described as bullying may be an affront to dignity at work (and may result in disciplinary action), but a one-off incident is not considered to be bullying. (NJ)

In contrast, the definition of workplace bullying from organisation NM portrays bullying as a form of harassment, and includes single incidents of negative behaviour within its scope:

Workplace harassment/bullying is unwanted and unprovoked behaviour that is offensive, intimidating or humiliating and is repeated, or significant enough as a single incident, and which has a detrimental impact upon a person's dignity, safety or sense of wellbeing. (NM)

It can be seen that these definitions are very similar in some respects, yet substantially different in others. Further confusing the situation, harassment is also commonly explained within policies as an overarching concept or umbrella term for all negative workplace behaviour including bullying, discrimination/racial harassment and sexual harassment. So policies offer an unclear distinction between bullying and harassment that may cause confusion in an already stressful situation. 
Definitions can also be distinguished on the basis of whether bullying is seen to encompass only repeated acts of negative behaviour, or whether single acts of negative behaviour are included as well. Whilst no definitions explicitly stated either the frequency or duration with which behaviours needed to be experienced in order to be classified as bullying, it seems that those definitions excluding single acts meet the frequency and duration definitional requirements recommended in the literature (see Zapf et al., 2011). The distinction between single and repeated acts can be seen clearly in the previous definitions, where organisation NJ clearly excludes one-off incidents, and organisation NM explicitly includes single acts.

With regards to the contested elements, only organisation NN explicitly includes power imbalance in their definition, whilst organisation NB's definition was the only one to include perpetrator intent. In addition, seven definitions emphasised "reasonable behaviour", and behaviour that "a reasonable person" would see as bullying. It is noted that the WorkSafe definition included "reasonable behaviour" and the inclusion of this term in policies may indicate practitioners are using the guidance as a source of advice; additionally, all but two $(n=8)$ interview participants mentioned they were aware of the WorkSafe guidelines.

\section{Analysis of supporting guidelines}

Policies should provide guidance for complainants of workplace bullying, for those accused of workplace bullying, for managers, and for bystanders who believe they may have witnessed bullying behaviour (see M. Vartia \& Leka, 2011). A summary of stakeholder guidance provided by each organisation is provided in Table 5.6.

\section{Guidance for complainants}

All organisations provided guidance for complainants of workplace bullying. The most common form of guidance for complainants was an outline of available complaint resolution options. A fairly comprehensive discussion of both informal and formal compliant resolution pathways was given by all organisations. Informal options included self-help, where complaints were encouraged to approach the alleged perpetrator themselves and ask for the behaviour to stop. The second informal option was generally to approach a manager to assist in resolving the complaint. In addition to informal options, formal internal and external options were provided. Internally this would include an investigation process following organisational guidelines. External resolution options suggested within policies include taking a complaint to the Employment Relations Authority, Police, a lawyer, or a union representative. 
Table 5.6 Additional stakeholder guidance provided

\begin{tabular}{|c|c|c|c|c|}
\hline Organisation & $\begin{array}{l}\text { Guidance for } \\
\text { complainants }\end{array}$ & $\begin{array}{l}\text { Guidance for } \\
\text { accused }\end{array}$ & $\begin{array}{l}\text { Guidance for } \\
\text { bystanders } \\
\text { (other than } \\
\text { managers) }\end{array}$ & $\begin{array}{l}\text { Guidance for } \\
\text { managers }\end{array}$ \\
\hline
\end{tabular}

\begin{tabular}{c|cccc}
\hline $\mathbf{N A}$ & Yes & Yes - minimal & Yes - minimal & Yes \\
$\mathbf{N B}$ & Yes & No & No & Yes - minimal \\
$\mathbf{N C}$ & Not provided & Not provided & Not provided & Not provided \\
$\mathbf{N D}$ & Yes & Yes - minimal & Yes - minimal & Yes \\
$\mathbf{N E}$ & Yes & Yes - minimal & Yes - minimal & Yes \\
$\mathbf{N F}$ & Yes & Yes & Yes & Yes \\
$\mathbf{N G}$ & Yes & No & Yes - minimal & Yes - minimal \\
$\mathbf{N H}$ & Yes & Yes - minimal & No & Yes \\
$\mathbf{N I}$ & Yes & No & No & No \\
NJ & Yes & No & No & Yes \\
NK & Yes & No & No & Yes \\
\hline NL & Yes & No & No & Yes - minimal \\
\hline NM & Yes & No & No & Yes - minimal \\
\hline NN & Yes & No & Yes - minimal & Yes \\
NO & Yes & No & No & No \\
\hline
\end{tabular}

\section{Guidance for accused}

Five of the fourteen organisations incorporated specific guidance for those accused of workplace bullying within their organisational anti-bullying policies. Guidance ranged from between half a page and a full page, and those accused of bullying were essentially advised to undertake some form of self-reflection, with policies advising respondents to be 'open to listening', 'understanding the issue from the complainants point of view', and considering 'changing behaviour' or 'apologising'. It was advised that the accused seek support and advice from sources such as family members, the organisation's Employee Assistance Program, and union representatives. Given those accused of workplace bullying can experience a range of negative psychological consequences regardless of whether a complaint is substantiated or not; the provision of detailed advice for those accused of bullying should be included within all policies (Jenkins et al., 2011). 


\section{Guidance for managers}

Specific guidance for managers in dealing with workplace bullying was provided by twelve organisations. It is recommended that guidance is provided for managers as they are often in a position to notice bullying behaviours, and are likely to lead informal resolution procedures. The guidance given to managers varied between organisations, with some providing extensive guidance in a separate document, and others providing very limited advice in a small section within the policy. Generally organisations provided around half a page of guidance for managers. This covered general principles to follow once a complaint has been made, such as handling complaints 'with sensitivity', and 'quickly'; 'investigating every complaint... of bullying'. Organisation NF provided extensive manager guidance (9pp), and covered a number of factors including steps to create a positive workplace environment, ensuring staff are aware of complaints processes, and a discussion of options once a complaint has been made. Policies generally delegate informal investigation responsibilities to line managers, and some policies seem to imply that line managers are also responsible for formal investigations; although policies generally advise 'discussing with HR' before any formal investigation commences.

\section{Guidance for bystanders}

Research has identified the important role of bystanders in the identification and reporting of bullying behaviours in the workplace, and that bystanders can be negatively impacted in ways similar to targets of bullying (M. A. Vartia, 2001). So, whilst the provision of specific guidance for bystanders within anti-bullying policies is an important consideration, only six organisations provided specific advice for bystanders who believe they have witnessed workplace bullying; of these, only one provided extensive advice. The limited advice provided by five organisations was generally in the form of bullet points, and encouraged bystanders to approach either the perpetrator, target, a manager, or other contact such as a human resources advisor; one organisational policy was incomplete and only included a heading but no further advice. The one organisation to provide more extensive advice for witnesses of bullying, in addition to the advice mentioned above, also provided a list of potential impacts of bullying to look out for.

\section{Investigation guidelines}

All organisations stated they had a complaint investigation process to deal with complaints of workplace bullying. These investigation processes were provided by ten of the organisations, with some integrated within anti-bullying/harassment policies, and some in separate documents. There was some variation in the steps provided by each organisation in conducting an investigation, but organisations generally recommended following the broad investigation process as follows: 
- Background and investigation preparation: generally involves receiving the complaint in writing, assigning investigators, notifying all respondents.

- Interview: complainant, respondents, any witnesses; emphasised that re-interviewing may be necessary.

- Write report and record outcome: assess evidence, write report on findings, determine whether any disciplinary action required, record outcome.

The inclusion of generally comprehensive complaint investigation processes may be a result of the section 103A(3) provisions in the Employment Relations Act 2000. As discussed in Chapter Two, the section $103 \mathrm{~A}(3)$ provisions oblige employers to carry out employment investigations in a procedurally fair and proper way. A failure to conduct a fair investigation may open the door for an unfair dismissal claim by an employee, should an improperly conducted investigation into alleged acts of workplace bullying result in the perpetrators dismissal.

\section{Thematic analysis of documents}

Key themes identified in the thematic analysis of anti-bullying documents include: that secondary intervention is of primary importance to departments, that mediation is seen as a preferred secondary intervention, and that policies communicate a minimal role for unions, and an inconsistent role for human resource practitioners.

\section{Secondary intervention of primary importance}

Policies seem to communicate that secondary responses to dealing with workplace bullying (and other forms of unacceptable behaviour) are more important than primary prevention initiatives. Policies devote significantly more attention to dealing with workplace bullying after it has occurred, than in explaining initiatives to prevent its occurrence (see Chapter Two for a discussion of primary interventions). Policy analysis revealed that a significant proportion of documents are devoted to the management of complaints and investigations into workplace bullying, which are secondary interventions. For instance, of the 11pp of advice provided by organisation NL, no specific, practical advice is given on how to prevent workplace bullying or other forms of unacceptable behaviour from occurring, other than recommending managers "monitor the workplace and take appropriate measures to prevent harassment".

Only policies from organisations ND and NF provided any specific, practical, and comprehensive guidance on positive actions which can be taken to help prevent the occurrence of workplace bullying and other unacceptable behaviour in the workplace. These guidelines were directed primarily at managers and generally contained within the "guidelines for managers" section. 
Organisation ND was the only organisation to provide specific guidance for "leaders and managers", "employees", and "human resources" on creating a positive workplace environment. Specific guidance included practices such as providing "clear guidelines for expected behaviour", whilst avoiding "pitting staff against each other".

\section{Mediation as a preferred secondary intervention method}

Policies and guidelines communicated that Public Service organisations view mediation as a preferred secondary intervention for managing workplace bullying. Mediation was generally described within policies as a method for complaint resolution; aligning with the role of secondary interventions as a means to resolve an existing conflict situation in the workplace.

Mediation as a method for resolving complaints was discussed in terms of both encouraging conversation between parties, and in helping to reach a resolution. Organisation NDs policy stated that "mediation is encouraged to help parties come to an agreed resolution". Similarly, organisation NA advised complainants to consider mediation if "you consider that a mediator would assist you to resolve matters with the person whose behaviour offends you".

Mediation was seen as applicable to both informal and external complaint resolution options. As part of an informal resolution process, organisation NI's policy advised that "informal mediation may be suitable" following a preliminary investigation by the organisation. In discussing mediation as part of the external resolution process, organisation NL advised complainants that they may take their complaint to the Ministry of Business Innovation and Employment' mediation service if they are "dissatisfied with the outcome of the processes followed by the Ministry to address their complaint". Mediation as a preferred secondary intervention was reinforced through the limited discussion of other intervention methods in the policies. Aside from the option of undertaking a formal investigation, no other secondary or tertiary interventions were discussed in any detail. As mentioned previously, employees could self-refer to the organisation's Employee Assistance Program, although there was no mention of counselling, coping mechanisms or sources of training.

\section{Policies communicate a minimal role for unions}

Organisational policies communicate that there is only a minimal role for unions in preventing and managing workplace bullying in Public Service organisations. The clearest indication that policies communicate a minimal role for unions is how little policies mentioned unions. Analysis of the documents revealed that the role of unions was not mentioned at all in any of the anti-bullying 
guidance provided by five of the fourteen organisations. Within the nine organisations who did mention the role of unions, it was clear that this role was very limited.

In those organisations who communicated that the role of unions was very minimal, reference to the role of unions was generally made no more than once across all policy components/documents provided. The most commonly communicated role for unions was as a point of contact for advice and support. Advice to contact a union was generally made in regard to choosing an appropriate complaint resolution option or for advice and support in general. Often general statements to contact a union were made in short sentences at the very end of paragraphs, such as that made by organisation NJ, stating that "[e]mployees can also seek support and advice from their family and friends, union or legal representative". Similarly, in discussing the resolution options for complainants, organisation NI stated that "complainants will be encouraged to seek advice from their union representative... on the most appropriate option to pursue". This statement seems to put the onus on the organisation to direct complainants to their union if appropriate.

Few organisations consistently referred to the role of unions throughout their anti-bullying policy and guidelines; those that did were still primarily centred on unions as a point of contact for advice, and were generally very short in comparison to the roles of other stakeholders. Organisation ND was also the only organisation to explicitly state the role of the union in developing the policy by stating in the policy introduction that "the policy has been developed in conjunction with the Public Services Association".

\section{The varying role of human resources across departments}

Organisational policies portray an inconsistent role for human resource practitioners in dealing with workplace bullying across departments. Some organisations provide a separate section clearly detailing the responsibilities of human resource practitioners in dealing with workplace bullying; these organisations communicate a greater responsibility for human resource practitioners and assign them a more central role in organisational anti-bullying initiatives. Organisation NH's policy states that HR has multiple roles including as a facilitator of process; as a source of advice; and as a coach for complainants. Advice for the HR Director of organisation NH is also specifically detailed within the policy:

- Make an initial assessment of the nature of the complaint to assess whether a formal investigation is required;

- Advise on a process to resolve it;

- Arrange for a formal investigation (if appropriate); and 
- Provide balance and objective support to all parties regarding the complaint and the decision maker(s). (NH)

However, other organisations simply refer to the role of human resource practitioners at relevant points within policies. Organisation NI states that "HR staff are available to all staff to advise on principles and procedures", with organisation NL stating the role of human resource practitioners is to "provide advice and assistance to managers as required"; These organisations communicate a lesser role for human resource practitioners in dealing with workplace bullying.

There is considerable variation with regard to how human resource practitioners are portrayed as a source of advice and point of contact for complainants. Most policies encourage complainants to contact their "immediate manager" for assistance in the first instance, and then their "one-up manager" if they are unable to discuss the complaint with their immediate manager. Other policies, for example organisation NI, state that "HR staff are available to all staff to advise"; although this is rare.

There is also variation in how policies portray the role of human resource practitioners in investigating complaints of workplace bullying. For informal complaints, managers generally appear to be the ones responsible for investigating complaints, with support from human resource practitioners. However, for more serious, formal complaints, or complaints against a manager, policies are more inconsistent. Some seem to indicate that an 'independent investigator will be appointed'; this may refer to either 'HR' or an 'external investigator', whilst others still delegate responsibility to managers. 


\section{Stage four: Analysis of interviews}

\section{Thematic analysis of interviews}

Analysis of the ten key informant interviews revealed a number of themes that can help in understanding how Public Service organisations deal with workplace bullying. Key themes identified include that bullying complaints are generally perceived as primarily performance management or relationship issues; that managerial competency in delivering performance feedback is perceived as a driver of bullying complaints; that there is a sense that organisations could do better in dealing with workplace bullying; that mediation is a useful tertiary intervention; and that unions are seen as a key stakeholder in the prevention and management of workplace bullying.

Table 5.7 Demographics of interview participants

\section{Participant Gender Age Range Role}

\begin{tabular}{l|lll} 
H1 & Male & $50-60$ & Senior Human Resource Manager \\
H2 & Male & $50-60$ & Senior Human Resource Manager \\
H3 & Female & $30-40$ & Senior Human Resource Manager \\
H4 & Female & $30-40$ & Senior Human Resource Manager \\
H5 & Female & $30-40$ & Human Resource Manager \\
H6 & Female & $50-60$ & Human Resource Advisor \\
U1 & Female & $40-50$ & Union Policy Advisor \\
U2 & Female & $40-50$ & Union Organiser \\
U3 & Female & $40-50$ & Union Organiser \\
U4 & Male & $40-50$ & Union Organiser
\end{tabular}

Interview participants were drawn from four Public Service departments and two unions. The departments are all relatively large (between approximately 3,000 and 10,000 employees), and undertake a range of activities important to New Zealand's economic and social wellbeing. Specific department roles include the development and delivery of policy, the provision of advice to government, the coordination of economic and social improvement programs, and the enforcement of regulation. The unions represent the interests of a large number of employees in the wider New Zealand public sector, and undertake a range of activities including advocacy, support, advice, and research. 


\section{Bullying claims unsubstantiated}

Human resource practitioners understood most allegations of workplace bullying to be unsubstantiated, and instead generally viewed them as performance management, relationship or behavioural issues. Participant H1 expressed the view that most complaints are either grounded in performance management or workplace relationship issues:

A lot of the people who say they are getting bullied are in fact not, generally we find that if someone says they are being bullied then it's usually because a manager has had a discussion with them around performance concerns, or there is some sort of relationship dynamic gone wrong in the office where they are not getting on with people. (H1)

Similarly, participant H3 explained that "people think that interpersonal conflict, 'like if I don't get on with you', then that's bullying, or if 'you're managing my performance', then that's bullying, or if 'you're setting expectations that I don't want to do', that's bullying". This seems to indicate that human resource practitioners do not believe staff understand what behaviours constitute bullying. In discussing the outcome of a recent bullying investigation, participant $\mathrm{H} 2$ recalled that "it was evident there were cultural, behavioural issues, not only by the complainant and the respondent, but the rest of the team as well; so it was just a poor culture of behaviour". Participant U1 also believed "the default response [of managers] is that it's not bullying, and it's obviously something to do with that person's performance or there must be something else going on there - I think that is the default".

Participants felt that a number of complainants misinterpret performance management as workplace bullying. Participant H1 believed that complaints often stemmed from when "a manager has had a discussion with them around performance concerns...or [when they] don't like what [their] manager has told [them] about performance concerns".

Participant U2 also believed a number of complaints stemmed from performance concerns; whilst acknowledging that performance management may also be used inappropriately by some managers:

You'll have members come to us... around a performance improvement plan, it'd be around their performance objectives or things like that, and it's not necessarily bullying, but then there's instances where it is bullying because the managers' using that as a tactic to deal with them. (U2)

Participant views on the validity of bullying accusations within their organisations appear to be based on both their own past experience, and the experiences of their colleagues. Participant $\mathrm{H} 2$ 
stated that "in the one's [investigations] I've done, I think I've only found one that was bullying, I know my colleague has done one down South. So yeah it probably wouldn't be twenty-five percent, probably five, ten percent".

\section{Managerial competency as a driver of bullying complaints}

Participants discussed how they saw managerial competency as a driver of bullying complaints. Managerial competency was seen as a particular issue around performance management with participant $\mathrm{H} 3$ expressing concerns around the ability of managers to effectively deal with performance issues:

Yeah, so I think managers' ability to deal with performance issues, and have, we call them courageous conversations, how to have a courageous conversation and deal with conflict, and their skills in that, or lack thereof; I don't know if it means they bully people, but it means that they probably do things that people think are bullying. (H3)

Furthermore, participant U2 explained that when performance issues are not dealt with immediately, a situation may escalate and result in a complaint of workplace bullying:

...instead of raising a work concern with them, it kind of goes on and on and on, if you know what I mean. It doesn't get dealt with to say 'well actually you didn't do this piece of work right today, let's work on how you can do it better in the future', it's kind of an attack scenario, you know, 'six months down the track you didn't do this, this and this right', instead of those early conversations being had, by skilled managers, on how to do that; I think that kind of festers away as well. (U2)

Participants also explained that complaints of workplace bullying may stem from the appointment of a new manager whose style or performance expectations differ from that of the previous manager. Participant U2 discussed how the shift to a manager who follows organisational processes rigidly may be perceived as workplace bullying:

So you'll get one manager that let's their staff do it [their job] a certain way, and then you'll get another manager come in and it's by the book. So the first thing they'll do is have the conversation around this is how I want you to do it, which is probably the correct way, but because the other manager didn't do it, that causes that tension and then the members start going [the manager is] bullying me because they're making me do this, this and this, and when you dig into it and you actually have to say to the member, well the managers doing things correctly, you've just not done it in the past. (U2) 
Similarly, participant $\mathrm{H} 1$ explained that:

often we will find that previous managers haven't addressed performance concerns with them [staff].... new manager comes along and has the discussion and the next minute the employee is saying hang on a minute, I've had years of satisfactory performance reviews and next minute I'm being told I can't do my job. So they'll flip to either the manager has either changed the job, which is one way they can go; or the manager doesn't like me and they are bullying me. (H1)

Participant H3 explained that "if managers are doing their job properly and managing performance, and having those conversations... that will probably solve a lot of issues... because most, I think, tend to come out of performance and things like that".

It was also expressed by participants that certain managerial styles may be perceived as workplace bullying. Participant $\mathrm{H} 2$ believed "the Authoritative style can quite easily cross into what is currently perceived as the definition of bullying ... [and] at the other end you have your laissezfaire type ones". It appears that organisations have previously failed to see workplace bullying as a managerial skill problem; although both human resource practitioners and union representatives recognised managerial competency as an issue. Participant H2 discussed how Public Service departments fail to "upskill our managers", and where "the best technical person ends up being the manager."

\section{The significance of intent in interpreting bullying complaints}

Participants discussed the role of perpetrator intent in ways that are inconsistent with recommended academic and practitioner definitions, and also with their own organisational policies. It appears that human resource practitioners apply the contested element of intent to bullying situations. In discussing two manager-peer bullying cases, participant $\mathrm{H} 1$ discussed how:

From our perspective, what we believe we have seen is that the manager has deliberately... I'm always of the view that you can't be an accidental bully. So from what I've heard and read in relation to those two cases, the manager has deliberately set out to treat the person badly ....to bully or wilfully disadvantage. (H1)

Participant N4 similarly discussed how alleged perpetrators may "be completely unaware that their behaviour is... causing this person to feel bullied, and simply raising the issue could be an end in itself'. This seems to indicate that if intent is not perceived, then bullying is not seen to have occurred. Participant H3 also described how intent may impact the outcome of a bullying case with regard to consequences for the alleged perpetrator: 
... if you found someone had bullied someone, you got to a disciplinary process, and then you thought okay, serious misconduct - dismissal, and then you'd think well what are the options, and my view is that it is in the intent and stuff, but if there's some mitigating factor around somebody genuinely didn't realise or didn't intend... you might say well okay final warning, I'm going to send you on these courses about personal interactions and things, and you'd put them on a really tight, structured performance improvement plan around those things, with clear expectations. (H3)

As discussed earlier, only organisation NBs policy included intent with their bullying definition. The participants who discussed the role of intent were not drawn from organisation NB, and were clearly inconsistent with their organisation's anti-bullying policy.

One union representative also consistently discussed intent in relation to workplace bullying. In describing how they would explain what bullying is to union members, participant U2 emphasised the role of intent:

So we say to them bullying is ongoing, and it's kind of with the intent to undermine you, to belittle you, to make you feel bad in the workplace. (U2)

It appears that in addition to the perception that staff do not understand workplace bullying, human resource practitioners, and perhaps also union representatives, understand bullying differently to how it is defined in the academic literature and in their own policies.

\section{A recognition that 'we could do better'}

Participants expressed some doubt in the effectiveness of organisational responses to effectively deal with workplace bullying in the Public Services, and thought improvements could be made in some areas. Participant U2 believed another resolution pathway was required in addition to the formal and informal routes:

Okay, if you have an issue around bullying you can raise an informal forum in the first instance, which you can get good results around, and then if you don't you raise it in the formal one and that usually results in an investigation. So there is no middle ground, kind of to say, well hey, what is the issue? Where can we resolve it without having to raise it informally? (U2)

With regards to the content of organisational anti-bullying policies, participants discussed how some may not be fit for purpose. Participant H2 believed the definition of workplace bullying 
within their policy emphasising single behaviours may need "another tweak", "cause one instance once tends to lead people to hang their hat on it".

Participants also expressed some doubt as to the effectiveness of policy implementation. Participant H1 believed that practices to support policies in their implementation phase were lacking, especially "the training and the culture change that goes with it? ...it looks like a nice policy, but it's all that other stuff about whether or not it's actually a lived policy - it's a practice". Participant U2 discussed how an organisation may "have policies in place, but they really don't have good practices around what to do with it, really practical practices".

\section{Mediation as a secondary and tertiary intervention}

Interview participants discussed mediation as a useful tool for repairing workplace relationships in line with the aim of tertiary interventions. Participant $\mathrm{H} 3$ discussed how following the conclusion of an investigation into workplace bullying, mediation can be used to repair damage done to relationships, and enable workers to return to the organisation:

So, if someone says no I never did that, I've done nothing wrong, I don't think mediation's helpful. I think that's where you need a formal investigation to make a finding. But where something has happened, and the people need to work together in the future, then yeah, mediation's certainly good. (H3)

Similarly, participant $\mathrm{H} 2$ explained how mediation can be used to establish clear expectations and prepare workers for their return to the workplace following the resolution of a conflict situation:

I've used the mediation service to sometimes get them into the room at the end of it and say right, you don't actually have to love each other, but when you're at work it needs to be respectful, professional, and all that sort of thing. So I'll get them into mediation and come up with some ground rules about how they communicate, how they behave around each other $(\mathrm{H} 2)$

In their role as a union representative, participant $\mathrm{U} 2$ also utilised mediation in helping complainants in an alleged case of workplace bullying overcome the significant harm caused. They explained how "we ended up taking them to mediation, because the hurt, the humiliation, and the impact that it had on these three people was huge".

To a more limited extent, participants also described how mediation has been used to resolve workplace conflict situations; although they appeared less confident in the effectiveness of mediation for this purpose. 


\section{Unions as a key stakeholder in dealing with workplace bullying}

Analysis of the interview data revealed unions as a key stakeholder, playing multiple roles in the prevention and management of workplace bullying. Participants discussed how the role of unions is generally valued by organisations when dealing with complaints of workplace bullying. Participant H1 stated that "we'd always much rather prefer somebody who was supported by the PSA than for example had started doing Legal 101, or somebody who got a diploma in mediation and had no experience from anywhere else".

Participants saw unions as having multiple roles in dealing with workplace bullying. They were seen as playing an important role as an intermediary between complainants and human resource personnel. Participant H3 stated that a number of complainants are "first going to the PSA, and then coming to us". However, it was recalled by participant U3 that a human resource advisor told a member to "contact the PSA, they are there for you, not us, we're there to support the manager".

Unions spent time communicating with human resource departments and advising them of potential cases of workplace bullying. Participant U2 discussed how a big part of their role is to "give the HR person a call and go look, do you know this is going on in this workplace? You might want to go in and have a look".

Participants were also seen as an interpreter in situations where there is a communication breakdown in the process of dealing with a complaint of workplace bullying. Participant U2 recalled that:

A lot of the time we chuck a delegate in that space to be the person who's hearing what the manager's saying to the staff member, and what the staff member's saying to the manager, because both of them interpret it completely wrong and they can't communicate with one another and hear one another. (U2)

\section{Development of anti-bullying policy}

Participants commonly discussed the role of unions in the development and review of anti-bullying policy. Participants discussed how unions had a strong interest in contributing to the development of policies, both in the being involved in the discussions, and in contributing their own research. In discussing the extent of union involvement in the development of an anti-bullying policy as part of a broader policy review exercise, participant $\mathrm{H} 4$ explained how all three unions operating within their organisation:

expressed a keen interest to be involved, not just in an after the fact review, but they had lots of contributing material that they wanted us to consider and factor in, and were much 
more engaged than with other topics, in actually actively working on drafting the materials.

Participant U1 discussed how unions are generally consulted when anti-bullying policies are developed or reviewed:

Most departments will consult us on the development or if they're reviewing their policies and stuff like that. So there'll be some point at which either the PSA elected reps, so delegates or staff are asked to contribute to that. So we'll make sure they look like best practice and that kind of stuff as far as we know it. (U1)

Two main ways unions have a say in policy development were discussed by participants. Union delegates may be sent a draft anti-bullying policy prepared by the organisation and then have a chance to provide feedback and make any recommendations for improvement, or unions may be involved with policy development from the outset of the process. In the former, participant U2 stated that organisations "send [the policy] to the delegates, they get the opportunity to have their feedback on it, and [the organisation] chooses to accept it or not. In an example of the latter, participant $\mathrm{U} 2$ discussed how in an upcoming policy review, the union delegates and organisational stakeholders are "all going to sit down together, and work on the policies together".

Organisations also explained how they did actually make constructive changes following union consultation. Participant H2 discussed how their organisation, following union consultation, "took on board what they [the union] said and made changes" to their draft anti-bullying policy "to make it easier, or not as stressful... for those going through it, and for those making the complaints".

\section{A source of innovation in dealing with workplace bullying}

Participants also discussed experiences which show unions also play an important role in developing innovative practices to deal with workplace bullying. Participant U3 discussed the development of phrase cards to make it easier for workers to communicate to others that their actions are inappropriate:

And we developed this little card that they have tucked in their pockets, and it just says "that's not the way we do things around here"...I guess it was created because, for that very reason, where someone isn't feeling that they could turn around and say to their colleague, who's another bloke, now don't talk to me like that, where they could just pull the card out and, you know, and they may have a laugh about it, but it's bringing it to their attention that that person doesn't want to be spoken to like that. (U3) 


\section{The central role of Human Resources}

Analysis of the interview data revealed that human resource practitioner's main roles in dealing with workplace bullying are related to policy development and complaint investigation. Human resource professionals discussed the HR department as the main group involved in the development of anti-bullying policies. Participant H2 discussed how policies were primarily developed by HR with limited input from managers and employees:

It was one of those policies which HR pretty much developed... So in terms of stakeholders it would probably be one of those policies that the managers and that didn't get a lot of input into... I mean when you're reviewing it sometimes we do bring in managers to bring in a different perspective with them being on the other end. But it's probably not one of those ones that you, given the complexity of it. (H2)

Participant H4 explained how HR did consult with internal stakeholders who are subject matter experts in relevant areas:

We discussed the changes with Health and Safety, and Advisory and obviously Employment Relations, and the people that were dealing more first hand with bullying type issues... our Integrity and Assurance... and Corporate Legal as well; so those are probably some of your key internal groups. We also talked with some of the groups like, we've got a Maori responsiveness unit, and you know Diverse Communities group... I think mainly it was probably more fair to say subject matter experts. (H4)

Whilst managers and employers were not directly involved in developing anti-bullying policy, participant H4 explained that 'staff' had participated in a 'State Services Commission integrity survey' that was used in the development of the organisations anti-bullying policy.

Union representatives also saw human resource practitioners as playing a central role in policy development. Participant U2 discussed how anti-bullying policies are "usually HR generated" and are "owned by HR". Participant (U4) explained that "managers and other organisational stakeholders are rarely involved in policy development". Participant U2 emphasised the negative consequences of HR's dominant role in policy development, explaining how staff have little input into policy development:

So I think the problem is all that kind of stuff sits with HR, they deal with it, they update it, they put it back into their system and go along on their merry way... They do it in the HR speak and in the HR way... but nothing out to staff, no staff get the ability to feedback on. (U2) 
Following the development of anti-bullying policies human resource practitioners were involved in the dissemination of policy information to staff. The dominant means of communicating policies to staff was through advertisement on the organisations intranet or HR site; although there was little other discussion of implementation other than human resource practitioners generally found it 'challenging'.

When asked if HR conducted any training specifically targeted at preventing workplace bullying, human resource practitioners stated they "did not believe any such training was undertaken". When answering this question, participant $\mathrm{H} 3$ and $\mathrm{H} 4$ were somewhat hesitant to answer this question, pausing for several seconds before answering that they did not provide any training. Participant H4 discussed how they were aware that "training could be useful" however stated they "were waiting on further information from the SSC".

Union representatives believed that a key role of human resource practitioners should be as a point of contact and source of advice for complainants of workplace bullying. However, as discussed by participant $\mathrm{U} 2$ below, union representatives believe HR is not fulfilling this role and have become more of a resource for managers:

And particularly what we are finding in the public sector organisations at the moment is HR is only a resource for managers. In the past their staff could ring up HR and ask for information and guidance, now HR is pushing back and saying that's not our role, you need to go and talk to your manager, and if the manager needs more information then I'll forward it to them. So how then does a staff member do it with a bullying case around a manager? So there's no internal resource for staff to go to now with HR having that we're a resource for managers. (U2)

Human resource professionals discussed how they were involved in the investigation of formal complaints of workplace bullying. Participant H5 explained that "if a bullying complaint came in, it would generally be the HR Advisors that would deal with it"; whilst participant H6 also acknowledged sometimes an "external investigator may be appointed". The importance of carrying out robust investigations of bullying complaints was emphasised by participant $\mathrm{H} 2$; however some discretion and flexibility was required given the complexity of bullying cases:

I think you don't want it to be too rigid, because you can create another problem for yourself. But just have all the key things, you know, fair and transparent process - all those sorts of things. So you know, people get the information, there's no hiding information... and like with our one at the end, when we write it up, the respondent and the complainant 
get a copy of it before it goes to the decision maker, and their comments are attached to the back of it, and then it all goes up to the decision maker. So they get to see where the reviewers have taken it. $(\mathrm{H} 2)$

Participant H6 also discussed how when they had been allocated as a person to conduct an investigation, they "actually go back and interview the complainant" to ensure that they "are really clear about what the issues are".

\section{Bullying and harassment poorly understood}

Participants struggled to clearly distinguish bullying from general harassment. Participants generally discussed similar features when attempting to define both bullying and harassment. For example, participant H4 discussed how "joking around" may be understood as harassment, but then also described bullying as "consisting of inappropriate jokes".

Participant H1 struggled to explain the difference between bullying and harassment, eventually discussing how bullying and harassment may be distinguished "by looking at each situation on its merits, and once you do that you can generally tell them apart". Participant H1 acknowledged that they were "unable to explain the difference between bully and harassment very well".

However, participants discussed sexual harassment as being clearly distinct from other forms of negative workplace behaviour. With participant H3 explaining how "legislation" and "our antibullying policy defines sexual harassment and discrimination". Whilst participant U3 discussed how they are trying to ensure organisations clearly distinguish between bullying and sexual harassment:

So now we're starting to make sure that's really separated out. You've got bullying, harassment to a degree, but sexual harassment is on its own. (U3) 


\section{Chapter Six: Discussion, implications and conclusion}

\section{Introduction}

This chapter discusses the findings of this research in relation to the literature, and offers insights into the use of anti-bullying interventions in the Public Service. Whilst the Public Service has made efforts to deal with the severe health and safety risks posed by workplace bullying, to effectively prevent and manage workplace bullying, organisational responses require further refinement. The findings of this study highlight the difficulty of effective workplace bullying prevention and management in a complex and contradictory public sector environment.

Human resource practitioners and union representatives both appear to play major roles in organisational anti-bullying initiatives; although anti-bullying policies may not fully reflect the extent of their involvement. It emerged that human resource practitioners and union representatives predominantly interpret allegations of manager-subordinate bullying as performance management issues, and allegations of peer-peer bullying as relationship issues. Furthermore, this research highlighted limitations within current primary intervention, and an apparent emphasis on mediation as a primary and tertiary intervention. It is suggested that stakeholder interpretations of bullying intervention are influenced by the current public sector environment, in addition to other environmental pressures.

\section{Key informants' roles and interpretations of workplace bullying intervention}

This research has expanded our understanding of the roles of human resource practitioners and union representatives in dealing with workplace bullying. The findings of this research indicate that both human resource practitioners and union representatives are heavily involved in dealing with workplace bullying in the New Zealand Public Service; although organisational policy may not always accurately reflect their roles and extent of involvement.

\section{The role of human resource professionals}

Human resource practitioners have an important role in dealing with workplace bullying (Cowan \& Fox, 2015; D'Cruz \& Noronha, 2010; Harrington et al., 2012; Salin, 2008b). This research extends our understandings of the role of human resource practitioners to the New Zealand Public Service environment, where they are primarily involved in policy development and formal complaint investigation. Human resource practitioners discussed how the HR department was 
primarily responsible for policy development, with some input from internal subject-matter experts such as health and safety practitioners. Line managers and employees were rarely directly involved in policy development, although human resource practitioners did attempt to explain how their views may be included; for example, through participation in an external survey used to inform policy development. The limited involvement of employees and line managers in policy development is in contrast to research highlighting greater numbers of both collective and management-initiated forms of employee voice in unionised organisations (Benson, 2000). However, these findings do align with results of other qualitative studies in the New Zealand public sector, where poor staff involvement has been identified (Plimmer, Norman, \& Gill, 2011).

Human resource practitioners were generally not assigned an investigative role in anti-bullying policies, however, in line with the findings of Cowan (2009), human resource practitioners frequently discussed investigating formal complaints of workplace bullying as part of their role. With regard to informal complaint investigation, this appears to be delegated to line managers, and highlights some devolution of HR responsibility; consistent with NPM practice. In line with research by Salin (2008b) and Harrington et al. (2012), some policies delegated both formal and informal complaint investigation responsibilities to line managers; clearly contradicting the role of the human resource practitioner in formal investigations. The devolution of HR practices to line managers has further been discussed as a response to the need for HR to adopt a performance orientation, and may reflect NPM reforms emphasising performance (Omari, 2006). There is some evidence to suggest HR struggles to achieve credibility within the New Zealand context generally (Rasmussen, Andersen, \& Haworth, 2010); and the devolution of HRM may also be explained as an attempt by HR to establish more of a strategic role, in the search for organisational credibility (Harrington, 2010).

Human resource practitioners are often described as a source of advice for complainants of workplace bullying (see Rayner and Lewis, 2011). In line with previous research, organisational policies generally portrayed human resource practitioners as a source of advice for complainants, alleged perpetrators, and also managers dealing with complaints of workplace bullying. However, in line with Salin's (2008b) findings, human resource practitioners were rarely listed as the first point of contact for complainants, and commonly listed after colleagues, family and line managers. Given the dominant role of human resource practitioners in policy development, this order may be a conscious effort to direct complainants to other sources of advice first; appearing to fit the trend of the devolution of HRM responsibility more generally (Harrington, 2010). 
Furthermore, in contrast to the policies, union representatives explained how they believe there has been a shift from human resource practitioners as a source of advice for non-manager complainants, to acting as a source of advice for managers who are accused of workplace bullying; at the expense of providing support for complainants. In line with recommendations in the literature (see M. Vartia and Leka, 2011), human resource practitioners also discussed how there has been increased focus on the provision of support for managers who are accused of workplace bullying, whilst also emphasising the importance of supporting all stakeholders equally. The admission that this balance was sometimes difficult to achieve lends support to the argument that human resource practitioners may experience role conflict with regard to maintaining their role as a neutral third party, and also seeking organisational legitimacy as a strategic partner. This finding may help in explaining targets negative accounts of HR in bullying situations, with targets often feeling unsupported by human resource practitioners (Ferris, 2009).

\section{The role of union representatives}

Research discussing the involvement of union representatives in the prevention and management of workplace bullying is severely limited. This research expands our understanding of the role of union representatives as portrayed in anti-bullying policies, and as discussed by union representatives and human resource practitioners. The findings of this study suggest that whilst anti-bullying policies communicate a minimal role for unions in dealing with workplace bullying, union representatives appear to play a much greater role in practice.

Policies provided limited discussion of unions, generally being mentioned no more than once, and in line with the literature (see E.G. Mikkelsen, 2004 and Lewis and Rayner, 2003), usually in relation to their role as a point of contact for advice and support; only one policy mentioned the role of unions in relation to policy development. The minimal discussion of unions in anti-bullying policy seems to align with the literature describing the erosion of employee voice and trade union marginalisation within NPM environments emphasising strengthened managerial prerogative (Bach \& Kessler, 2008). Unions also commonly hold management accountable for initiatives through the inclusion of practices into organisational policy, and minimal discussion of unions within policies may be reflective of attempts by HR to ensure that unions do not excessively limit HR prerogative, and undermine HR power as they seek to establish greater organisational legitimacy (Verma, 2005).

However, the limited discussion of union involvement in policies was in stark contrast to the key stakeholder role of union representatives discussed by participants. Union representatives were described as an intermediary between complainants and human resource practitioners; as an 
interpreter in conflict situations; as actively engaged in policy development; and as a source of innovation in dealing with workplace bullying. The active role of unions described by human resource practitioners and union representatives seems to align with the concept of unions as strategic organisational partners; perhaps stemming from union-department partnership agreements within the Public Service. The key role played by union representatives may also stem from a lack of HR capability in the post-NPM environment, or of the devolution of HR practices to managers who don't have the skills to carry them out in practice. It appears that union representatives fill a gap for practical guidance around the prevention and management of workplace bullying where human resource practitioners and the State Services Commission fail to provide guidance.

\section{Key informant interpretations of workplace bullying complaints}

Human resource practitioners perceived the majority of workplace bullying complaints to be 'unsubstantiated'. Union representatives also discussed how they believed 'the default response' of human resource practitioners in allegations of bullying is that 'it's not bullying'. Whilst it was not the initial intention of this research to specifically examine manager-subordinate and peer-peer cases of bullying, human resource practitioners and union representatives were found to commonly interpret alleged manager-subordinate bullying as performance related issues, and peerpeer bullying as interpersonal or relationship issues; rather than legitimate bullying behaviours.

The interpretation of the majority of bullying claims as unsubstantiated is surprising as human resource practitioners did emphasise the importance 'getting to the bottom of issues', and emphasising the importance of thorough and fair investigations; a finding also supported by Cowan (2008). However, if practitioners make an initial assumption that an allegation is not bullying before conducting an investigation, this may influence the outcome of an investigation; especially given that human resource practitioners seem to conduct a proportion of formal investigations. So it may be that human resource practitioner's pre-conceptions that complaints are unsubstantiated, based on past experience, shape the outcome of investigation findings. Future research should explore these interpretations further, as they have important intervention implications; for example investigation training for human resource practitioners.

In cases of alleged bullying between managers and subordinates, human resource practitioners discussed unsubstantiated complaints as being related to performance management processes; where a subordinate has perceived the evaluation of their work performance as bullying. In alignment with these findings, Harrington (2010) found that human resource practitioners typically interpreted employee allegations of bullying against a manager as a performance management 
issue. Similar results were also reported by Blackwood (2015), with key informants reporting that claims of performance-related bullying were likely the result of a dislike for the results of performance appraisals.

This study also revealed, somewhat surprisingly, that union representatives interpreted some allegations of manager-employee bullying as negative employee responses to legitimate performance management practices. This finding is important because union representatives are traditionally critical of performance management practices, given the potential for their misuse (Taylor, 2013). It must be noted however, that one union representative did also believe that in some instances managers use performance management practices as a 'tactic' to 'deal with' employees.

In further explaining employee claims of workplace bullying related to performance management, participants discussed how these 'usually' stem from poor managerial skills in performance appraisal. These findings are again in line with those of Harrington et al. (2015), and also supports claims by Needham (2003), that New Zealand managers suffer from a culture of conflict avoidance; and research indicating poor managerial capability within the New Zealand public sector (Plimmer et al., 2011). This seems to support research discussing weak public sector HRM (see Colley et al., 2012), in an environment where HR activities such as performance appraisal have been devolved to line managers without the necessary training and support; characteristic of NPM environments where rapid implementation of private sector managerial practices were undertaken by de-centralised HR departments, lacking appropriate expertise (Omari, 2006). It is noted that most policies explicitly state that performance management is not bullying, and is also detailed in State Services Commission and WorkSafe New Zealand guidance. It may be that policies are thus poorly implemented or lack practical guidance, pointing towards a primary intervention gap that is discussed in the next section.

The interpretation of manager-peer bullying, and peer-peer bullying complaints as largely unsubstantiated, aligns with the bullying statistics provided by organisations, where very few complaints are upheld as legitimate acts of bullying/harassment. These findings seem to suggest one of two things: either bullying complaints are actually performance management or relationship issues, and complainants are misunderstanding bullying behaviour; or human resource practitioners are interpreting bullying as predominantly performance management and relationship issues, when in fact they are legitimate bullying behaviours. Regardless, there is a clear need for more effective intervention, especially if harm is caused by a complainant's perception of being bullied (Parzefall \& Salin, 2010). 
Given the alignment of these findings with the emerging literature on human resource practitioner interpretations of workplace bullying, it appears there may be a common interpretation emerging in relation to bullying intervention. It may be that the contradictory nature of the public sector environment accentuate these role pressures affecting key informant interpretations of workplace bullying, and make bullying particularly difficult to deal with; this process is explored further in the model for future research presented later in this chapter.

\section{A primary intervention gap}

This research has highlighted a potential primary intervention gap. As discussed in Chapter Three, effective primary intervention can reduce the incidence of workplace bullying and help to avoid the associated severe individual and organisational costs. In line with existing research (e.g. Salin 2008b), the development of an organisational anti-bullying policy was the main intervention used by Public Service departments in the prevention of workplace bullying. All 14 organisations who provided documents had anti-bullying policies that generally adhered to current recommendations from the literature with regard to the inclusion of core anti-bullying policy elements (see Table 5.2). In explaining this, it is noted that the New Zealand public sector has relatively high rates of unionisation compared to the private sector, with there being some evidence to suggest that unionised workplaces have more practices enshrined within policy (Verma, 2005). Relatively comprehensive policy and investigation processes and procedures may also be reflective of bureaucratic public sector environments where formal rules and procedures are emphasised; possibly a legacy of traditional public management. It has been noted that the existence of policies may raise employee expectations of organisations in dealing with workplace bullying (Salin, 2008b), and given the existence of policies in all organisations, it may be that inadequate policy implementation is responsible for the high levels of bullying complaints.

However, whilst most policy elements were generally adequate, organisations seemed to grapple with the terms bullying and harassment. Human resource practitioners and union representatives struggled to distinguish between bullying and harassment; with 'bullying' and 'harassment' generally seen as being similar, whilst participants discussed bullying as clearly distinct from 'sexual harassment'. This is significant given that 'sexual harassment' is legally defined, whereas general 'harassment' of the type discussed by participants, and 'bullying' are not. Furthermore, organisational policies generally discussed bullying and harassment using similar definitions; however these were clearly different from sexual harassment and discrimination. To further complicate the situation, harassment was also used by some organisations as an overarching term for all forms of negative workplace behaviour. 
Unclear definitions of bullying and harassment may cause confusion for complainants in an already stressful situation (Caponecchia \& Wyatt, 2009). So whilst both bullying and harassment have negative impacts on targets, and they seem to describe similar undesirable behaviours (Einarsen et al., 2011), consistency is likely important within and across Public Service organisations. This is to provide for centralised training initiatives and professional development programmes in an environment where there is increased provision of State Services Commission guidance, and to enable the comparison of statistics and monitoring of sector-wide trends (Richards \& Daley, 2003).

It could be helpful to only use the term bullying to describe bullying behaviours (Caponecchia \& Wyatt, 2009); and be clearly distinguished from both sexual harassment and discrimination which have their own legal definitions. It could be recommended that agencies adopt the WorkSafe definition, which has already been adopted by several agencies examined; however the status of 'harassment' and 'bullying' appear equally ambiguous within these guidelines. These findings seem to align with Cowan (2009) who suggests that workplace bullying is (still) in an "ambiguous state of denotative hesitancy", similar to that of sexual harassment in the 1980s, but which has since been successfully clarified in legislation. The case of sexual harassment seems to support calls by a number of researchers (see Blackwood \& Bentley, 2013; Yamada, 2011) for the development of a clear and unambiguous legislative definition of workplace bullying.

Further to policy content, it is noted that policies primarily emphasised secondary interventions to manage complaints of workplace bullying, such as complaint investigation processes, and rarely discussed primary prevention interventions. Whilst emphasising initiatives to manage workplace bullying within policies, such as complaint and investigation processes, is in line with recommendations from the literature (eg. Salin, 2008); it is questioned whether policies should incorporate further guidance on primary initiatives to prevent workplace bullying in the first instance. For example, guidance on antecedent identification or the development of positive workplace behaviours. Given that a number of Public Service departments had guidelines supporting their policies any further guidance could be incorporated within these; ensuring that core policy documents do not become cluttered or overly long (Richards \& Daley, 2003). The development of more specific guidance, also aligns with calls by participants of a need for further practical guidance to assist in dealing with workplace bullying. 


\section{Mediation as a preferred secondary and tertiary intervention}

Mediation was discussed as a method for both the resolution of conflict and for the restoration of relationships. In line with the literature (see Keashly \& Nowell, 2003), anti-bullying policies described mediation as an intervention to 'resolve' workplace bullying situations. To a limited extent, participants also discussed the use of mediation as a means to resolve bullying situations; although this was only seen as effective if parties agreed something had occurred and there was some agreement on the facts of the situation; likely in low-level conflict situations. Interestingly, participants mainly discussed mediation as a tertiary intervention to restore workplace relationships 'following the completion of an investigation' where 'people need to work to work together in the future'; a somewhat surprising finding, given that mediation's effectiveness in restoring workplace relationships has been questioned (Fisher \& Keashly, 1991).

Based on the findings of this research, Figure 6.1 seeks to explain how mediation is used by Public Service departments in relation to Glasl's stages of conflict escalation. Mediation as a secondary intervention for resolving conflict was described within anti-bullying policies and by some participants as useful in situations of moderately escalated conflict. However, human resource practitioner's discussion of parties' failure to admit any wrongdoing as a barrier to effective mediation is in line with the literature, and seems to indicate that in some instances, the situation may have reached an escalated stage of conflict (i.e. Glasl's phase three), where mediation is unsuitable for effective conflict resolution. At this stage it appears that the best option for effective resolution is a formal investigation; in line with power intervention approaches recommended in escalated conflict (Zapf \& Gross, 2001).

It thus appears that the point where conflict begins to de-escalate is upon completion of an independent investigation. Following this, it is suggested that conflict has reduced to a level where parties can further discuss the issue and where mediation may be useful for the restoration of workplace relationships. The findings of this research thus seem to indicate that it is important for departments to focus on restoration of relationships after an investigation, as the use of mediation for the restoration of relationships following an investigation indicates that conflict has still not fully de-escalated to a level where it will not re-escalate (Keashly \& Nowell, 2003). 


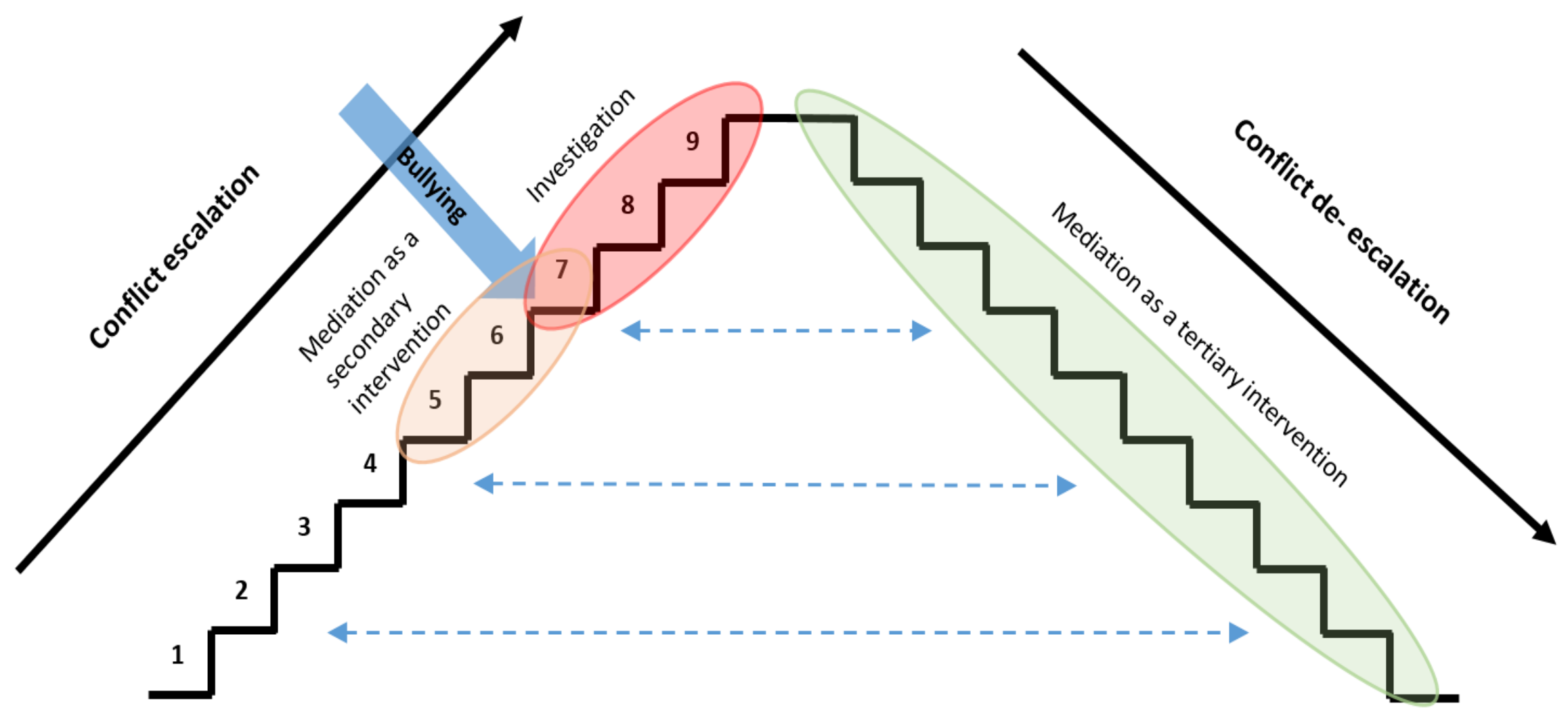

Figure 6.1 Model showing use of mediation at stages of conflict escalation and de-escalation, adapted from Glasl (1994) and Gross (2001) 
In further attempting to explain the use of mediation as a tertiary intervention, it is noted that participants commonly discussed using the Ministry of Business, Innovation and Employment's (MBIE) mediation service. Research by Morris (2015) has identified that MBIE mediators utilise a range of mediation styles in employment mediation; including styles for both dispute resolution, and relationship restoration. The mixing and matching of mediation styles is not generally recommended (Folger \& Bush, 2005), and Morris acknowledges this as a unique, but effective method within this context. The use of mediation as a means to restore workplace relationships following the resolution of bullying complaints, may well be a product of MBIEs unique approach to mediation, and could be a fruitful area for future research.

\section{Intervention within a challenging public sector environment: A model for future research}

This research aimed to provide practical insights into effective interventions for the prevention and management of workplace bullying within the complex New Zealand Public Service environment. This study highlighted inconsistent Public Service responses to workplace bullying, and seems to reflect academic descriptions of public sector environments characterised by ad-hoc and contradictory practices (see Table 2.1). It is suggested that factors in the current public sector environment are hindering effective Public Service responses to deal with workplace bullying.

Based on the findings of this research, and in line with a pragmatic research process, model 6.2 is offered as a model for future research, and as a potential explanation for the difficulties encountered in dealing with Public Service workplace bullying in the current environment. It is argued that factors within the current public sector environment influence stakeholder interpretations of the workplace bullying experience, and shape practical responses to effectively dealing with workplace bullying.

The model begins with the pragmatic aim, or the human problem that is seeking a practical resolution. In a research sense, this is likely to refer to the overarching research aim or research question (Feilzer, 2010); for example, the effective prevention and management of workplace bullying. Stakeholders including human resource practitioners, union representatives, victims, line managers, senior management, health and safety practitioner and others are likely to be important in providing insights into the development of effective interventions (Baillien \& De Witte, 2009). 


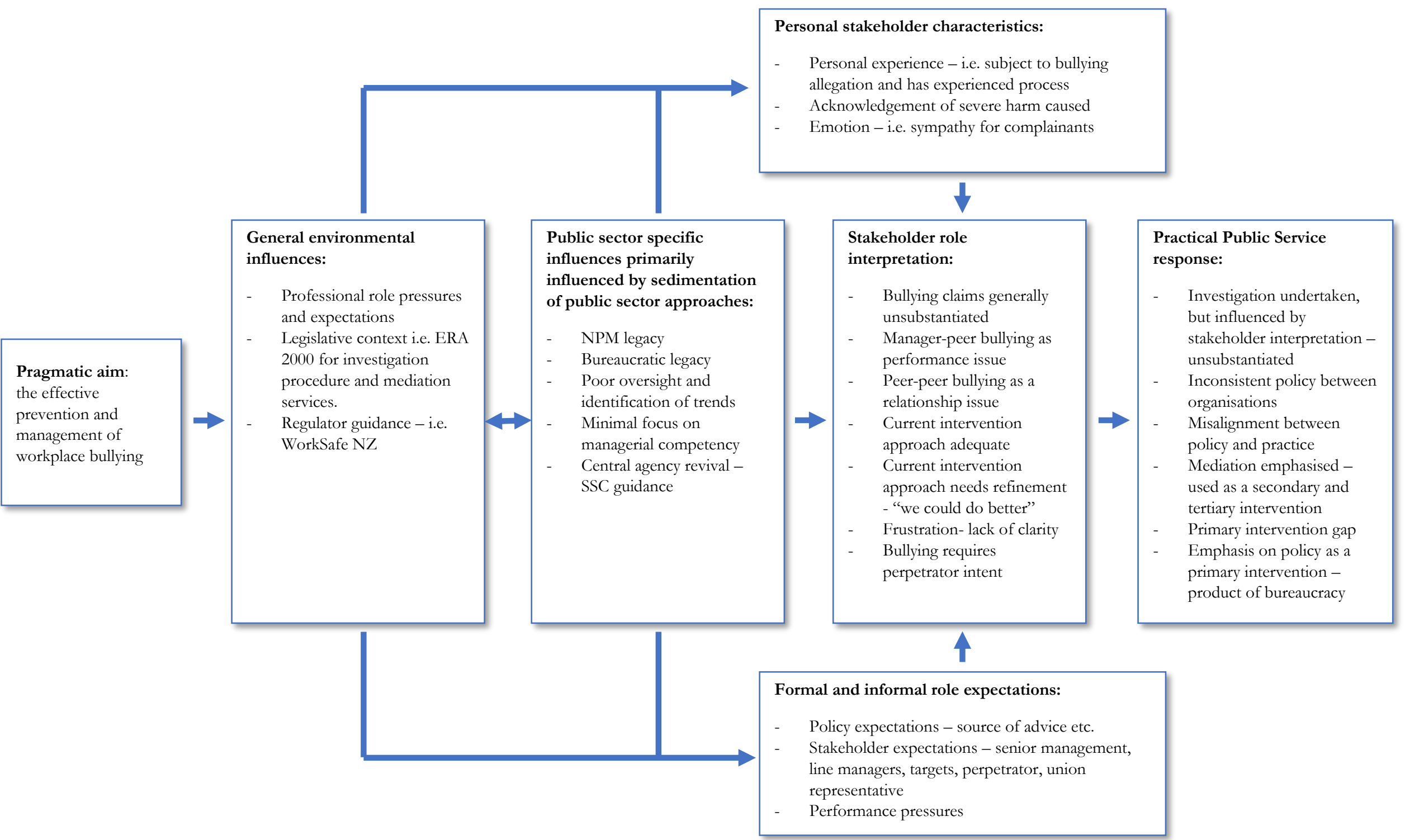

Figure 6.2 Model for future research: Showing influence of environmental factors on stakeholder interpretations of workplace bullying intervention 
This study has highlighted the role of human resource practitioners in activities such as policy development and complaint investigation, and union representatives as an intermediary, an interpreter in conflict situations, as actively engaged in policy development, and as a source of innovation in dealing with workplace bullying (Fox \& Cowan, 2015). It is emphasised that workplace bullying is a highly subjective phenomenon, with stakeholders interpreting bullying intervention in different ways; for instance victims and human resource practitioners are seen to have different interpretations of what outcome constitutes effective intervention (Ferris, 2009).

A number of factors may shape stakeholder's interpretations of workplace bullying intervention, and it is suggested that a range of factors influence all stakeholder responses regardless of the context. These factors could include professional role pressures and expectations; the New Zealand legislative context such as the ERA 2000 investigation procedure requirement and the establishment of mediation services; and regulator guidance such as from WorkSafe NZ. However, it is argued that the public sector environment is influenced by an additional group of factors that may help to explain the difficulty of effective public sector intervention, and associated high levels of workplace bullying. These factors could include the sedimentation of traditional bureaucratic and NPM characteristics; historically poor oversight and identification of trends; and minimal focus on developing core managerial competencies (Colley et al., 2012; Omari, 2006).

It also appears that stakeholders may be influenced by a further two sets of characteristics; personal factors, and role expectations. Personal factors could include experience with processes such as being alleged of workplace bullying; whilst role expectations may stem from formal expectations set out in policy, or potentially informal expectations from other stakeholders including targets and senior management. It is likely that these influence stakeholders directly; however, it seems likely that contextual factors also influence these as well.

All four sets of factors are then argued to influence stakeholder interpretations of primary, secondary and tertiary bullying intervention. For example, stakeholder interpretations identified in the current study include that bullying claims are generally unsubstantiated; that manager-peer bullying is a performance issue; and that peer-peer bullying is a relationship issue. These interpretations are then seen to influence the practical response of stakeholders. Responses may include that an investigation is undertaken, but that claims are found to be unsubstantiated; that policy responses are inconsistent between organisations; that there is misalignment between policy and practice; that mediation is emphasised and used as a secondary and tertiary intervention; that a primary intervention gap results; and that there is an emphasis on policy as a primary intervention. 
It can be seen that the pragmatic aim of effective workplace bullying intervention is highly subjective, with a number of factors, likely unique to each individual, influencing their understanding of what constitutes effective intervention. This emphasises the importance of multiple stakeholder involvement in intervention initiatives, with consultation of all stakeholders considered important (Einarsen \& Hoel, 2008).

In explaining the relationship between the public sector environment and other factors, it is suggested that the current environment may either act in addition to existing factors, or possibly amplify the impact of general external pressures. For example, whilst employees may generally interpret performance appraisal as workplace bullying, this effect is intensified in public sector environments, because employees expectations conflict with use of private sector management processes as they may be driven by public service motivation and guided by public service ethos rather private sector notions of performance (Omari, 2006).

This model has offered insights into factors that may influence interpretations of effective workplace bullying intervention. However, it is suggested that future research could explore the potential for the integration of this model with a model explaining personal and work environment factors influencing bullying (Chappell \& Di Martino, 2006); or with enabling, precipitating and motivating factors (Salin, 2003).

\section{Implications for practice}

An important aspect of pragmatism is that it results in practical outcomes to help solve human problems. This research thus presents a number of practical implications for New Zealand Public Service responses to workplace bullying.

Firstly, this research suggests that there is a need for organisations to place more emphasis on the development and implementation of primary interventions to prevent bullying. It is likely a greater focus is needed on policy implementation, especially policy communication and performance appraisal training as part of a focus on developing core managerial competencies; especially given the devolution of practices such as complaint investigation to line managers. There may need to be some emphasis on ensuring consistency across managers, given cases may stem from a change in management; if there are several 'acceptable' styles of performance management, then employee training in what to expect from performance management may be useful. Further to primary intervention, the lack of understanding as to what constitutes 'bullying' appears to be hindering the effectiveness of primary interventions; especially with regard to confusion between 'bullying' and 'harassment'. Organisations should distinguish behaviours carefully, perhaps no longer using 
'harassment' as an overarching term, and using another term such as 'negative workplace behaviours' to limit ambiguity.

Secondly, it is important for organisations to account for the context of the organisational environment and recognise the impact that this might have on intervention initiatives. It appears that factors in the current public sector environment may result in higher levels of workplace bullying and make effective prevention and management difficult. However, as new approaches to public administration are implemented, this mix is likely to change. New contradictions may emerge and thus in line with pragmatic research, much of what we know about bullying prevention and management should be treated as a provisional truth. This has the implication that organisations should consistently review evidence based research, and regularly review policies and practices, to ensure they account for factors in the current environment.

Thirdly, this study also highlights the usefulness of organisations recognising workplace bullying as a form of escalated conflict. The use of mediation as a tertiary intervention seems to highlight that conflict is continuing despite the completion of a formal investigation to resolve the issue. Given that unresolved conflict has the potential to re-escalate, the implication for organisations is that they likely need to provide further support for those involved in workplace bullying incidents following the completion of an investigation. This may involve the use of mediation, or counselling, and an emphasis on line managers and human resource practitioners monitoring targets and perpetrators to ensure conflict does not re-escalate.

Fourthly, this research has highlighted the potential for union representatives to play an important role in dealing with workplace bullying. In the current study, unions appeared to be a key contributor of practical and innovative ideas to assist Public Service departments in the prevention and management of workplace bullying. Union representatives were generally viewed positively by human resource practitioners; despite being marginalised in organisational policies. The key contribution of union representatives highlights the importance of organisations including them in intervention initiatives from the out-set, and incorporating these ideas within, for instance, organisational anti-bullying policy. 


\section{Limitations and future research directions}

This research explored Public Service interventions for preventing and managing workplace bullying, and has provided insights into effective interventions used by Public Service departments, and the role of human resource professionals and union representatives in dealing with workplace bullying. However, whilst several potential limitations must be acknowledged, these provide opportunities for future research.

Firstly, this research examined anti-bullying documents from fourteen organisations, and explored six human resource practitioners and four union representative's interpretations of Public Service anti-bullying interventions. Whilst this research has contributed to our knowledge of effective intervention more generally, future studies should explore the applicability of these findings to other contexts.

Secondly, this qualitative research provided an in-depth analysis of the perspective of two stakeholders; human resource practitioners and union representatives. Whilst these perspectives are important, it is acknowledged that workplace bullying is a highly subjective phenomenon, and the inclusion of further perspectives could have provided a more comprehensive discussion. In addition to victim perspectives, given the importance of mediation and evidence of HR practice devolution, future research could explore the role and perceptions of mediators and line managers who are likely to provide additional insights into effective intervention.

\section{Conclusion}

This study has provided new insights into workplace bullying interventions in the New Zealand Public Service. The use of a pragmatic, exploratory mixed-model research approach, drawing on organisational documents, and interviews with human resource practitioners and union representatives is unique. It has deepened our understandings of the complex and subjective phenomenon of workplace bullying from the perspective of an under-researched group of stakeholders.

This research has highlighted potential inconsistencies and contradictions within public sector responses to workplace bullying, and discussed potential intervention implications. Opportunities to test the insights from the current study have been identified. Perhaps most importantly, in alignment with a pragmatic research approach, this study has highlighted practical opportunities for the Public Service to further develop effective intervention initiatives. 


\section{References}

Ariza-Montes, A., Leal-Rodríguez, A. L., \& Leal-Millán, A. G. (2015). A comparative study of workplace bullying among public and private employees in Europe. Journal of Occupational and Environmental Medicine, 57(6), 695-700. doi:10.1097/JOM.0000000000000437

Bach, S., \& Kessler, I. (2008). HRM and the New Public Management. In P. Boxall, J. Purcell, \& P. Wright (Eds.), The Oxford Handbook of Human Resource Management. 'Oxford University Press'.

Baillien, E., \& De Witte, H. (2009). Why is organizational change related to workplace bullying? Role conflict and job insecurity as mediators. Economic and Industrial Democracy, 30(3), 348371. doi:10.1177/0143831X09336557

Baillien, E., Neyens, I., De Witte, H., \& De Cuyper, N. (2009). A qualitative study on the development of workplace bullying: Towards a three way model. Journal of Community \& Applied Social Psychology, 19(1), 1-16. doi:10.1002/casp.977

Bartlett, J. E., \& Bartlett, M. E. (2011). Workplace Bullying: An integrative literature review. Advances in Developing Human Resources, 13(1), 69-84. doi:10.1177/1523422311410651

Beale, D. (2011). An Industrial Relations Perspective of Workplace Bullying. In S. Einarsen, H. Hoel, D. Zapf, \& C. Cooper (Eds.), Bullying and harassment in the workplace (pp. 283-300). Boca Raton: CRC Press.

Benson, J. (2000). Employee voice in union and non-union Australian workplaces. British Journal of Industrial Relations, 38(3), 453-459. doi:10.1111/1467-8543.00173

Bentley, T., Catley, B., Gardner, D., O’Driscoll, M. P., Trenberth, L., \& Cooper-Thomas, H. (2009). Understanding stress and bullying in New Zealand workplaces: Final report to OHS steering committee. Wellington, New Zealand.

Bentley, T. A., Catley, B., Cooper-Thomas, H., Gardner, D., O’Driscoll, M. P., Dale, A., \& Trenberth, L. (2012). Perceptions of workplace bullying in the New Zealand travel industry: Prevalence and management strategies. Tourism Management, 33(2), 351-360. doi:10.1016/j.tourman.2011.04.004

Better Public Services Advisory Group. (2011). Better Public Services Advisory Group Report. Wellington, New Zealand.

Blackwood, K. (2015). Workplace bullying in the New Zealand nursing profession: The case for a tailored approach to intervention. (PhD), Massey University, Albany. Retrieved from http://mro.massey.ac.nz/xmlui/bitstream/handle/10179/7212/02 whole.pdf?sequence =2\&isAllowed $\overline{ }_{\mathrm{y}}$ Massey University database. 
Blackwood, K., \& Bentley, T. (2013). Out of step? The efficacy of trans-tasman law to combat workplace bullying. New Zealand Journal of Employment Relations, 38(1), 27.

Boon, J., \& Verhoest, K. (2016). By design or by drift: How, where, and why HRM activities are organized in the public sector. Review of Public Personnel Administration, 1-25. doi:10.1177/0734371X15626775

Bowen, G. A. (2009). Document analysis as a qualitative research method. Qualitative research journal, 9(2), 27-40. doi:10.1108/13522750310470055

Bowling, N. A., \& Beehr, T. A. (2006). Workplace harassment from the victim's perspective: A theoretical model and meta-analysis. Journal of Applied Psychology, 91(5), 998-1012. doi:10.1037/0021-9010.91.5.998

Boyne, G. A. (2002). Public and private management: What's the difference? Journal of management studies, 39(1), 97-122. doi:10.1111/1467-6486.00284

Bradbury, J., \& Hutchinson, M. (2015). Workplace bullying: Modelling construct validity in an Australian public sector workforce. Journal of Empirical Studies, 2(1), 1-16. doi:10.18488/journal.66/2015.2.1/66.1.1.16

Branch, S. (2008). You say tomatoe and I say tomato: Can we differentiate between workplace bullying and other counterproductive behaviours. International Journal of Organisational Behaviour, 13(2), 4-17.

Braun, V., \& Clarke, V. (2006). Using thematic analysis in psychology. Qualitative research in psychology, 3(2), 77-101. doi:10.1191/1478088706qp063oa

Bryman, A., \& Bell, E. (2003). Business research methods. Oxford: Oxford University Press.

Bryson, J. M., Crosby, B. C., \& Bloomberg, L. (2014). Public value governance: Moving beyond traditional public administration and the new public management. Public Administration Review, 74(4), 445-456. doi:10.1111/puar.12238

Buelens, M., \& Van den Broeck, H. (2007). An analysis of differences in work motivation between public and private sector organizations. Public Administration Review, 67(1), 65-74. doi:10.1111/j.1540-6210.2006.00697.x

Burnes, B., \& Pope, R. (2007). Negative behaviours in the workplace: A study of two Primary Care Trusts in the NHS. International Journal of Public Sector Management, 20(4), 285-303. doi:10.1108/09513550710750011

Caponecchia, C., \& Wyatt, A. (2009). Distinguishing between workplace bullying, harassment and violence: A risk management approach. Journal of Occupational Health and Safety, Australia and New Zealand, 25(6), 439. 
Catley, B., Bentley, T., Forsyth, D., Cooper-Thomas, H., Gardner, D., O'Driscoll, M., \& Trenberth, L. (2013). Managing workplace bullying in New Zealand: Perspectives from occupational health and safety practitioners. Journal of Management \& Organization, 19(05), 598-612. doi:10.1017/jmo.2014.2

Caverley, N. (2005). Civil service resiliency and coping. International Journal of Public Sector Management, 18(5), 401-413. doi:10.1108/09513550510608868

Chapman, J., \& Duncan, G. (2007). Is there now a new 'New Zealand model'? Public Management Review, 9(1), 1-25. doi:10.1080/14719030600853444

Chappell, D., \& Di Martino, V. (2006). Violence at work (3rd ed.). Geneva: International Labour Office.

Cherryholmes, C. H. (1992). Notes on pragmatism and scientific realism. Educational Researcher, 21(6), 13-17.

Colley, L., McCourt, W., \& Waterhouse, J. (2012). Hybrids and contradictions: Human resource management in the contemporary public sector. International Journal of Public Administration, 35(8), 507-512. doi:10.1080/01900692.2012.687958

Cooper-Thomas, H., Gardner, D., O’Driscoll, M., Catley, T., Bentley, T., \& Trenberth, L. (2013). Neutralizing Workplace Bullying: The buffering effects of contextual factors. Journal of Management Psychology, 28(4), 384-407. doi:10.1108/JMP-12-2012-0399

Cooper, C., Dewe, P., \& O'Driscoll, M. (2001). Organizational stress: A review and critique of theory, research, and applications. Thousand Oaks, CA: Sage.

Corbin, J., \& Strauss, A. (2008). Basics of qualitative research: Techniques and procedures for developing grounded theory (3rd ed.). Thousand Oaks, CA: Sage

Cowan, R. L. (2009). Walking the tightrope: Workplace bullying and the human resource professional. (PhD), $\begin{array}{llll}\text { Texas A\&M } & \text { University. } & \text { Retrieved }\end{array}$ http:/ / oaktrust.library.tamu.edu/bitstream/handle/1969.1/ETD-TAMU-2009-127497/COWAN-DISSERTATION.pd?sequence=2

Cowan, R. L. (2011). "Yes, we have an anti-bullying policy, but...:" HR professionals' understandings and experiences with workplace bullying policy. Communication Studies, 62(3), 307-327. doi:10.1080/10510974.2011.553763

Cowan, R. L. (2012). It's complicated: Defining workplace bullying from the human resource professional's perspective. Management Communication Quarterly, 26(3), 377-403. doi:10.1177/0893318912439474

Cowan, R. L., \& Fox, S. (2015). Being pushed and pulled: A model of US HR professionals' roles in bullying situations. Personnel Review, 44(1), 119-139. doi:10.1108/PR-11-2013-0210 
D'Cruz, P., \& Noronha, E. (2010). The exit coping response to workplace bullying: The contribution of inclusivist and exclusivist HRM strategies. Employee Relations, 32(2), $102-$ 120. doi:10.1108/01425451011010078

de Waal, A. A. (2010). Achieving high performance in the public sector: What needs to be done? Public Performance \& Management Review, 34(1), 81-103. doi:10.2753/PMR1530-9576340105

Dewey, J., Boydston, J. A., \& Ross, R. (1983). The middle works, 1899-1924 (Vol. 13): SIU press.

Djurkovic, N., McCormack, D., \& Casimir, G. (2008). Workplace bullying and intention to leave: The moderating effect of perceived organisational support. Human Resource Management Journal, 18(4), 405-422. doi:10.1111/j.1748-8583.2008.00081.x

Duffy, M. (2009). Preventing workplace mobbing and bullying with effective organizational consultation, policies, and legislation. Consulting Psychology Journal: Practice and Research, 61(3), 242-262. doi:10.1037/a0016578

Duffy, M., \& Sperry, L. (2007). Workplace mobbing: Individual and family health consequences. The Family Journal, 15(4), 398-404. doi:10.1177/1066480707305069

Dunleavy, P., \& Hood, C. (1994). From old public administration to new public management. Public Money and Management, 14(3), 9-16. doi:10.1080/09540969409387823

Einarsen, S., \& Hoel, H. (2008). Bullying and mistreatment at work: How managers may prevent and manage such problems. In A. Kinder, R. Hughes, \& C. Cooper (Eds.), Employee wellbeing and support: A workplace resource (pp. 161-173). Chichester, UK: John Wiley.

Einarsen, S., Hoel, H., \& Notelaers, G. (2009). Measuring exposure to bullying and harassment at work: Validity, factor structure and psychometric properties of the Negative Acts Questionnaire-Revised. Work \& Stress, 23(1), 24-44. doi:10.1080/02678370902815673

Einarsen, S., Hoel, H., Zapf, D., \& Cooper, C. (2011). The concept of bullying and harassment at work: The European tradition. In S. Einarsen, H. Hoel, D. Zapf, \& C. Cooper (Eds.), Bullying and harassment in the workplace: Developments in theory, research, and practice (2nd ed., pp. 3-40). Boca Raton, FL: CRC Press.

Einarsen, S., \& Skogstad, A. (1996). Prevalence and risk groups of bullying and harassment at work. European Journal of Work and Organizational Psychology, 5(1), 185-202.

Feilzer, M. Y. (2010). Doing mixed methods research pragmatically: Implications for the rediscovery of pragmatism as a research paradigm. Journal of mixed methods research, 4(1), 616. doi:10.1177/1558689809349691

Ferris, P. A. (2009). The role of the consulting psychologist in the prevention, detection, and correction of bullying and mobbing in the workplace. Consulting Psychology Journal: Practice and Research, 61(3), 169-183. doi:10.1037/a0016783 
Fisher, R. J., \& Keashly, L. (1991). The potential complementarity of mediation and consultation within a contingency model of third party intervention. Journal of Peace Research, 28(1), 2942. doi:10.1177/0022343391028001005

Fodchuk, K. M. (2007). Work environments that negate counterproductive behaviors and foster organizational citizenship: Research-based recommendations for managers. The PsychologistManager Journal, 10(1), 27-46. doi:10.1080/10887150709336611

Folger, J., \& Bush, R. B. (2005). The promise of mediation (2nd ed.). San Francisco: Jossey-Bass.

Fox, S., \& Cowan, R. L. (2015). Revision of the workplace bullying checklist: The importance of human resource management's role in defining and addressing workplace bullying. Human Resource Management Journal, 25(1), 116-130. doi:10.1111/1748-8583.12049

Fox, S., \& Stallworth, L. E. (2009). Building a framework for two internal organizational approaches to resolving and preventing workplace bullying: Alternative dispute resolution and training. Consulting Psychology Journal: Practice and Research, 61(3), 220-241. doi:10.1037/a0016637

Francis, C. (2012, April 20). Building and Housing department CEO warned. Stuff. Retrieved from http://stuff.co.nz

Gardner, M. E. (1993). Human resource management and industrial relations in the public sector: Macmillan.

Gardner, S., \& Johnson, P. (2001). The leaner, meaner workplace: Strategies for handling bullies at work. Employment Relations Today, 28(2), 23-36. doi:10.1002/ert.1012

Glasl, F. (1994). Conflict management: A handbook for managers and consultants (4th ed.). Bern, Switzerland: Haupt.

Glendinning, P. M. (2001). Workplace bullying: Curing the cancer of the American workplace. Public Personnel Management, 30(3), 269-286. doi:10.1177/009102600103000301

Grbich, C. (2012). Qualitative data analysis: An introduction (2nd ed.). Thousand Oaks, CA: Sage.

Guest, G., Bunce, A., \& Johnson, L. (2006). How many interviews are enough? An experiment with data saturation and variability. Field Methods, 18(1), 59-82. doi:10.1177/1525822X05279903

Harrington, S. (2010). Workplace bullying through the eyes of buman resource practitioners: A bourdieusian analysis. (PhD), University of Portsmouth, Portsmouth.

Harrington, S., Rayner, C., \& Warren, S. (2012). Too hot to handle? Trust and human resource practitioners' implementation of anti-bullying policy. Human Resource Management Journal, 22(4), 392-408. doi:10.1111/1748-8583.12004 
Harrington, S., Warren, S., \& Rayner, C. (2015). Human Resource Management practitioners' responses to workplace bullying: Cycles of symbolic violence. Organization, 22(3), 368-389. doi:10.1177/1350508413516175

Hoel, H., \& Cooper, C. (1999). The role of 'intent'in perceptions of workplace bullying. Paper presented at the 9th European Congress on Work and Organizational Psychology: Innovations for Work, Organization and Well-being.

Hoel, H., \& Cooper, C. (2000). Destructive conflict and bullying at work. Manchester: Manchester School of Management, UMIST Manchester.

Hoel, H., \& Einarsen, S. (2011). Investigating complaints of bullying and harassment. In S. Einarsen, H. Hoel, D. Zapf, \& C. Cooper (Eds.), Bullying and harassment in the workplace: Developments in theory, research, and practice (2nd ed., pp. 341-357). Boca Raton, FL: CRC Press.

Hoel, H., \& Giga, S. I. (2006). Destructive interpersonal conflict in the workplace: The effectiveness of management interventions. Manchester: University of Manchester.

Hoel, H., \& Salin, D. (2003). Organisational antecedents of workplace bullying. In S. Einarsen, H. Hoel, D. Zapf, \& C. Cooper (Eds.), Bullying and emotional abuse in the workplace (pp. 203-218). London: Taylor and Francis.

Hogh, A., Mikkelsen, E. G., \& Hansen, A. M. (2011). Individual consequences of workplace bullying/mobbing. In S. Einarsen, H. Hoel, D. Zapf, \& C. Cooper (Eds.), Bullying and harassment in the workplace: Developments in theory, research, and practice (pp. 107-128). Boca Raton, FL: CRC Press.

Hood, C. (1995). The "New Public Management" in the 1980s: variations on a theme. Accounting, Organizations and Society, 20(2-3), 93-109. doi:10.1016/0361-3682(93)E0001-W

Hurrell, J. J., \& Murphy, L. R. (1996). Occupational stress intervention. American Journal of Industrial Medicine, 29(4), 338-341. doi:10.1002/(SICI)1097-0274(199604)29:4<338::AIDAJIM11>3.0.CO;2-2

Ironside, M., \& Seifert, R. (2003). Tackling bullying in the workplace. In S. Einarsen, H. Hoel, D. Zapf, \& C. Cooper (Eds.), Bullying and emotional abuse in the workplace: The collective dimension (pp. 383-398). London: Taylor and Francis.

Ittner, H., Bollen, K., \& Euwema, M. (2009). Mediation in hierarchical conflict: No place for perceived justice? Paper presented at the XIVth European Congress of Work and Organizational Psychology Santiago de Compostella, Spain.

Jenkins, M. (2011). Practice note: Is mediation suitable for complaints of workplace bullying? Conflict Resolution Quarterly, 29(1), 25-38. doi:10.1002/crq.21035 
Jenkins, M., Winefield, H., \& Sarris, A. (2011). Consequences of being accused of workplace bullying: An exploratory study. International Journal of Workplace Health Management, 4(1), 3347. doi:10.1108/17538351111118581

Johan Hauge, L., Skogstad, A., \& Einarsen, S. (2007). Relationships between stressful work environments and bullying: Results of a large representative study. Work \& Stress, 21(3), 220-242. doi:10.1080/02678370701705810

Johnson, R. B., \& Onwuegbuzie, A. J. (2004). Mixed methods research: A research paradigm whose time has come. Educational Researcher, 33(7), 14-26. doi:10.3102/0013189X033007014

Jun, J. S. (2009). The limits of Post-New Public Management and beyond. Public Administration Review, 69(1), 161-165. doi:10.1111/j.1540-6210.2008.01960.x

Keashly, L., \& Nowell, B. L. (2003). Conflict, conflict resolution and bullying. In S. Einarsen, H. Hoel, D. Zapf, \& C. Cooper (Eds.), Bullying and emotional abuse in the workplace (pp. 339-358). London: Taylor and Francis.

Keashly, L., \& Nowell, B. L. (2011). Conflict, conflict resolution, and bullying. In S. Einarsen, H. Hoel, D. Zapf, \& C. Cooper (Eds.), Bullying and harassment in the workplace: Developments in theory, research, and practice (pp. 423-445).

Kelemen, M. L., \& Rumens, N. (2008). An introduction to critical management research. Thousand Oaks, CA: Sage.

Kim, E., \& Glomb, T. M. (2010). Get smarty pants: Cognitive ability, personality, and victimization. Journal of Applied Psychology, 95(5), 889-901. doi:10.1037/a0019985

Kothari, C. R. (2004). Research methodology: Methods and techniques: New Age International.

Lamontagne, A. D., Keegel, T., Louie, A. M., Ostry, A., \& Landsbergis, P. A. (2007). A systematic review of the job-stress intervention evaluation literature, 1990-2005. International Journal of Occupational and Environmental Health, 13(3), 268-280. doi:10.1179/oeh.2007.13.3.268

LaMontagne, A. D., Keegel, T., \& Vallance, D. (2007). Protecting and promoting mental health in the workplace: Developing a systems approach to job stress. Health Promotion Journal of Australia, 18(3), 221-228. doi:10.1071/HE07221

Lavigna, B. (2015). Commentary: Public service motivation and employee engagement. Public Administration Review, 75(5), 732-733. doi:10.1111/puar.12429

Law, R., Dollard, M. F., Tuckey, M. R., \& Dormann, C. (2011). Psychosocial safety climate as a lead indicator of workplace bullying and harassment, job resources, psychological health and employee engagement. Accident Analysis \& Prevention, 43(5), 1782-1793. doi:10.1016/j.aap.2011.04.010 
Lewis, D., \& Rayner, C. (2003). Bullying and human resource management: A wolf in sheeps clothing? In S. Einarsen, H. Hoel, D. Zapf, \& C. Cooper (Eds.), Bullying and emotional abuse in the workplace: International perspectives in research and practice (pp. 370-382). London: Taylor and Francis.

Leymann, H. (1990). Mobbing and psychological terror at workplaces. Violence and Victims, 5(2), 119-126.

Leymann, H. (1996). The content and development of mobbing at work. European Journal of Work and Organizational Psychology, 5(1), 165-184.

Leymann, H., \& Gustafsson, A. (1996). Mobbing at work and the development of post-traumatic stress disorders. European Journal of Work and Organizational Psychology, 5(2), 251-275.

Lutgen-Sandvik, P. (2008). Intensive remedial identity work: Responses to workplace bullying trauma and stigmatization. Organization, 15(1), 97-119. doi:10.1177/1350508407084487

Mathisen, G. E., Einarsen, S., \& Mykletun, R. (2011). The relationship between supervisor personality, supervisors' perceived stress and workplace bullying. Journal of Business Ethics, 99(4), 637-651. doi:10.1007/s10551-010-0674-Z

Matthiesen, S. B., \& Einarsen, S. (2007). Perpetrators and targets of bullying at work: Role stress and individual differences. Violence and Victims, 22(6), 735-753. doi:10.1891/088667007782793174

Meglich-Sespico, P., Faley, R. H., \& Knapp, D. E. (2007). Relief and redress for targets of workplace bullying. Employee Responsibilities and Rights Journal, 19(1), 31-43. doi:10.1007/s10672-006-9030-y

Mellish, T. (2001). Bullying is a trade union issue. In N. Tehrani (Ed.), Building a culture of respect: Managing bullying at work (pp. 201-220). Boca Raton, FL: CRC Press.

Merchant, V., \& Hoel, H. (2003). Investigating complaints of bullying. In S. Einarsen, H. Hoel, D. Zapf, \& C. Cooper (Eds.), Bullying and emotional abuse in the workplace (pp. 259-269). London: Taylor and Francis.

Mikkelsen, E. G. (2004). Coping with exposure to bullying at work-results from an interview study. Paper presented at the The 4th International Conference on Bullying and Harassment in the Workplace, Bergen, Norway, June 28.

Mikkelsen, E. G., \& Einarsen, S. (2002). Basic assumptions and symptoms of post-traumatic stress among victims of bullying at work. European Journal of Work and Organizational Psychology, 11(1), 87-111. doi:10.1080/13594320143000861 
Mikkelsen, E. G., \& Einarsen, S. (2006). Psychosocial rehabilitation positively affects victims' health and wellbeing. Paper presented at the Fifth International Conference on Bullying and Harassment in the Workplace, June 15-17, Dublin Ireland.

Morris, G. (2015). Eclecticism versus purity: Mediation ttyles used in New Zealand employment disputes. Conflict Resolution Quarterly, 33(2), 203-227. doi:10.1002/crq.21153

Needham, A. W. (2003). Workplace bullying: A costly business secret. Auckland, New Zealand: Penguin Books.

Nielsen, M. B., \& Einarsen, S. (2012). Outcomes of exposure to workplace bullying: A metaanalytic review. Work \& Stress, 26(4), 309-332. doi:10.1080/02678373.2012.734709

Nielsen, M. B., Matthiesen, S. B., \& Einarsen, S. (2010). The impact of methodological moderators on prevalence rates of workplace bullying: A meta-analysis. Journal of Occupational and Organizational Psychology, 83(4), 955-979. doi:10.1348/096317909X481256

Nielsen, M. B., Notelaers, G., \& Einarsen, S. (2011). Measuring exposure to workplace bullying. In S. Einarsen, H. Hoel, D. Zapf, \& C. Cooper (Eds.), Bullying and harassment in the workplace: Developments in theory, research, and practice (2nd ed., pp. 149-174). Boca Raton, FL: CRC Press.

NZ Companies Office. (2015). Union membership return report 2015.

NZ State Services Commission. (2003). Creating a positive work environment: Respect and safety in the Public Service workplace. Retrieved from Welington, New Zealand: http://www.ssc.govt.nz/upload/downloadable files/Creating a Positive Work Enviro nment.pdf

NZ State Services Commission. (2010). Understanding the code of conduct: Guidance for State servants. Retrieved from http://www.ssc.govt.nz/sites/all/files/UnderstandingtheCodeApril2010.pdf

NZ State Services Commission. (2014). Integrity and conduct survey 2013. Retrieved from Wellington, New Zealand: http://www.ssc.govt.nz/sites/all/files/integrity-and-conduct-survey-2013report.pdf

NZ State Services Commission. (2015a). Core guide 1: What is the Performance Improvement Framework? Wellington, New Zealand Retrieved from http://www.ssc.govt.nz/sites/all/files/pifcore-guide-1-dec2015 0.pdf.

NZ State Services Commission. (2015b). Human resource capability in the New Zealand State services. Wellington, New from http://www.ssc.govt.nz/sites/all/files/HRCReport-2015.pdf.

NZ State Services Commission. (2016a). Human resource capability. Wellington, New Zealand Retrieved from http://www.ssc.govt.nz/sites/all/files/HRCReport-2016.pdf. 
NZ State Services Commission. (2016b). Positive Workplace Behaviours Guidance. Wellington, New Zealand Retrieved from http://www.ssc.govt.nz/sites/all/files/positive-workplacebehaviours-april2016.pdf.

O'Driscoll, M. P., Cooper-Thomas, H. D., Bentley, T., Catley, B. E., Gardner, D. H., \& Trenberth, L. (2011). Workplace bullying in New Zealand: A survey of employee perceptions and attitudes. Asia Pacific Journal of Human Resources, 49(4), 390-408. doi: $10.1177 / 1038411111422140$

O'Leary, Z. (2014). The essential guide to doing your research project. Thousand Oaks, CA: Sage.

Omari, M. (2006). The Public Sector: an environment prone to bullying? Public Policy, 1(2), 110123.

Palmer, G. (2014). The impact of the State Sector Act on public services. Retrieved from Wellington, New Zealand:

https://www.psa.org.nz/assets/Campaigns/Rethinking+the+State+Sector+Act+final.p $\underline{\mathrm{df}}$

Parzefall, M.-R., \& Salin, D. M. (2010). Perceptions of and reactions to workplace bullying: A social exchange perspective. Human Relations, 63(6), 761-780. doi:10.1177/0018726709345043

Patton, M. Q. (2005).Qualitative research Retrieved from http://onlinelibrary.wiley.com/

Plimmer, G., Norman, R., \& Gill, D. (2011). Skills and people capability in the future state: Needs, barriers and opportunities. In B. Ryan \& D. Gill (Eds.), Future state: Directions for public management in New Zealand. Wellington, New Zealand: Victoria University Press.

Plimmer, G., Proctor-Thomson, S., Donnelly, N., \& Sim, D. (2016). The mistreatment of Public Service workers at work: Identifying key risk and protective factors. Public Money and Management.

Plimmer, G., Wilson, J., Bryson, J., Blumenfeld, S., Donnelly, N., \& Ryan, B. (2013). Workplace dynamics in New Zealand public services: A survey report prepared for the Public Service Association (PS A). Wellington, New Zealand.

Proctor-Thomson, S., Donnelly, N., \& Plimmer, G. (2011). Constructing workplace democracy: Women's voice in New Zealand Public Services. Wellington, New Zealand.

Quick, J. D., Quick, J. C., \& Nelson, D. L. (1998). The theory of preventive stress management in organizations. In C. Cooper (Ed.), Theories of organizational stress (pp. 246-268). Oxford: Oxford University Press.

Radin, B. (2006). Challenging the performance movement: Accountability, complexity, and democratic values: Georgetown University Press. 
Rasmussen, E., Andersen, T., \& Haworth, N. (2010). Has the strategic role and professional status of human resource management peaked in New Zealand? Journal of Industrial Relations, 52(1), 103-118. doi:10.1177/0022185609353992

Rayner, C., \& Cooper, C. L. (2006). Workplace bullying. In K. E. Kelloway, J. Barling, \& J. J. Hurrell (Eds.), Handbook of workplace violence (pp. 121-145). Thousand Oaks, CA: Sage.

Rayner, C., \& Lewis, D. (2011). Managing workplace bullying: The role of policies. In S. Einarsen, H. Hoel, D. Zapf, \& C. Cooper (Eds.), Bullying and harassment in the workplace: Developments in theory, research and practice (2nd ed., pp. 327-340). Boca Raton, FL: CRC Press.

Reichertz, J. (2004). Abduction, deduction and induction in qualitative research (B. Jenner, Trans.). In U. Flick, E. von Kardorff, \& I. Steinke (Eds.), A companion to qualitative research (pp. 159164). Thousand Oaks, CA: Sage.

Richards, J., \& Daley, H. (2003). Bullying policy: Development, implementation and monitoring. In S. Einarsen, H. Hoel, D. Zapf, \& C. Cooper (Eds.), Bullying and emotional abuse in the workplace: International perspectives in research and practice (pp. 247-258). London, England: Taylor \& Francis.

Ryan, B., \& Gill, D. (2011). Introduction. In B. Ryan \& D. Gill (Eds.), Future state: Directions for public management in New Zealand. Wellington: Victoria University Press.

Saam, N. J. (2010). Interventions in workplace bullying: A multilevel approach. European Journal of Work and Organizational Psychology, 19(1), 51-75. doi:10.1080/13594320802651403

Safe Work Australia. (2016). Guide for preventing and responding to workplace bullying. Canberra, ACT, Australia

Retrieved from

http://www.safeworkaustralia.gov.au/sites/SWA/about/Publications/Documents/827/ Guide-preventing-responding-workplace-bullying.pdf.

Salin, D. (2001). Prevalence and forms of bullying among business professionals: A comparison of two different strategies for measuring bullying. European Journal of Work and Organizational Psychology, 10(4), 425-441. doi:10.1080/13594320143000771

Salin, D. (2003). Ways of explaining workplace bullying: A review of enabling, motivating and precipitating structures and processes in the work environment. Human Relations, 56(10), 1213-1232. doi:10.1177/00187267035610003

Salin, D. (2008a). Organisational responses to workplace harassment: An exploratory study. Personnel Review, 38(1), 26-44. doi:10.1108/00483480910920697

Salin, D. (2008b). The prevention of workplace bullying as a question of human resource management: Measures adopted and underlying organisational factors. Scandinavian Journal of Management, 24(1), 221-231. doi:10.1016/j.scaman.2008.04.004 
Salin, D., \& Hoel, H. (2011). Organisational causes of workplace bullying. In S. Einarsen, H. Hoel, D. Zapf, \& C. Cooper (Eds.), Bullying and harassment in the workplace: Developments in theory, research, and practice (2nd ed., pp. 227-243). Boca Raton, FL: CRC Press.

Samkin, G., \& Schneider, A. (2010). Accountability, narrative reporting and legitimation: The case of a New Zealand public benefit entity. Accounting, Auditing \& Accountability Journal, 23(2), 256-289. doi:10.1108/09513571011023219

Samnani, A.-K. (2013). Embracing new directions in workplace bullying research: A paradigmatic approach. Journal of Management Inquiry, 22(1), 26-36. doi:10.1177/1056492612451653

Saunders, P., Huynh, A., \& Goodman-Delahunty, J. (2007). Defining workplace bullying behaviour professional lay definitions of workplace bullying. International Journal of Law and Psychiatry, 30(4), 340-354. doi:10.1016/j.illp.2007.06.007

Schwickerath, J., \& Zapf, D. (2011). Inpatient treatment of bullying victims. In S. Einarsen, H. Hoel, D. Zapf, \& C. Cooper (Eds.), Bullying and harassment in the workplace: Developments in theory, research and practice (pp. 397-422). Boca Raton, FL: CRC Press.

Scott, G., Bushnell, P., \& Sallee, N. (1990). Reform of the core public sector: New Zealand experience. Governance, 3(2), 138-167. doi:10.1111/j.1468-0491.1990.tb00112.x

Scott, R., \& Boyd, R. (2016). Results, targets and measures to drive collaboration: Lessons from the New Zealand Better Public Services reforms. In J. Butcher \& D. Gilchrist (Eds.), The Three Sector Solution: Delivering Public Policy in Collaboration with Not-for-profits and Business (pp. 235-257). Canberra, ACT: ANU Press.

Shuttleworth, K. (2012, April 20). Housing boss 'manhandled' staff. The New Zealand Herald. Retrieved from http://www.nzherald.co.nz

Skogstad, A., Einarsen, S., Torsheim, T., Aasland, M. S., \& Hetland, H. (2007). The destructiveness of laissez-faire leadership behavior. Journal of Occupational Health Psychology, 12(1), 80. doi:10.1037/1076-8998.12.1.80

Skogstad, A., Matthiesen, S. B., \& Einarsen, S. (2007). Organizational changes: A precursor of bullying at work? International Journal of Organization Theory and Behavior, 10(1), 58.

Skogstad, A., Torsheim, T., Einarsen, S., \& Hauge, L. J. (2011). Testing the work environment hypothesis of bullying on a group level of analysis: Psychosocial factors as precursors of observed workplace bullying. Applied Psychology, 60(3), 475-495. doi:10.1111/j.14640597.2011.00444.x

State Sector Act 1988.

Svennevig, J. (2001). Abduction as a methodological approach to the study of spoken interaction. Norskrift, 103, 1-22. 
Taylor, P. (2013). Performance management and the new workplace tyranny: A report for the Scottish Trades Union Congress. Glasgow, University of Strathclyde.

Tehrani, N. (2011). Workplace bullying: The role for counselling. In S. Einarsen, H. Hoel, D. Zapf, \& C. Cooper (Eds.), Bullying and harassment in the workplace: Developments in theory, research, and practice (pp. 381-396). Boca Raton, FL: CRC Press.

Tetrick, L. E., \& Quick, J. C. (2003). Prevention at work: Public health in occupational settings. In J. C. Quick \& L. E. Tetrick (Eds.), Handbook of occupational health psychology (pp. 3-17). Washington, DC: American Psychological Association.

Tracy, S. J., Lutgen-Sandvik, P., \& Alberts, J. K. (2006). Nightmares, demons, and slaves: Exploring the painful metaphors of workplace bullying. Management Communication Quarterly, 20(2), 148-185. doi:10.1177/0893318906291980

Tuckey, M. R., Dollard, M. F., Hosking, P. J., \& Winefield, A. H. (2009). Workplace bullying: The role of psychosocial work environment factors. International Journal of Stress Management, 16(3), 215. doi:10.1037/a0016841

van Hoek, R., Aronsson, H., Kovács, G., \& Spens, K. M. (2005). Abductive reasoning in logistics research. International Journal of Physical Distribution \& Logistics Management, 35(2), 132-144. doi:10.1108/09600030510590318

Vartia, M., \& Leka, S. (2011). Interventions for the prevention and management of bullying at work. In S. Einarsen, H. Hoel, D. Zapf, \& C. Cooper (Eds.), Bullying and harassment in the workplace: Developments in theory, research, and practice (2nd ed., pp. 359-379). Boca Raton, FL: CRC Press.

Vartia, M. A. (2001). Consequences of workplace bullying with respect to the well-being of its targets and the observers of bullying. Scandinavian Journal of Work, Environment \& Health, 27(1), 63-69.

Venetoklis, T., \& Kettunen, P. (2015). Workplace bullying in the Finnish public sector: Who, me? Review of Public Personnel Administration, 36(4), 370-395. doi:10.1177/0734371X15587982

Verma, A. (2005). What do unions do to the workplace? Union effects on management and HRM policies. Journal of Labor Research, 26(3), 415-449. doi:10.1007/s12122-005-1013-5

Woodrow, C., \& Guest, D. E. (2014). When good HR gets bad results: Exploring the challenge of HR implementation in the case of workplace bullying. Human Resource Management Journal, 24(1), 38-56. doi:10.1111/1748-8583.12021

WorkSafe NZ. (2014). Preventing and responding to workplace bullying: Best practice guidelines. Wellington: WorkSafe NZ Retrieved from https://www.worksafe.govt.nz/worksafe/informationguidance/all-guidance-items/bullying-guidelines/workplace-bullying. 
WorkSafe Victoria. (2012). Your guide to workplace bullying-prevention and response. WorkSafe Victoria Retrieved from https://www.worksafe.vic.gov.au/ data/assets/pdf file/0008/42893/WS Bullying_G uide Web2.pdf.

Yamada, D. C. (2011). Workplace bullying and the law. In S. Einarsen, H. Hoel, D. Zapf, \& C. Cooper (Eds.), Bullying and harassment in the workplace: Developments in theory, research, and practice (2nd ed., pp. 469-484). Boca Raton, FL: CRC Press.

Zapf, D. (1999). Organisational, work group related and personal causes of mobbing/bullying at work. International Journal of Manpower, 20(1/2), 70-85. doi:10.1108/01437729910268669

Zapf, D. (2004). Negative social behaviour at work and workplace bullying. Paper presented at the The Fourth International Conference on Bullying and Harassment in the Workplace Bergen, Norway.

Zapf, D., \& Einarsen, S. (2011). Individual antecedents of bullying: Victims and perpetrators. In S. Einarsen, H. Hoel, D. Zapf, \& C. Cooper (Eds.), Bullying and harassment in the workplace: Developments in theory, research, and practice (pp. 177-200). Boca Raton, FL: CRC Press.

Zapf, D., Einarsen, S., Hoel, H., \& Vartia, M. (2003). Empirical findings on bullying in the workplace. In S. Einarsen, H. Hoel, D. Zapf, \& C. Cooper (Eds.), Bullying and emotional abuse in the workplace: International perspectives in research and practice (pp. 103-125). London, England: Taylor \& Francis.

Zapf, D., Escartin, J., Einarsen, S., Hoel, H., \& Vartia, M. (2011). Empirical findings on prevalence and risk groups of bullying in the workplace. In S. Einarsen, H. Hoel, D. Zapf, \& C. Cooper (Eds.), Bullying and harassment in the workplace: Developments in theory, research and practice (2nd ed., pp. 75-105). Boca Raton, FL: CRC Press.

Zapf, D., \& Gross, C. (2001). Conflict escalation and coping with workplace bullying: A replication and extension. European Journal of Work and Organizational Psychology, 10(4), 497-522. doi:10.1080/13594320143000834

Zapf, D., Knorz, C., \& Kulla, M. (1996). On the relationship between mobbing factors, and job content, social work environment, and health outcomes. European Journal of Work and Organizational Psychology, 5(2), 215-237. doi:10.1080/13594329608414856 


\title{
Appendices
}

\section{Appendix A: Participant information sheet}

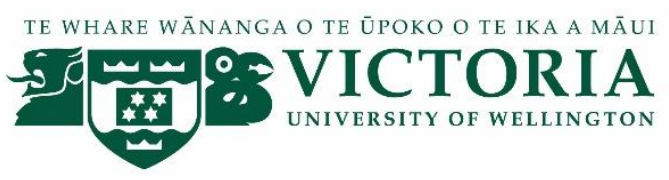

\section{INFORMATION SHEET AND INVITATION TO PARTICIPATE}

\section{Practices to address workplace bullying in the New Zealand Public Services}

\author{
Researcher: Hamish Crimp, School of Management, Victoria University of Wellington \\ I am a Masters student in Human Resource Management and Industrial Relations at Victoria University \\ of Wellington. I am currently undertaking a research project which will explore the role of organisational \\ stakeholders in the development and implementation of workplace anti-bullying/harassment strategies in \\ the New Zealand Public Services. This research has been approved by the Victoria University of \\ Wellington Ethics Committee with approval number 0000022331.
}

\section{Invitation}

I would like to invite those who are involved in the development and implementation of workplace antibullying or harassment strategies in the Public Services to participate in this study. Participation will be limited to an interview of no longer than one hour, or involvement in a focus group. Your participation is completely voluntary and you may decline to answer questions, terminate the interview or leave the focus group at any time. If you are participating in a focus group you must agree to keep the identities and opinions of all focus group participants confidential. If you wish to withdraw from this research project, you can do so at any time before 29th February 2016.

\section{Confidentiality}

This research is confidential. I will not use participant names or identifying details of any organisation in final reports, publications or presentations if it could lead to the identification of individual participants. Direct quotes may be used in the final report however they will not be attributed to any individual participant.

With your permission interviews will be audio recorded and transcribed. Only my supervisors and I will read the notes or transcript of the interview. The interview transcripts, summaries and any recordings will be kept securely and destroyed 5 years after the research ends.

What will the project produce?

The information from my research will be used in the preparation of my Masters thesis. Two copies of the final thesis will be placed on closed reserve at the Victoria University library. Results of the research 
may also be published in both academic and professional journals and disseminated at academic and professional conferences.

\section{Interview Summary}

If you would like to receive a summary of your interview, this can be emailed to you following the interview. There is space on your consent form for you to provide your email address.

\section{Research Summary}

If you are interested in the final results of this study, I can email you a summary of research findings following completion of the examination process sometime after May 2016. There is space on your consent form for you to provide your email address.

Who to contact if you have any questions about the research

If you have any questions, either now or in the future, please feel free to contact either:

\section{Researcher contact information}

\section{Supervisor contact information}

\section{Human Ethics Committee information}

Human Ethics approval has been obtained from the Victoria human Ethics Committee. If you have any concerns about the ethical conduct of the research you may contact the Victoria University HEC Convener: Associate Professor Susan Corbett. Email susan.corbett@vuw.ac.nz or telephone +64-4-463 5480. 


\section{Appendix B: Research consent form}

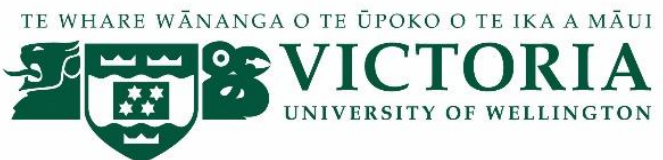

\section{CONSENT TO PARTICIPATE IN INTERVIEW}

\section{Practices to address workplace bullying in the New Zealand Public Services}

Thank you for your interest in this research.

I have read through the attached information sheet and have been provided with adequate information relating to the nature and objectives of this research project. I have understood that information and have been given the opportunity to seek further clarification or explanations.

I understand that any information I provide will be kept confidential to the researchers. The published results will not use my name, and no opinions will be attributed to me in any way that will identify me. I understand that all raw data recording my views will be securely stored and access restricted to the researcher and their supervisor. I understand that I can request a summary of my interview to be emailed to me. Results of the research may be published in both academic and professional journals and disseminated at academic and professional conferences. I understand that I can withdraw from this research project at any time before 29th February 2016.

\section{I agree to take part in this interview}

I agree to this interview being audio recorded

I wish to receive a summary of my interview and have added my email address below

I wish to receive a summary of the results of this research and have added my email address below

Signature of participant:

Name of participant:

Date:

Email (optional): 


\title{
Appendix C: Semi-structured interview guide
}

\author{
Semi-Structured Interview Guide
}

\section{Project Introduction}

\section{Explain consent form and ask participant to sign}

\section{Background Information}

- What is your role?

- How long have you been at [insert organisation name]?

- How many years have you been in your role [HR, etc]

\section{Workplace bullying definitions}

What behaviours do you consider to be bullying in the workplace? Why?

How do you know what workplace bullying looks like?

How do you know when it is bullying and when it is not?

\section{Workplace bullying experiences}

- What is your experience with workplace bullying in [insert organisation name]? position responsibilities, relevant expertise or skills

- What support is available to you from internal and external sources?

\section{Policy development}

- What were your observations of the development of anti-bullying policies and practices? 
- Have you been involved in workplace bullying policy development? If so how?

- What do you believe are the barriers to the development of an effective anti-bullying strategy at [insert organisation name]?

- How do you believe the development of anti-bullying strategy could be improved at [insert organisation name]?

\section{Policy implementation}

- What were your observations of the implementation of anti-bullying policies and practices?

- Have you been involved in the implementation of workplace bullying policy? If so how?

- What do you believe are the barriers to the implementation of an effective anti-bullying strategy at [insert organisation name]?

- How do you believe the implementation of anti-bullying strategy could be improved at [insert organisation name]?

\section{Antecedents/drivers of workplace bullying}

- What factors do you believe cause workplace bullying?

Internal, external, management, work environment factors

\section{Miscellaneous}

- Are there any other points you would like to raise which you think might be relevant to this research? 